\title{
A Case Study Investigating Therapy Methods Used by Speech Language Pathologists Working with Children with Autism Spectrum Disorders
}

\author{
Julia Byers Van Volkenburg \\ West Virginia University, jbyers9@mix.wvu.edu
}

Follow this and additional works at: https://researchrepository.wvu.edu/etd

Part of the Educational Assessment, Evaluation, and Research Commons, Speech and Hearing Science Commons, and the Speech Pathology and Audiology Commons

\section{Recommended Citation}

Van Volkenburg, Julia Byers, "A Case Study Investigating Therapy Methods Used by Speech Language Pathologists Working with Children with Autism Spectrum Disorders" (2021). Graduate Theses,

Dissertations, and Problem Reports. 8344.

https://researchrepository.wvu.edu/etd/8344

This Dissertation is protected by copyright and/or related rights. It has been brought to you by the The Research Repository @ WVU with permission from the rights-holder(s). You are free to use this Dissertation in any way that is permitted by the copyright and related rights legislation that applies to your use. For other uses you must obtain permission from the rights-holder(s) directly, unless additional rights are indicated by a Creative Commons license in the record and/ or on the work itself. This Dissertation has been accepted for inclusion in WVU Graduate Theses, Dissertations, and Problem Reports collection by an authorized administrator of The Research Repository @ WVU.

For more information, please contact researchrepository@mail.wvu.edu. 
A Case Study Investigating Therapy Methods Used by Speech Language Pathologists Working with Children with Autism Spectrum Disorders

\author{
Julia Van Volkenburg
}

Dissertation submitted

to the College of Education and Human Services at West Virginia University

in partial fulfillment of the requirements for the degree of

Doctor of Education in

Curriculum and Instruction

\author{
Keri Duncan Valentine, Ph.D., Chair \\ Allison Swan Dagen, Ph.D. \\ Francene Kirk, Ed.D. \\ Dennis M. Ruscello, Ph.D. \\ Samuel Stack, Ph.D.
}

Department of Curriculum and Instruction/Literacy Studies

\title{
Morgantown, West Virginia \\ 2021
}

Keywords: Speech Language Pathology, Autism Spectrum Disorders, Language Therapy, Creative Dramatics

Copyright 2021 Julia Van Volkenburg 


\begin{abstract}
A Case Study Investigating Therapy Methods Used by Speech Language Pathologists Working with Children with Autism Spectrum Disorders
\end{abstract}

\author{
Julia Van Volkenburg
}

This study was an in-depth examination of the experiences of five speech language pathologists (SLPs) working with children with Autism Spectrum Disorders (ASD) during language therapy sessions. This case study aimed to better understand the various therapy techniques being used by the SLPs through interviews and a reflective journal kept by the researcher. It also sought to examine the ways those therapy techniques may have included creative dramatics. Through thematic analysis, major and minor themes emerged from the interviews. The main theme of the study was the importance of individualizing therapy for students with ASD. Individualizing therapy was supported by minor themes involving the severity of the child's ASD, special interests of the student, and incentives for communication. The other main themes were temporality issues, counseling caregivers, and traditional therapy versus creative therapy. The SLPs identified interventions they used in their practice. They also discussed their most successful interventions and the interventions that were most enjoyed by their students. This study also investigated whether SLPs were using creative dramatics with students with ASD. Three of the SLPs interviewed were successfully using creative dramatics. Role playing was the most popular and successful creative dramatic therapy technique listed by the SLPs. Lastly, this study found a need for further research not only on the treatment experiences of SLPs during language therapy, but also exploring creative dramatics as a therapy intervention. 


\section{ACKNOWLEDGEMENTS}

It is with gratitude that I thank all who have helped me with this dissertation. First, I would like to thank Dr. Keri Valentine, the chairperson of my doctoral committee. She has been an invaluable mentor and advisor who has guided me through this process with her wisdom and dedication for my academic pursuits. I also want to thank my esteemed committee members, Dr. Alison Swan Dagen, Dr. Francene Kirk, Dr. Dennis Ruscello, and Dr. Samuel Stack for their patience, guidance, and support during my dissertation process. I am indebted to my entire doctoral committee. Words cannot articulate the appreciation I have for the opportunity to work with this tremendous group.

I also want to thank my husband, Jeff Van Volkenburg, for his continuous encouragement, unwavering support, and love during this entire process. He is my inspiration for hard work to accomplish one's dreams. I want to thank my parents, Judy and George Byers, for being the model of true educators and academics. I send them my gratitude for supporting my studies and for showing me the value of education. I want to thank my children, David and Juliana, for their hugs and love during this time. I want them to know that if they work hard enough, they can accomplish anything. I also want to thank my beloved dog, Zeus, who was by my side during long evenings of writing. Lastly, I want to thank my mother-in-law, Julie Van Volkenburg, for always encouraging me to pursue my studies.

I want to recognize my friend, former colleague, and special educator, Beth Vincent. For years, at Jayenne Elementary we collaborated to maintain a language group for our students with ASD. We explored creative dramatic techniques and even put on plays in her classroom. It was a "golden time" for us, and experience that was life-changing for me as an SLP. 
Lastly, I want to thank my students for inspiring me to study ASD. They have made me a better SLP. I especially want to thank my first student with ASD, Sam, whose love for creative dramatics inspired me to pursue it further as an essential therapy technique. 


\section{TABLE OF CONTENTS}

Page

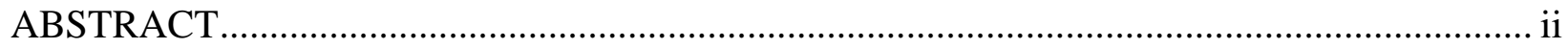

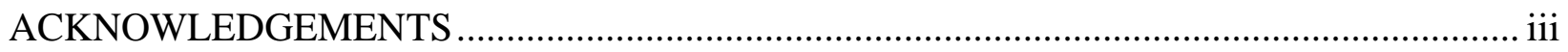

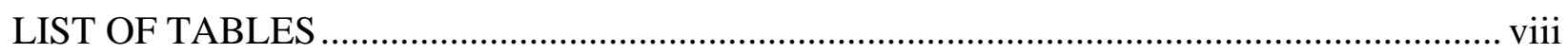

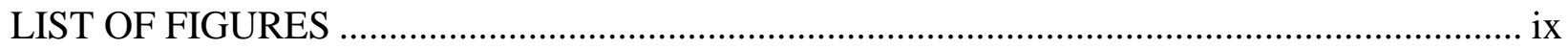

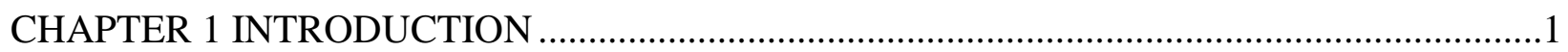

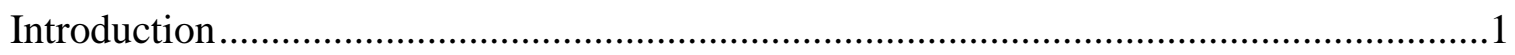

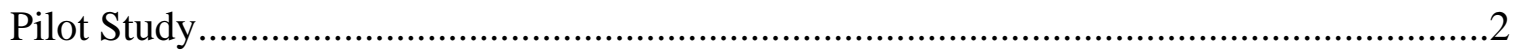

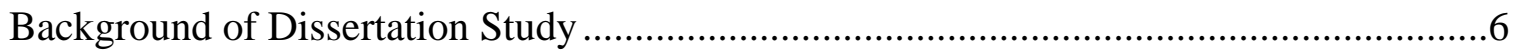

Historical Perspective ............................................................................................

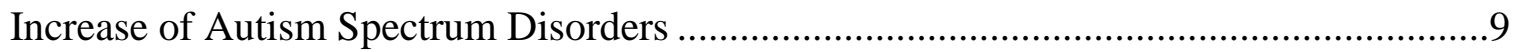

Lack of Research on Lived Experiences of Speech Language Pathologists ....................10

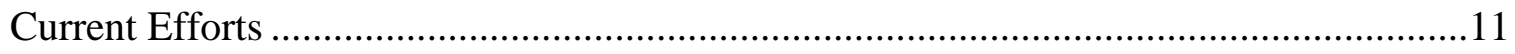

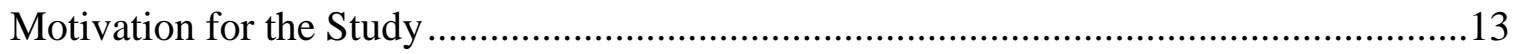

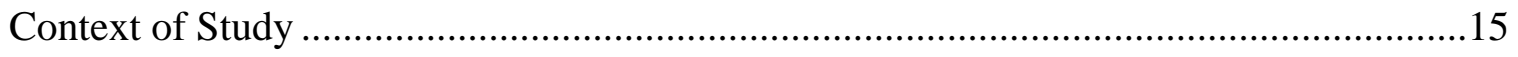

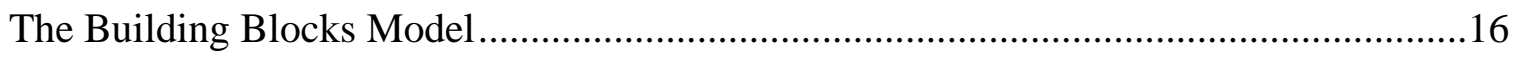

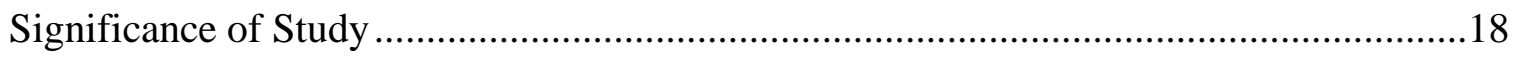

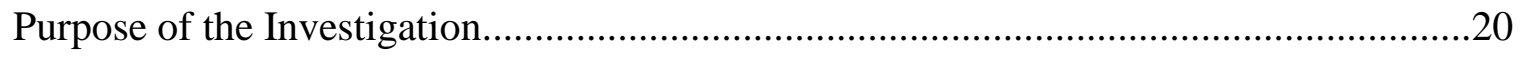

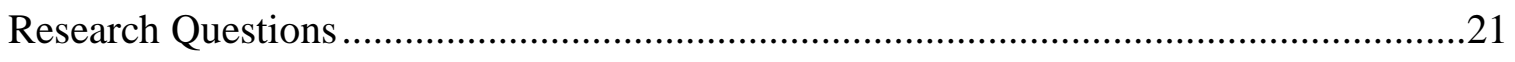

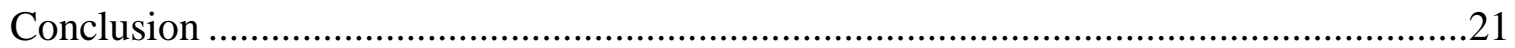

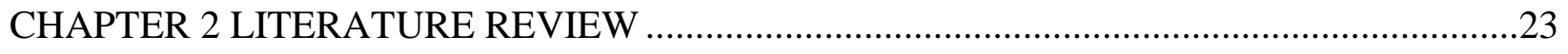

Background on Autism Spectrum Disorder .........................................................23

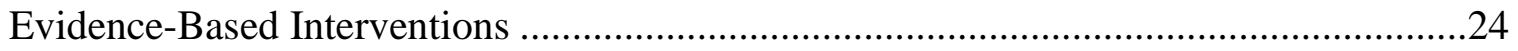

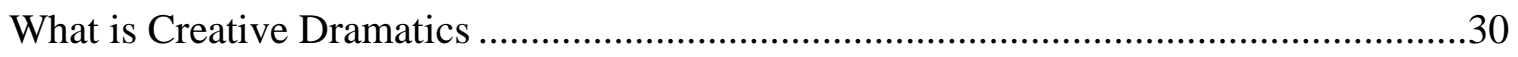

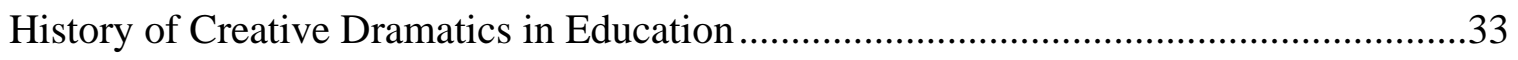

Creative Dramatics Influence on Pedagogy …............................................................37

Creative Dramatics Used with Students with ASD ...................................................40 


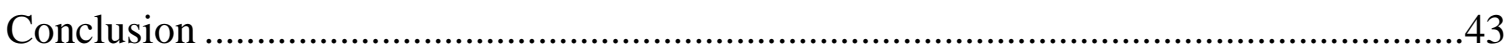

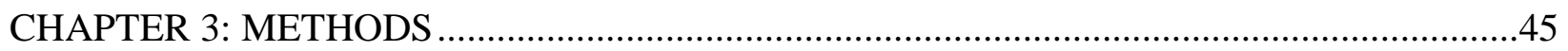

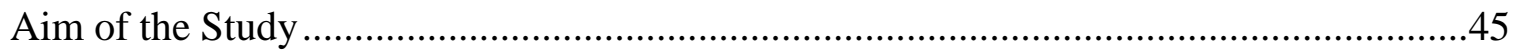

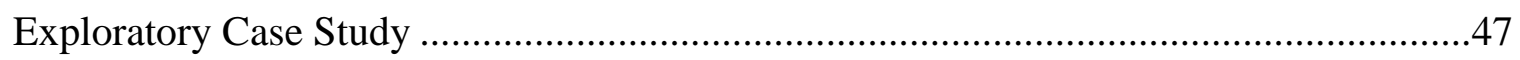

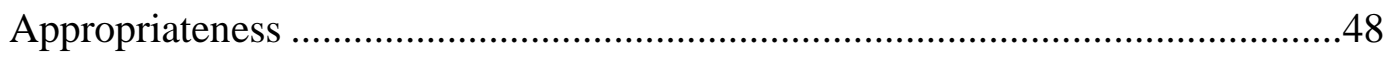

Boundary of the Investigation.............................................................................

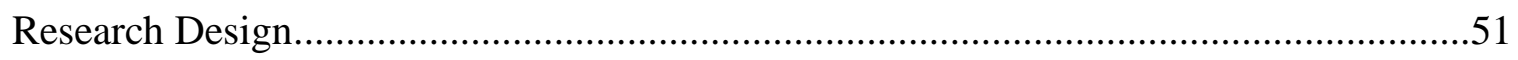

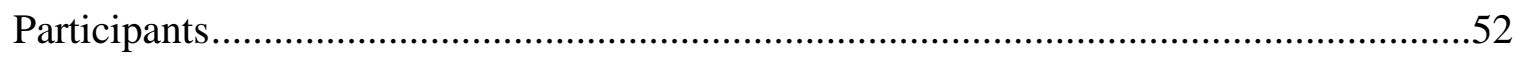

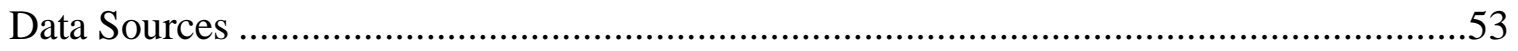

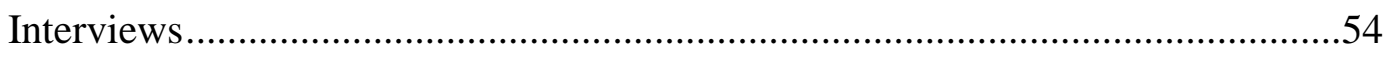

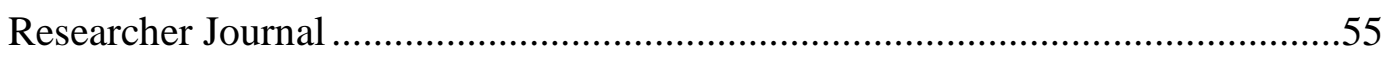

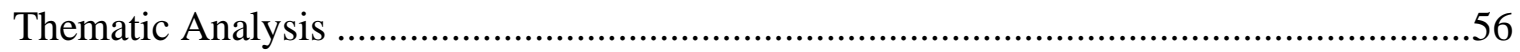

Step 1: Familiarizing yourself with your data.....................................................58

Step 2: Generating the Initial Codes ………………….....................................59

Step 3: Searching for Themes ………………………….............................62

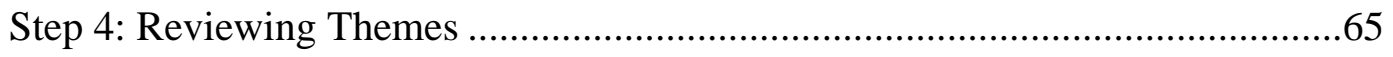

Step 5: Defining and Naming Themes.............................................................65

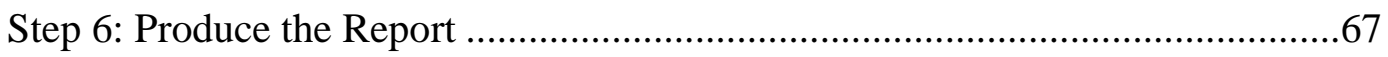

Actions to Ensure Quality Research Conclusions ..............................................................67

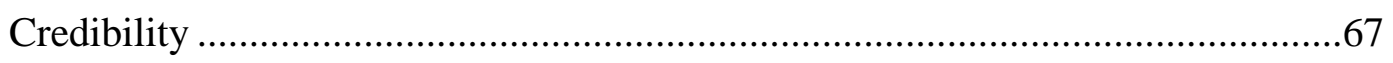

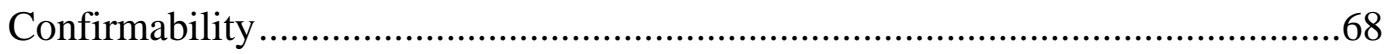

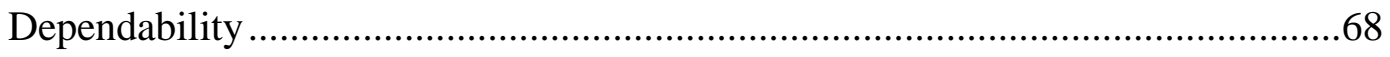

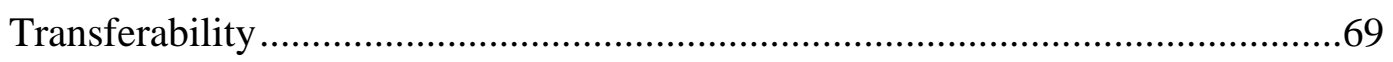

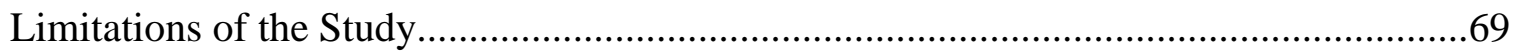

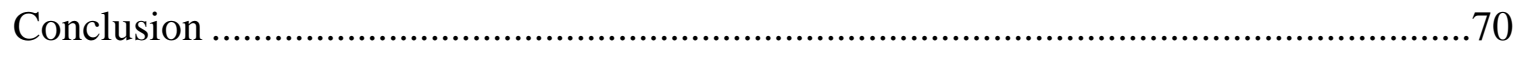

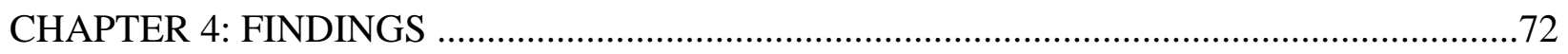

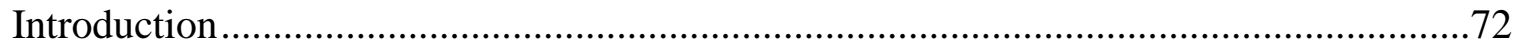

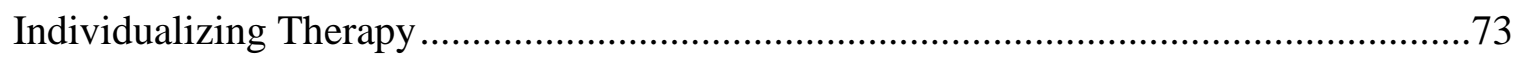




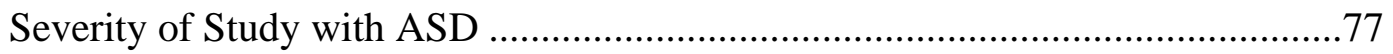

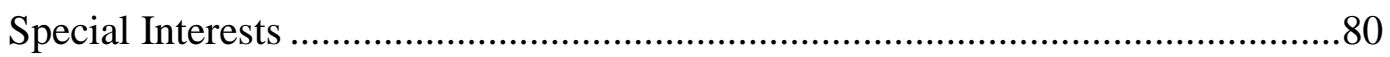

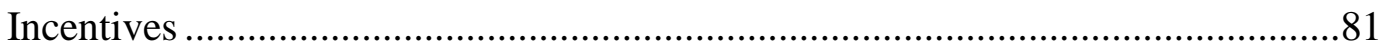

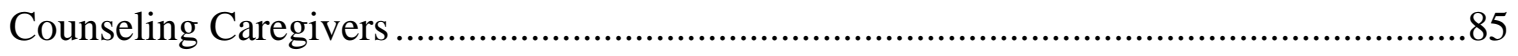

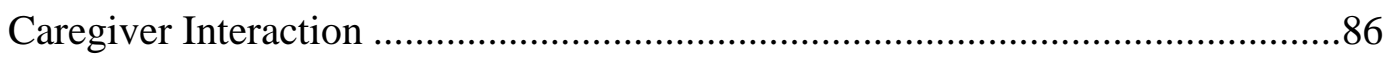

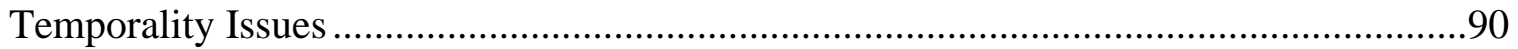

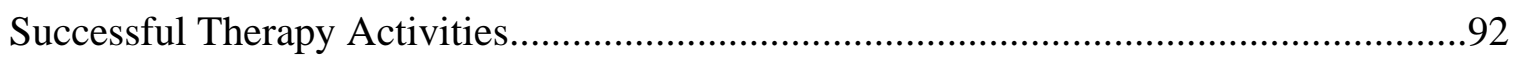

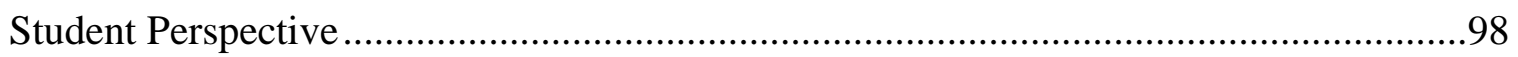

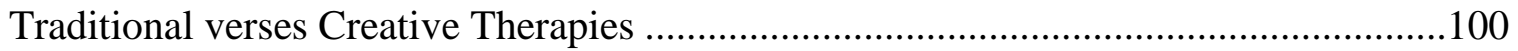

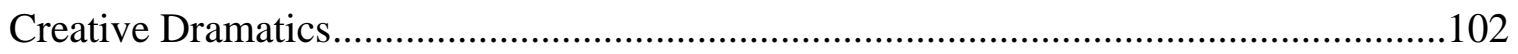

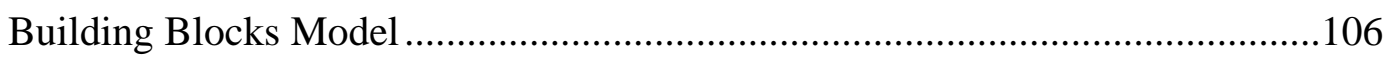

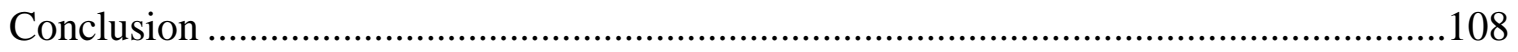

CHAPTER 5: CONCLUSIONS ------------------------------------------------------------------------ 110

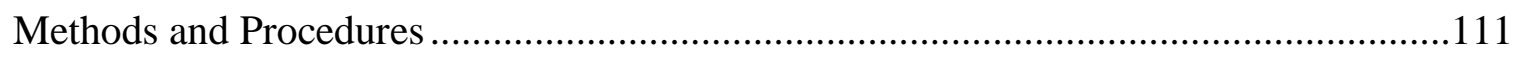

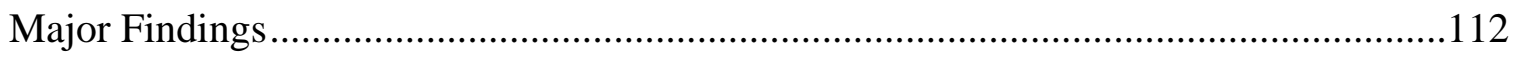

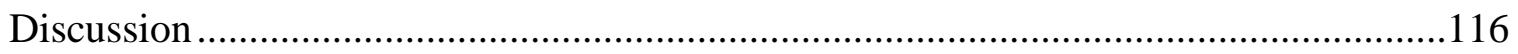

Conclusions and Implications for Practice .........................................................121

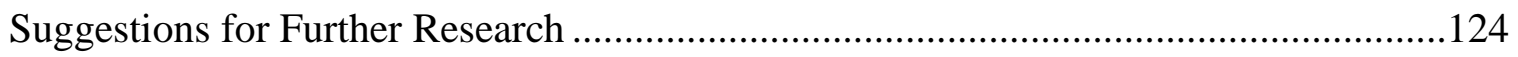

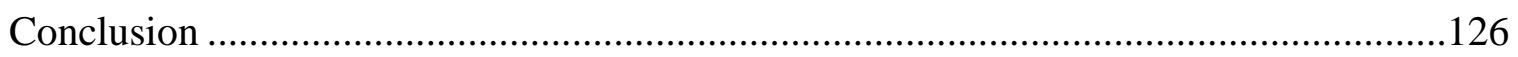

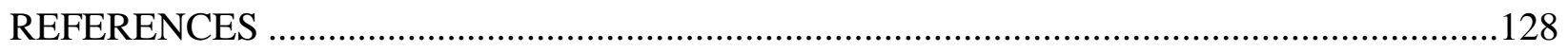

APPENDIX A. PILOT STUDY CREATIVE DRAMATICS THERAPY PLANS ...................157

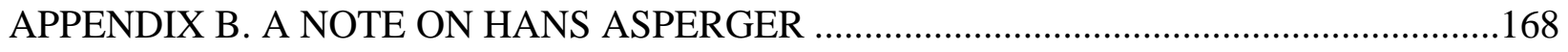

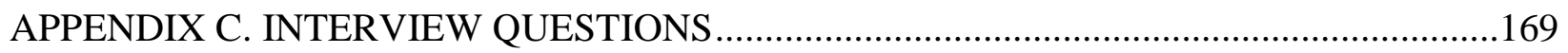

APPENDIX D. PARTICPANT RECRUITMENT LETTER ..............................................170 


\section{LIST OF TABLES}

Page

Table 2.1: EVIDENCE-BASED COMMUNICATION INTERVENTIONS ............................26

Table 3.1: BACKGROUND OF PARTICIPANTS ................................................................53

Table 3.2 BRAUN AND CLARK (2006) THEMATIC ANALYSIS FRAMEWORK ...............57

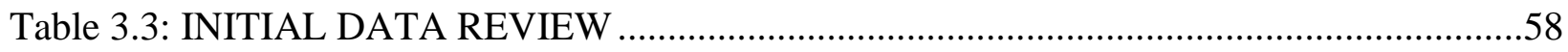

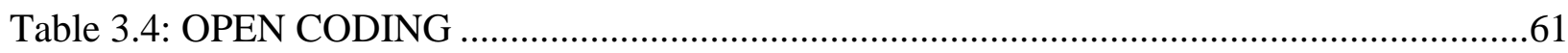

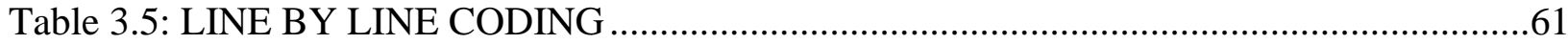

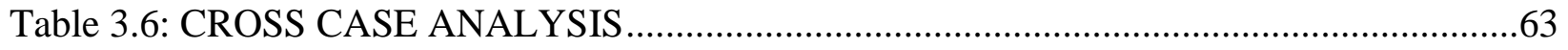

Table 3.7: THEMES FROM INTERVIEWS........................................................................67

Table 4.1: PROMINENT THEMES FROM INTERVIEWS …............................................73

Table 4.2: THERAPY ACTIVITIES USED WITH CHIDREN WITH ASD .............................74

Table 4.3: MOST SUCCESSFUL THERAPY ACTIVITIES ...................................................92

Table 4.4: MOST ENJOYED THERAPY ACTIVITIES ..................................................99 
LIST OF FIGURES

Page

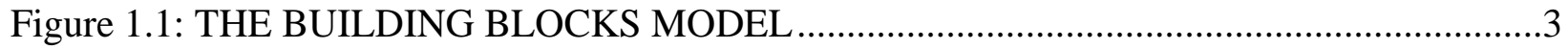

Figure 1.2: CREATIVE DRAMATIC TECHNIQUES FOR EDUCATORS (WAY, 1967) .........17

Figure 1.3: DETAILED BUILDING BLOCKS MODEL .......................................................18 


\section{CHAPTER 1: INTRODUCTION}

Samantha, a nonverbal 5-year-old female diagnosed with Autism Spectrum Disorder, was intently listening to the story Goldilocks and the Three Bears. As I read the book, I acted out the various scenes, encouraging my language group of students with Autism Spectrum Disorder to do the same. We pretended to be Goldilocks and eat from the different sized porridge bowls, sit in the different sized chairs, and sleep in the different sized beds. Finally, we pretended to be the family of bears who discovered Goldilocks sleeping in our home. Samantha stared at the book throughout most of the activities. At the end of the day when I walked into the classroom, she came up to me, put her hands up imitating a bear, and said, "Roar, Roar, Bear." These were her first spoken words.

\section{Introduction}

Samantha was in a pragmatics language group that I led. We worked on her language skills for months using traditional language therapy techniques. She was working on phase one of the Picture Exchange Communication System (PECS) (Frost \& Bondy, 2002). She had to hand me a picture of a preferred item, which was a spinning toy, with assistance from the special education teacher aide. I would immediately give Samantha her spinning toy as a reinforcement. Yet, she would not hand me the picture independently without the help of the special education teacher aide. Also, we were working on labeling objects, turn taking skills, and expressing basic wants and needs using picture cards and picture communication boards. We had also been working on not hitting others with a personalized social story created for her. Though she did not demonstrate improvement through traditional language treatment, she immediately responded to creative dramatic exercises, such as the one described above, where she acted out Goldilocks and the Three Bears, using her first spoken words. She started to engage actively in language 
activities through creative dramatic-based strategies. Further, she began taking my hand, when I walked into her classroom, and pointing to puppets that she wanted to play with during our language sessions. Her distracting behaviors of screaming, getting out of her seat, and biting her hands decreased. Most importantly, her verbal language skills significantly improved. Samantha was the inspiration for me to explore and pursue creative dramatics as a treatment for children with Autism Spectrum Disorder (ASD).

\section{Pilot Study}

I conducted a qualitative pilot research study for this dissertation in September of 2011. This pilot study aimed to analyze and evaluate the reactions of educators to the implementation of the Building Blocks Model with children with ASD. The feedback provided by educators observing the application of the Building Blocks Model demonstrated practical benefits and potential limitations. The research for this study was guided by the following questions:

- In what ways does using creative dramatics through the Building Blocks Model facilitate language development in children with ASD?

- What do educators perceive to be the potential benefits or limitations of the Building Blocks Model as applied to children with ASD?

Design research was my methodological approach. I designed the Building Blocks Model as a tool for educators, particularly speech language pathologists (SLPs), to use with students with ASD. It is based on Brian Way's (1967) creative drama techniques for educators. Figure 1.1 below shows a visual representation for the Building Blocks Model. It includes seven components of creative dramatic educational techniques including concentration, pantomime, movement to sound, moods and emotions/role playing, voice and diction, storytelling, and 
playing/improvisation. It is hierarchical model with each building block adding and expanding on the targeted skills of the previous building block.

\section{Figure 1.1}

The Building Blocks Model

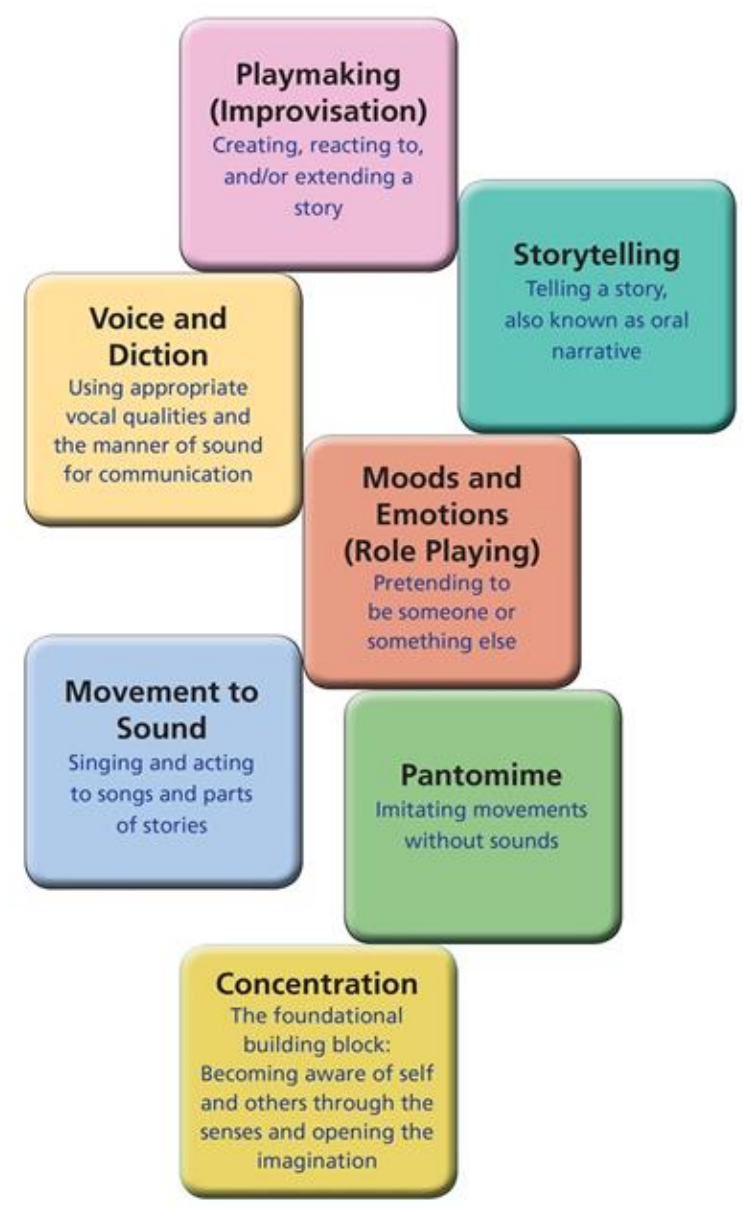

Design research allowed me to test out my model and gain valuable insights and reflections about the model from the participants. Participants were selected through convenience sampling. Participants were contacted through personal and professional connections using email requests to participate in the research interviews. These participants worked with the researcher 
at the time of the study. However, their participation in the study was completely optional. There was no pressure to participate in the study and no repercussions if the potential participants chose not to participate in the study. The data gathered through the responses to the research questions was collected and analyzed comprehensively to determine the participants' perceptions of the Building Blocks Model facilitating language development for children with ASD.

The participants included a special education teacher and a special education aide who worked for the Marion County School System in West Virginia. They observed me conduct my language group for students with ASD using a creative dramatics lesson from the Building Blocks Model three times weekly for two weeks (see Appendix A for pilot study creative dramatic therapy plans). The participants completed an educational questionnaire after every language group. This questionnaire inquired about their opinions on the effectiveness of the Building Blocks Model and any changes they felt needed to be made to the model. After the twoweek period of observation of the Building Blocks Model, the participants were interviewed privately by the researcher. The purpose of this interview was to gain information as to their reactions and opinions to the Model. After the interviews were conducted, the researcher compared, coded, and evaluated the findings using content analysis. The results of the pilot study findings were presented to the participants to establish the internal validity of the study. The special education teacher and aide confirmed the findings.

The results of the pilot study indicated that the special education teacher and aide felt that the Building Blocks Model engaged the students and required less redirection to tasks than other treatments. They noted that the students demonstrated an increased understanding of programmatic language following the Building Blocks Model exercises. They found the students 
had an increased expression of appropriate pragmatic language. Lastly, they felt that the Model provided opportunities for practice of pragmatic language skills.

The participants found limitations in the Building Blocks Model and provided recommendations to improve it. They pointed out that the level of engagement with the Model was dependent on the verbal skills of the student. Thus, a student with limited verbal skills had difficulty with the higher-level Building Blocks such as storytelling or Playmaking/Improvisation. They recommended that there needed to be more time for each activity with delivery of the Model as well.

Since the participants worked with these children daily, they had a unique perspective on their student's educational abilities. If they felt the Model was not effective in facilitating language development, it would call into question use of the Model as a future tool. It might also indicate the need for the Model to be modified. This pilot study provided initial insight concerning whether educators felt the Model was effective in a classroom environment. Just as important, the study provided initial observations concerning whether educators felt comfortable using the Model. It is recommended that more expansive studies with other educators and SLPs be conducted using the Model. Lastly, an intention of this pilot study was that it would begin research to expand the use of different therapy techniques for children with ASD. Best practice continues to be discrete trial training and PECS for working with ASD students; however, creative dramatics offers another option that could be used to increase language skills.

While the Building Blocks Model showed promise in the case study, its effectiveness cannot be generalized without further investigation. Further research must be done by testing the Model in a classroom environment, as well as evaluating the therapy environment. Also, it can be studied as a possible tool that parents can use to generalize therapy techniques for the home 
environment. Research might also be done on the effectiveness of the Model with ASD children of varying levels of communication skills, as well as different ages.

\section{Background of Dissertation Study}

The Center for Disease Control [CDC] estimates that approximately 1 in 54 children is diagnosed with ASD, "a developmental disability that can cause significant social, communication, and behavioral challenges" (CDC, 2020a, para.1). A major challenge for children with ASD is communicating with others (American Psychiatric Association, 2013; American Speech-Language-Hearing Association (ASHA) 2015; World Health Organization 2001). Children with ASD often have various communication deficits, such as trouble talking, understanding and interacting socially with others, and exhibiting restrictive and repetitive patterns of behavior (ASHA, 2015; Rimland, 2015; Sicile-Kira, 2014).

The spoken language abilities of children with ASD range from some degree of verbal communication to no verbal communication (ASHA, 2015). There are some children who are high functioning with ASD and only have difficulties with figurative language skills. An example is when they are told that it is raining cats and dogs, they literally believe that it is raining cats and dogs. There are others diagnosed with ASD who have greater social language difficulties and oral language difficulties too. Difficulty with figurative language, conversational skills and routines, and even significant oral language deficits are all characteristic of social language disorders associated with ASD. They have trouble with conversational skills and social routines (such as appropriately gaining attention, entering a conversation appropriately, and maintaining a conversation). They may also have difficulty recognizing, understanding, and expressing emotions. Lastly, some children with ASD are nonverbal and have significant oral language deficits. These children communicate their wants and needs with augmentative and 
assistive communication devices. These are all characteristic of social language disorders associated with ASD (ASHA, 2015; Happé, 1994; Manolitsi \& Botting, 2011; Myers \& Johnson, 2007). Examples of assistive and augmentative devices are the ProLoQu2go app on the iPad, a Go Talk device, or a low functioning communication board/book in which a student chooses pictures to express his/her wants and needs (Mirenda, 2009; Sennott \& Bowker, 2009).

Regardless of verbal abilities, all children with ASD have some degree of deficit with their social language skills (American Psychiatric Association, 2013). Traditional therapies often utilize such interventions as Discrete Trial Training and PECS to facilitate communication for children with ASD (Autism Task Force 2011; Sicile-Kira, 2014; Bondy \& Frost, 2001, 1998; Duffy \& Healy 2011; Wilkinson, 2014). Discrete trial training breaks down the components of a behavior and then teaches them using positive behavioral contingencies (Smith, 2001). PECS is a communication system that uses pictures to communicate wants and needs of an individual. PECS also uses positive reinforcers (Bondy \& Frost, 2001). Both programs are behaviorally oriented, which some may argue do not simulate natural language acquisition activities (Flippin et al., 2010; Rabideau et al., 2018). Consequently, there are new frontiers to be explored in helping children with ASD communicate more effectively and naturally, such as the experience I shared concerning Samantha. This made me wonder if other (SLPs) encountered similar experiences in their practice.

\section{Historical Perspective}

An individual with ASD was historically seen as having a mental disorder. Eugen Blueler, a Swiss psychiatrist, first used the term Autism in 1911 to describe individuals with specific characteristics of schizophrenia (Bleuler, 1950). The 1920s marked a time in which

Autism was considered curable through diet and various supplements. However, in the 1930s, 
electroshock therapy was used to treat individuals with Autism characteristics. It was not until the early 1940s that Autism was seen separate from mental health disorders as a specific set of symptoms for a unique disorder. Leo Kanner, an Australian psychiatrist working at John's Hopkins University School of Medicine, and Hans Asperger, an Austrian pediatrician, were the pioneers of this effort (see Appendix B for a note on Hans Asperger). They had separately observed the characteristics of repetitive patterns of behavior and severe communication deficits as unique for individuals and believed these individuals should not be labeled with mental health disorders, but presented with a neurological disorder (Sicile-Kira, 2014). Kanner was the first individual to identify Autism as a separate neurological condition in 1943. He wrote a seminal paper entitled, "Autistic Disturbances of Affective Contact in Nervous Child” in the Journal of Psychopathology, Psychotherapy, Mental Hygiene, and Guidance of the Child. He pointed out that children he observed with this condition were not "feebleminded" as had previously been described (Silverman, 2012). Kanner (1943) detailed the symptoms of Autism, describing individuals afflicted with it "by [a] powerful desire for aloneness and sameness" (p. 249). He also noted that Autism differed from schizophrenia because the symptoms did not gradually increase as children got older, but were steady. He also believed the cause of Autism was lack of warmth from parents.

Asperger's paper entitled, “Autistic Psychopathy in Childhood,” published in 1944, was similar to Kanner's because he also provided new disorder characteristics where individuals had strong preferences for routines or sameness, lack of affect, and increased involuntary manipulation of objects. Importantly, Asperger's paper described normal to increased intelligence of children with this condition (Pearce, 2005). 
Kanner's view of parents as responsible for Autism persisted. In the 1950s and 1960s, psychologist Bruno Bettelheim popularized the theory that "refrigerator mothers" caused Autism through a series of published articles and books (Feinstein, 2010). Anna Jean Ayres, an occupational therapist and child psychologist, published research in 1972 that children with Autism may also have sensory behavior difficulties. She created what is known as Sensory Integration Theory and Therapy. Sensory Integration Therapy exposes an individual to sensory stimuli in an organized manner to help improve tolerance of sensory input (Preis \& McKenna, 2014).

The Diagnostic and Statistical Manual of Mental Disorders (3 ${ }^{\text {rd }}$, ed.; DSM-3; American Psychiatric Association, 1980), included Infantile Autism in the manual. This category was replaced with Autism in 1987 and included a more specific symptom checklist (Verhoeff, 2013). Four years later (1991), the United States government listed Autism as an eligibility category for assistance. This meant that Autism was its own individual category that entitled children to receive special education services (Brock et al., 2001).

\section{Increase of Autism Spectrum Disorders}

Unfortunately, the prevalence of ASD continues to rise. As mentioned, the current rate of ASD is 1 in 54 children (CDC, 2020b). However, the prevalence rate varies across different areas of the Unites States. It is highest in localities such as New Jersey, where it is 1 in 32 . The lowest rates were found in Colorado, where the official rate is 1 in 76 . Autism Speaks (2020) noted that the CDC has hypothesized, "This may be due to how Autism is diagnosed and documented in different communities" (para. 4). As such, the prevalence rates may be higher than actually documented in certain communities. (CDC, 2020c). As rates of ASD continue to increase, there also needs to be more focus on the multitude of components that may comprise an 
individual ASD diagnosis. One of the many issues arising from increased ASD diagnoses is how to assist the growing population of children with ASD with their communication needs. It is critical that speech and language therapies are made available to help the diverse population of children with ASD. SLPs will necessarily be devoting increasing amounts of time to assist these students if current statistical trends continue in the years and decades ahead.

\section{Lack of Research on Lived Experiences of Speech Language Pathologists}

As SLPs are increasingly supporting the communication needs of children with ASD, I questioned what their experiences might entail and how these might be shifting as more children with ASD require their services. While lived-experience research approaches, such as the case study approach used in this inquiry, offer a viable way to investigate the experiences of being a SLP and a treatment utilized by a practitioner, they are currently lacking in the research literature. There are a few quantitative studies of job satisfaction of SLPs such as Blood et al. (2002) that conducted surveys and Pezzei and Oratio (1991) used questionnaires to measure job satisfaction of public school SLPs. While most SLPs share personalized therapy stories with others at conferences and professional meetings, the existence of an SLP is a solitary profession. Usually a school has a single SLP or shares an SLP with other schools. This dynamic leads to a lack of sharing information between professionals as day-to-day interactions are minimal. This is an inherent weakness in this segment of the profession that inhibits the spread of information and reduces collaborative approaches to solving difficult cases. SLPs working in the primary and secondary educational systems inherently rely on learning about the profession through continuing education from journal articles and conferences. However, most SLPs in the public school system are not provided with financial resources to extend their working knowledge of acute issues to address systematically the more severe cases they experience. Irrespective of the 
level of experience or education, working with children with ASD is very challenging. It is beneficial for SLPs to gain insight and experiences from others working with this particular population and also consult with the research literature. However, the traditional school-based approach inhibits the type of interaction that is necessary for growth amongst the most isolated practitioners in the field.

\section{Current Efforts}

SLPs who work with students with ASD currently employ a variety of research-based interventions to increase their communication skills. These interventions are Discrete Trial Training, Functional Communication Training, Video Modeling, PECS, Voice Output Communication Aide Devices, Peer Mediated Instruction and Intervention, Naturalistic Language Strategies, Joint Action Routine, Social Narratives, and Imitation and Modeling (Lofland, 2014). These research-based interventions are described in detail in Chapter 2.

There is research discussing the use of drama to help children with ASD with increasing social and communication skills (Beadle-Brown et al., 2018; Cerbo \& Rabi, 2019; Mpella \& Evaggelinou, 2018). There is also research in the area of drama therapy (D'Amico et al., 2015; Godfrey \& Haythorne, 2013). Drama therapy can be traced back to mental hospitals in the 18th century Europe where patients would create plays to help them with their psychological issues (Maynard, 2018). Peter Slade is considered the founder of the modern approach. He coined the term "dramatherapy" in a British Medical Lecture in 1939 (Jones, 2010). He also outlined the ways in which drama is therapeutic for children in his book Drama Therapy as an Aid to Becoming a Person (1959). Slade insisted that drama can be used in education as well: "Slade is not only a pioneer in the use of drama as education in Great Britain, but also in the use of drama as therapy" (Weaver, 1996, p.15). While acting at his local arts center in the 1930's, Slade 
noticed that improvisation helped his peers' confidence. That led him to beginning drama classes for children where he noticed that children's behavior improved as well.

While this research shows benefits to social skills and socialization, there is little focused on the promotion of language development. Currently, researchers and professionals are using and promoting drama therapy to help children with ASD with social skills. For example, Tricomi \& Gallo-Lopez (2012) and Chasen (2011) each created complete drama therapy program guides for children with ASD. There are also active community programs that children and young adults with ASD have started utilizing in the United States. While not a definite conclusion, the early research indicates that individuals with ASD can interact with others using drama to increase social skills and socialization (Kempe \& Tissot, 2012). The most relevant of the early adherents to this type of treatment arise from The Miracle Project in Santa Monica, California. Elaine Hall created this program, which was featured on a 2008 Emmy winning documentary entitled Autism: The Musical. Other notable programs are the Red Kite Project of the Chicago Children's Theater, Des Moines Playhouse, Phoenix Theater, and the Florida Repertory Theater in Fort Myers, Florida (Reading et al., 2016).

There is also research on drama therapy programs and drama activities to promote social skills of children with ASD. There is evidence that drama activities can increase social skills with ASD. These drama activities may include mirror facial expressions and emotions, rhyming, singing, movement activities, role play, and improvisation. Goldstein and Winner (2012) found that children with ASD and learning disabilities who participated in an acting training drama class for a ten month period had an increase with theory of mind skills and cognitive social empathy skills. Another study was conducted by Lerner et al. (2011) on children with high functioning ASD who attended a six week camp using socio-dramatic affective-relational 
intervention (SDARI). This involved drama activities focusing on social skills. The children who attended SDARI exhibited an increase in recognizing emotions in voices. However, there are very few research studies in this area (Guli et al., 2013). The few drama programs that have been studied empirically with successful results include the Social Competence Intervention Program (SCIP) developed by Guli et al. (2008). The SCIP increased overall social skills in young adults with ASD. Building on this work, Minne and Semrud-Clikeman (2012) modified The Social Competence Intervention Program specifically for young children which uses socio-dramatic play activities to increase theory of mind skills. The Sociodramatic Affective Relational Intervention (SDARI) is another successful therapy program that uses dramatic training activities to successfully increase the ability to read nonverbal cues in high functioning adolescents with ASD (Lerner et al, 2011). Despite these recent developments, there is minimal research regarding SLPs using drama activities with their students to promote language development. The research that does exist, took place in the 1950s and 1970s (Balyeat, 1970; Bush, 1978; Hahn, 1955 McIntyre \& McWilliams, 1959). More specifically, there is no current research data concerning SLPs who might be using creative dramatics to support the language development of children with ASD.

\section{Motivation for the Study}

I view the world primarily through the lens of a humanitarian. All children should have a right to an equal education and a right to learn. My own grandmother had a moderate to severe hearing impairment which impacted her educational development. In her case, I viewed firsthand the revolutionary changes to a person's life when the right "tool" is found, in the form of a hearing aid that she acquired as an adult. 
The goal of an educator is to provide the individual tools for each child to reach his or her potential, regardless of disability or background. Therefore, it is understandable that SLPs are advocates for their students with disabilities and strive to give them the same quality education as their peers. Educating students with disabilities along with regular peers brings a level of empathy and understanding to regular educational peers that can enrich their lives. However, children with disabilities must be aided to achieve their potential.

For educators who work in the schools with children with ASD, the struggle to improve the lives of children is a part of daily existence. My main goal in the schools has been to increase the language skills of those afflicted with this disorder. Based on my years of experience using creative dramatics with my students with ASD at Jayenne Elementary School in the Marion County of School System in Fairmont, West Virginia, I believe that creative dramatics is an effective tool for students with ASD. I organized a bi-weekly social language group for my students where we engaged in varied creative dramatic experiences such as singing, movements to sound, pantomime, putting on plays, etc. My personal experiences suggest that traditional therapies for students with ASD are not always successful. These therapies often facilitate stimulus/response contingencies from students and promote robot-like responses from students that cannot be generalized into everyday life.

I share my students' frustration with their limited communication potential and have especially experienced their parents' and caregivers' frustrations. I started using creative dramatics to gain my students' attention and provide "fun activities" for them to engage in. I never imagined that they would enjoy the activities as much as they do, nor experience such success with them. My students now initiate language interactions by asking to play with puppets or to dance a story. They are engaged not only with the activity, but with me and their peers. I 
have witnessed an increase in attention, motivation, grammar, vocabulary, and pragmatic language skills. Therefore, I bring to this study the backdrop of a professional who believes in creative dramatics as a beneficial language technique for students with ASD. However, as an individual trained in the sciences, I know that my view cannot be an endpoint. Wholistic analysis, rich data gathering with in-depth interviews, and spending time to understand the practices and experiences of other SLPs working with children with ASD are needed to assure that my experiences are reflective across a spectrum of providers and their students.

Lastly, I believe that all students need to be exposed to the arts throughout the curriculum. Unfortunately, I have seen that students with disabilities have little exposure to the arts because they are pulled out of regular classrooms for speech therapy, occupational therapy, and/or physical therapy at the expense of participating in music, art, and/or media time. The reality is that our educational system values a child's time in math, science, and/or reading. It is unfair, and counterproductive that students with disabilities are not given equal opportunities to explore their own creative abilities, especially since these experiences could lead to important outlets for them, even provoking language development. Therefore, I believe it is critical that creative opportunities be available to all students, whether in the regular education curriculum, special education curriculum, or in speech therapy.

\section{Context of Study}

The experiences of the SLPs working with children with ASD reveals the humanitarian nature of this dissertation. The purpose of the dissertation is not to obtain rigidly defined empirical data. Working with children with ASD, all of whom fall within a broad spectrum of behavior, necessitates a broad-based understanding of those concepts that may be applicable to entire groups or more narrow subgroups of children with ASD. Exploring the experiences of 
SLPs who have encountered children throughout this broad spectrum begins to shed light on the wider community of SLPs which can further drive consensus, albeit with the inherent uncertainty that any study on a spectrum of subjects entails.

\section{The Building Blocks Model}

I developed the Building Blocks Model after years of working with students with ASD in the regular and special education classroom and in a speech therapy setting. The Building Blocks Model is a creative dramatics model based on Brian Way's techniques. Brian Way (1967), a creative dramatist, outlined a hierarchical series of creative drama techniques for educators to use to facilitate dramatic expression with students in his seminal text, Development through Drama. His creative dramatic techniques are based on developmental learning and designed to nurture the whole child. These hierarchical techniques are concentration, pantomime, movement to sound, moods and emotions (role playing), voice and diction, storytelling, and playmaking/improvisation.

Way's model is a hierarchical model because like building blocks each stage provides the foundational skills to complete successfully the others. Thus, the skills and development obtained through the preceding stages are continuously reinforced as each stage utilizes the components of the previous stages. By the time a child reaches the playmaking/improvisational level, he or she has internalized all the skills of the preceding building stages. This is the innate strength of Way's model. Figure 1.2 below depicts Way's (1967) creative dramatic educational stages. 


\section{Figure 1.2}

Creative Dramatic Techniques for Educators (Way, 1967)

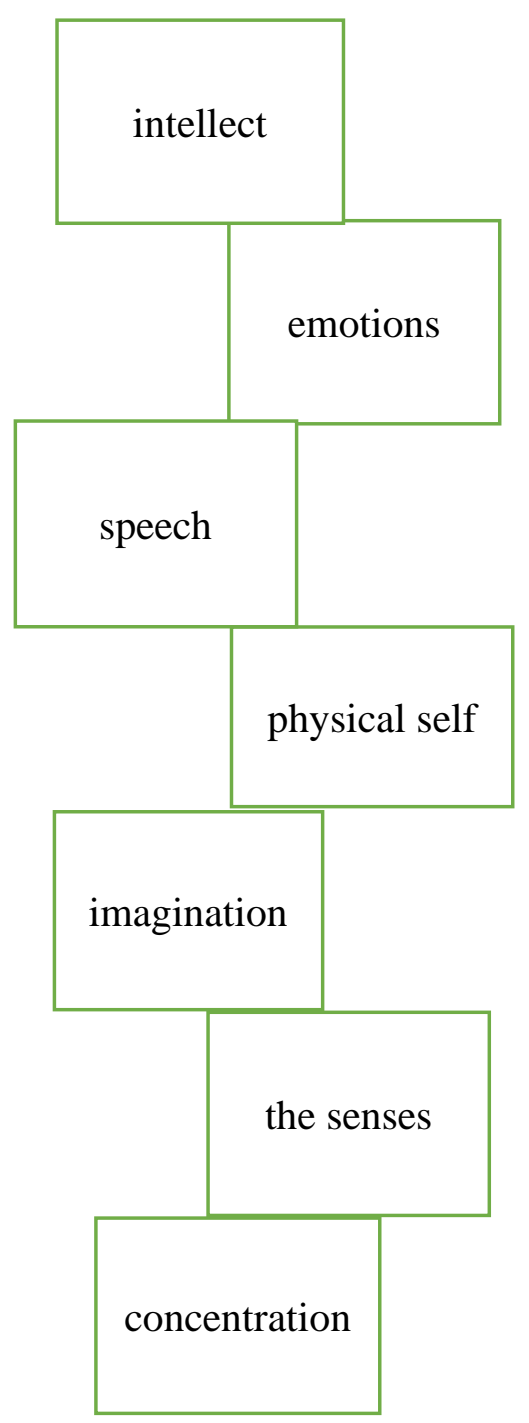

The Building Blocks Model is a practical guide, based on the seven components of Way's drama technique stages that I have adapted for general education teachers, special education teachers, and SLPs to maximize language development across clinical and educational settings for students with ASD. The Building Blocks Model employs Way's techniques because the positive results achieved are gained through using dramatic expression for maximum language growth in students with ASD. Every child, regardless of his or her disability and 
severity, can participate in and benefit from this model. Especially for early childhood educators who encounter children with ASD in their classrooms. The Building Blocks Model can be used as an innovative tool to develop further their communication abilities. I propose using the

Building Blocks Model as a lens to analyze the practices and experiences of a selected group of SLPS who provide services to children with ASD. Figure 1.3 below details each block of the Building Blocks Model.

\section{Figure 1.3}

\section{Detailed Building Blocks Model}

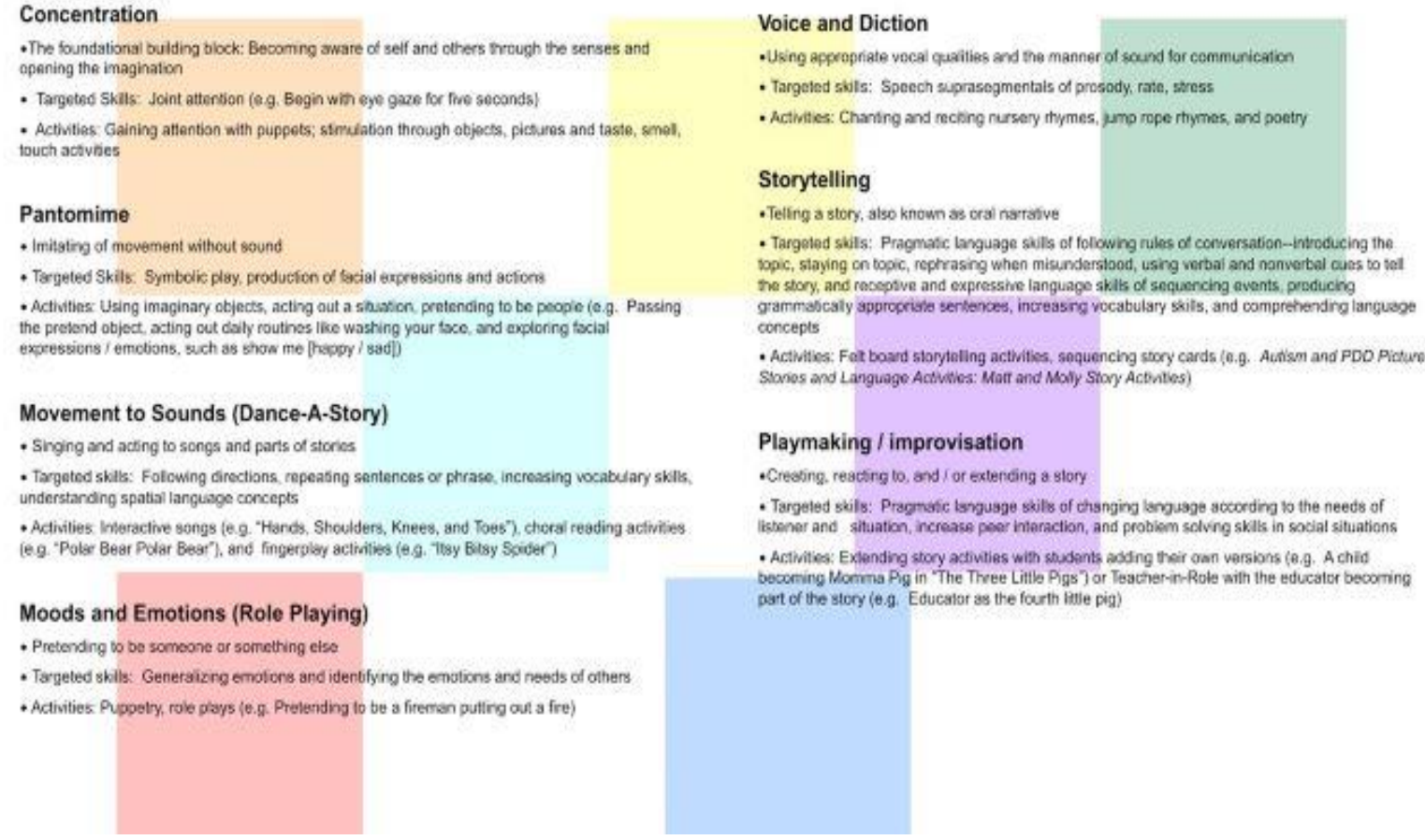

Significance of Study

ASD is a pressing health crisis in our society (Bernstein, 2014); therefore, it is critical to find innovative techniques to help facilitate language development in children with ASD. There continues to be no single standard treatment or approach that is recognized as most beneficial in helping children with ASD (Interagency Autism Coordinating Committee, 2012). New ideas and 
approaches need to be studied and evaluated (Maglione et. al., 2012). After all, children spend a majority of their time in the educational setting. It is important that not only special educators and support staff have tools available to increase communication skills for these students, but that regular educators do as well (Schwartz \& Drager, 2008). This is especially relevant with the directives contained in No Child Left Behind Act (2002) and its push to mainstream as many students with specialized needs as possible into the regular education environment. Unfortunately, not all educators have received in-depth training on how to help children with ASD learn to their abilities (Alexander et al., 2015; Hendricks, 2011). This is combined with the fact that there is not one standard approach that appears to be most effective. Educators need resources to help children with ASD that are practical, effective, and can be easily used in their educational environment. Thus, it is critical that new treatment approaches are explored, and educators are properly instructed concerning the use of these approaches in their educational practice.

As mentioned previously, being an SLP, especially a school based SLP, is an isolated profession and little has been done to understand their experiences working with an increasingly diverse population of those in need of language support, notably, children with ASD. This study is significant in that it looks across these practitioners to better understand their daily lives as they exist in relation to students, families, and the larger educational systems that impact their work. Because this study focuses on actual treatment activities, it will identify specific practices and techniques, the roles of parents and teachers, and at times the presence and absence of community among SLPs. In this way, this study also contributes to understanding the scope of various therapy techniques used in educational settings with children with ASD. Autism is a national health crisis in our society; therefore, it is critical to continue to investigate innovative 
techniques that might help facilitate language development in children with ASD. The field of speech language pathology has expressed a dire need to find additional therapy methods to help children with ASD (Interagency Autism Coordinating Committee, 2017; Maglione et al., 2012; McConnell, 2002). Working with children with ASD is often a frustrating experience for SLPs because of the lack of methods and ideas available (Stone, 1987; Schwartz \& Drager, 2008; Plumb \& Plexico, 2013). Additionally, there is a lack of agreed upon approaches to help all students. While the intent of this study is not to support one approach over another, it will assist professionals in realizing that multiple approaches are being used with great success.

\section{Purpose of Investigation}

This research study was designed to provide an in-depth examination of the experiences of SLPs working with children with ASD (e.g., experiences during therapy, working with families, and other aspects of being an SLP with their children with ASD). In addition, this study focused on a secondary aim: to better understand the various therapy techniques being used by SLPs working with children with ASD and to examine whether any of those techniques included aspects of creative dramatics. Currently, evidence-based therapies, such as Video Modeling and Social Stories, are considered best practices for working with students with ASD (ASHA, 2006; National Autism Center, 2011). However, these practices omit creative dramatics, an option that could be used to increase language development in a more stimulating and generalizable way. Drama-based interventions like creative dramatics have not been studied in-depth to determine if it is a viable intervention (O’Sullivan, 2015). Creative dramatics have been shown to help students with ASD in small scale studies. For example, creative dramatics have been shown to increase empathy skills (Schrandt et al., 2009), increase social interaction (Guli et al., 2013), and increase paralinguistic communication skills (Potter \& Whittaker, 2001) with students with ASD. 
My intention is that this study will stimulate a springboard for further research to increase the number of available evidence-based treatments designed to improve the natural language skills of children with ASD.

This case study research design used interviews and a reflective journal as data collection sources to investigate SLPs' strategies implemented in the treatment of children with ASD. As interviews were the primary data source, SLPs were asked to talk in-depth about specific language strategies, including their experiences using various approaches. This allowed me to determine which treatments SLPs were using and if they were integrating creative dramatics and/or components of the Building Blocks Model in their treatment regimens.

\section{Research Questions}

Two research question were used to guide the case study research design reported in this dissertation. The purpose of this study was to identify the different treatments used by practitioners in the treatment of children with ASD and to determine the extent to which creative dramatics was employed.

- Primary Research Question: What are the experiences of SLPs utilizing different treatment methods to improve the language skills of children with ASD?

- Secondary Research Question: To what degree do SLPs use creative dramatics in language therapy?

\section{Conclusion}

In conclusion, the increasing rates of ASD have caused a national health crisis in the United States. As more children are diagnosed, we need a better understanding of the therapy opportunities offered to children as well as a better understanding of the experiences of SLPs working with these children. Since SLPs are communication specialists, trained to treat the 
language deficits in children with ASD, it is important for the profession to study creative dramatics as a therapy tool. And while drama therapy and drama activities are increasingly being used with children with ASD, there is little research to determine if SLPs are using these techniques in language therapy and how they are being implemented. 


\section{CHAPTER 2: LITERATURE REVIEW}

\section{Background on Autism Spectrum Disorder}

According to the Autism Society of America, "autism is a complex developmental disability that typically appears during the first three years of life and affects a person's ability to communicate and interact with others" (2012, p. 1). No definitive cause for ASD has been discovered. Researchers continue to search for causes, as well as for effective treatments for ASD (ASHA, 2015; Autism Society of America, 2012; Mayo Clinic Staff, 2018; Sicile-Kira, 2014).

There are many different symptoms of ASD, however, the typical symptomology primarily consists of communication deficits and repetitive and restrictive behaviors. These repetitive behaviors can include rocking, pacing, hand flapping, and echolalia. Examples of restrictive behaviors may include lining up objects and intense preoccupation in certain interests. Since ASD is a spectrum disorder, its symptoms can range from mild to severe. Children with ASD also exhibit a variety of unique symptoms that contribute to the need for individualized learning (Sicile-Kira, 2014). Even identical twins with ASD will likely exhibit different deficits (Geschwind, 2011; Ronald \& Hoekstra, 2011). Researchers, educators, and parents continue to struggle with guidelines and best practice treatments to help children with ASD (Wilkinson, 2014). However, any individual diagnosed with ASD typically presents with a significant deficit with social language (American Psychiatric Association, 2013). These social language difficulties can range from mild, such as robotic speech and avoidance of eye contact, to severe lack of awareness, often with a complete lack of social reciprocity (Tubbs, 2008). Children with ASD also have trouble with figurative language. Typically, they have difficulty navigating the true meaning of figurative language (Kalandadze et al., 2018). Figurative language is non-literal 
language: "Generally, in figurative language, the intended meanings of the words, sentences and expressions used do not coincide with their literal meanings" (Gluksberg, 2001, as cited in Kalandadze et al., 2018, p. 99). Figurative language includes generalizations, similes, metaphors, idioms, and hyperboles. A generalization is a broad statement about a group or thing that is not always accurate, such as blondes are not as an intelligent as brunettes. Similes are a comparison of two unlike things using the word such as like and as. An example is "my love is like a rose." Metaphors are also a comparison of two unlike things without words such as like and as, which make the comparison more obvious, such as "her hands were icicles." Lastly, hyperboles are exaggerations that are not to be taken literally, for example, "I am so hungry that I could eat a horse." Children with ASD generally have difficulty with all forms of figurative language and need to have direct instruction on how to interpret and understand them.

\section{Evidence-Based Interventions}

There are evidence-based interventions that have been tested empirically and found to improve the communication skills of children with ASD (see Table 2.1 below). These researchbased interventions are Discrete Trial Training, Functional Communication Training, Video Modeling, PECS, Voice Output Communication Aid Devices, Peer Mediated Instruction and Intervention, Naturalistic Language Strategies, Joint Action Routine, Social Narratives, and Imitation and Modeling (Lofland, 2014). The two most common treatments, Discrete Trial Training and PECS, are heavily reliant on presenting repetitive training routines to achieve a desired communication skill (Bondy \& Frost, 1998, 2001; Duffy \& Healy 2011; Sicile-Kira, 2014). PECS is a reward-based visual communication system that teaches initiation and helps a child learn how to communicate (Bondy \& Frost, 1998, 2001). It is a nonverbal communication system, while the Discrete Trial Training is a verbal behavior-based technique in which the 
desired behavior is shaped by multiple trials (Smith, 2001). Please refer to Table 2.1 for a summary of evidence-based communication interventions 
Table 2.1

Evidence-Based Communication Interventions

\begin{tabular}{|c|c|c|c|c|}
\hline $\begin{array}{l}\text { Intervention/ } \\
\text { Creator }\end{array}$ & Description & Benefits & Advantages & Disadvantages \\
\hline $\begin{array}{l}\text { Discrete Trial } \\
\text { Training (DTT) } \\
\text { Ivar Lovaas }\end{array}$ & $\begin{array}{l}\text { A behavior-based technique } \\
\text { in which the desired } \\
\text { behavior is shaped by } \\
\text { multiple trials. }\end{array}$ & $\begin{array}{l}\text { Improves attention. } \\
\text { communication, social } \\
\text { skills, self-help, and } \\
\text { cognitive skills. }\end{array}$ & $\begin{array}{l}\text { Implemented for one or in } \\
\text { groups; breaks down } \\
\text { complex behaviors to } \\
\text { manageable single ones; } \\
\text { easy to keep data; and } \\
\text { emphasizes vocal } \\
\text { communication. }\end{array}$ & $\begin{array}{l}\text { Expensive, time consuming, rigid } \\
\text { program, and mainly best for young } \\
\text { children. }\end{array}$ \\
\hline $\begin{array}{l}\text { Functional } \\
\text { Communication } \\
\text { Training } \\
\text { V. Mark Durand } \\
\text { and Edward Gary } \\
\text { Carr }\end{array}$ & $\begin{array}{l}\text { Therapy technique of } \\
\text { replacing maladaptive } \\
\text { behavior with a more } \\
\text { appropriate behavior via a } \\
\text { communication response } \\
\text { and reinforcing the } \\
\text { appropriate behavior }\end{array}$ & $\begin{array}{l}\text { Increases appropriate } \\
\text { communication; } \\
\text { facilitates autistic } \\
\text { leading; and decreases } \\
\text { negative behaviors. }\end{array}$ & $\begin{array}{l}\text { Used with anyone } \\
\text { regardless of ability level; } \\
\text { easily taught to teachers } \\
\text { and parents; decreases } \\
\text { difficult behaviors; } \\
\text { decreases frustration; and } \\
\text { increases communication. }\end{array}$ & $\begin{array}{l}\text { Behavior has to serve a signal } \\
\text { purpose; the cause of the behavior } \\
\text { has to be appropriately identified; } \\
\text { and requires intensive collaboration } \\
\text { between SLP and behavior } \\
\text { specialist to implement. }\end{array}$ \\
\hline $\begin{array}{l}\text { Video Modeling } \\
\text { Monika Steinborn } \\
\text { and Terry J. } \\
\text { Knapp }\end{array}$ & $\begin{array}{l}\text { Intervention of presenting a } \\
\text { video of a desired behavior } \\
\text { or interaction. }\end{array}$ & $\begin{array}{l}\text { Increases } \\
\text { communication, social } \\
\text { skills, self-help skills, } \\
\text { and daily living skills. }\end{array}$ & $\begin{array}{l}\text { Individualized to each } \\
\text { student; limited time } \\
\text { planning; visual } \\
\text { representation and may be } \\
\text { applied to many situations. }\end{array}$ & $\begin{array}{l}\text { Student must have attention skills. } \\
\text { Limits use of communication } \\
\text { gestures and does not increase } \\
\text { spontaneous interaction between } \\
\text { child and peers. }\end{array}$ \\
\hline $\begin{array}{l}\text { Picture Exchange } \\
\text { Communication } \\
\text { System (PECS) } \\
\text { Andy Bondy and } \\
\text { Lori Frost }\end{array}$ & $\begin{array}{l}\text { Reward-based visual } \\
\text { communication system that } \\
\text { teaches initiation and helps } \\
\text { a child learn incentives for } \\
\text { communication. }\end{array}$ & $\begin{array}{l}\text { Improves } \\
\text { communication } \\
\text { particularly the Ability } \\
\text { to express wants and } \\
\text { needs. Teaches } \\
\text { initiation and turn } \\
\text { taking. }\end{array}$ & $\begin{array}{l}\text { Individualized and } \\
\text { communication is tangible. } \\
\text { Expandable program. }\end{array}$ & $\begin{array}{l}\text { Requires caregiver and teacher } \\
\text { support; can be limiting (may not } \\
\text { have pictures to represent } \\
\text { communication needs), continual } \\
\text { training cost, expense to train } \\
\text { program }\end{array}$ \\
\hline
\end{tabular}




\begin{tabular}{|c|c|c|c|c|}
\hline $\begin{array}{l}\text { Voice Output } \\
\text { Communication } \\
\text { Aide } \\
\text { Prentke Romich } \\
\text { Company }\end{array}$ & $\begin{array}{l}\text { AAC Device produces } \\
\text { recorded digitized speech } \\
\text { for user. }\end{array}$ & $\begin{array}{l}\text { Gives "a voice," fosters } \\
\text { communication, } \\
\text { decreased frustration, } \\
\text { provides the } \\
\text { opportunity to express } \\
\text { wants and needs. }\end{array}$ & $\begin{array}{l}\text { Many choices, social } \\
\text { acceptance, variety of costs, } \\
\text { portable, durable, }\end{array}$ & $\begin{array}{l}\text { Cons may require constant } \\
\text { programming, have to have device } \\
\text { to communicate, distracting } \\
\text { functions }\end{array}$ \\
\hline $\begin{array}{l}\text { Peer Mediated } \\
\text { Instruction and } \\
\text { Intervention } \\
\text { DiSalvo \& } \\
\text { Oswald }\end{array}$ & $\begin{array}{l}\text { Observing and learning } \\
\text { skills from peers }\end{array}$ & $\begin{array}{l}\text { Increases joint } \\
\text { attention, } \\
\text { communication skills, } \\
\text { pragmatic skills, and } \\
\text { play. Allows increased } \\
\text { opportunities for } \\
\text { meaningful social } \\
\text { interactions with peers. }\end{array}$ & $\begin{array}{l}\text { Improved social acceptance } \\
\text { in school; variety of peers } \\
\text { to choose as mediator; and } \\
\text { student may be more } \\
\text { comfortable with peer than } \\
\text { adult. }\end{array}$ & $\begin{array}{l}\text { Lack of generalizability and } \\
\text { maintenance with peer mediated } \\
\text { instruction; peers must be } \\
\text { adequately trained; and requires } \\
\text { constant assessment and } \\
\text { modification. }\end{array}$ \\
\hline $\begin{array}{l}\text { Social Narratives/ } \\
\text { Social Stories } \\
\text { Carol Gray }\end{array}$ & $\begin{array}{l}\text { Short stories that consist of } \\
\text { object statements that } \\
\text { address how to } \\
\text { communicate appropriately } \\
\text { and effectively in various } \\
\text { situations and circumstance }\end{array}$ & $\begin{array}{l}\text { Increase appropriate } \\
\text { social interaction and } \\
\text { decrease of negative } \\
\text { behaviors. }\end{array}$ & $\begin{array}{l}\text { Individualized, } \\
\text { inexpensive, and target } \\
\text { unlimited skills. }\end{array}$ & $\begin{array}{l}\text { Requires significant amount of time } \\
\text { to write the story: story may have to } \\
\text { be continually modified: and may } \\
\text { need prompts to be effective. }\end{array}$ \\
\hline $\begin{array}{l}\text { Imitation and } \\
\text { Modeling Therapy } \\
\text { Based on the work } \\
\text { of Baer \& } \\
\text { Deguchi; Bandura }\end{array}$ & $\begin{array}{l}\text { Modeling and having the } \\
\text { student imitate } \\
\text { communication targets. }\end{array}$ & $\begin{array}{l}\text { Improves } \\
\text { communication and } \\
\text { social skills. Provides a } \\
\text { natural foundation to } \\
\text { learn more complex } \\
\text { skills. }\end{array}$ & $\begin{array}{l}\text { Efficient and builds on } \\
\text { foundations for many skills. }\end{array}$ & $\begin{array}{l}\text { Promotes robotic speech and lack of } \\
\text { speech generalizability. }\end{array}$ \\
\hline
\end{tabular}


Functional Communication Training is a therapy method that consists of replacing maladaptive behavior with a more appropriate behavior via a communication response and reinforcing the appropriate behavior (Carr and Durand, 1985). An example of this is a child who is constantly trying to gain attention by screaming or hitting who can be taught to replace screaming by using a card that says "talk to me" to gain attention appropriately (LaRue et al., 2009, p. 166).

Video modeling is a type of observational learning (Corbett \& Abdullah, 2005). This treatment regimen consists of viewing a person demonstrating appropriate communication skills. The goal is for the child to replicate those appropriate communication skills.

Voice Output Communication Aide Devices are a type of Assistive Technology and are geared for nonverbal individuals (Schlosser \& Blischak, 2001). A Boston University Study found that $30 \%$ of people diagnosed with ASD are nonverbal (Berdik, 2014). Nonverbal communication means that either a person does not have spoken language or has limited verbal communication skills which are not considered functional (Rudy, 2019). Voice output devices are electronic portable devices that allow words or messages to be recorded and then "speak" when accessed by touch, eye gaze, key, etc. It provides a method for children to be able to communicate their wants and needs and participate in verbal communication exchanges with others (Schepis et al., 1998). Overall, children with ASD prefer visual learning and frequently improve their communication skills when technology is utilized (Grandin, 1995). Technology tends to provide visual clues that trigger a response (Cardin \& Wilcox, 2011).

Peer Mediated Instruction and Intervention is a strategy wherein peers assist children with ASD to engage in natural social situations to learn how to communicate effectively in these social situations (Chang \& Locke, 2016). The typically developing child is taught how to help 
their peers with ASD increase appropriate communication and behavior skills (Chan et al., 2009).

Social narratives or social stories are short stories that consist of object statements which demonstrate ways to communicate appropriately and effectively in various situations and circumstances. Gray (1998) created the concept of the social story as a therapy technique for children with ASD. Social Stories are personalized and may use words and/or visuals such as pictures. They focus on teaching cues to help the individual understand how to behave in specific social situations (Gray \& Garland, 1993).

These interventions have proven successful for students with ASD. However, while varied approaches to therapy and treatments for children with ASD have been suggested, most have achieved only mixed results depending on the individual child (Duffy \& Healy, 2011). This is due to the fact that each child with ASD presents a different pattern of symptomology. For this reason, there is no single standard practice of treatment for students with ASD in the fields of special education or speech language pathology. All of the treatments have seen moderate levels of success in the ASD population (Charlop-Christy et al., 2002; Prelock et al., 2011; Smith, 2001). However, Discrete Trials and PECS have difficulty with generalization of skills and have been criticized for their routine and often robotic responses (Duffy \& Healy 2011). They also do not address understanding and expressing emotions (Delprato, 2001, p. 323). The generalizability of social stories has overall been called into question in the research (Test et al., 2011). Video modeling has been more effective in basic scripts/conversation, but has been criticized as not as effective in more complex social communication interactions (Sng et al., 2014). A concern of voice output devices is that while such devices increase interaction with child and adult, they may limit use of communication gestures and not facilitate spontaneous 
interaction between child and peers (Schepis et al., 1998). It is unclear whether there is generalizability and maintenance with peer mediated instruction. Also, the peer providing the instruction was critical. It was most effective if it was a sibling (Zhang \& Wheeler, 2011). Lastly, functional communication training is often not as successful for SLPs to use without the collaboration of another professional, which is not always possible. Functional communication training for a child with ASD usually is more effective if an SLP and behavior specialist work together. It usually takes both professionals to establish a successful program. Even with the collaboration of professionals, it may take a prolonged length of time to document positive changes in language behaviors (LaRue et al., 2009).

Currently, there are researched-based intervention options for students with ASD. However, it is up to the SLP to find the most appropriate interventions for the student with ASD. Even then, the success may be mixed. Thus, the field is in need for new approaches, especially treatments like creative dramatics that encourage more spontaneous communication.

\section{What is Creative Dramatics?}

Creative dramatics is a group experience wherein each child is guided through a process of self-expression and interaction with others (Siks, 1983). Creative dramatic activities include puppetry, imaginative playmaking, storytelling, pantomime, sound to movement, and improvisation. The purpose of creative dramatics is not performance for an audience, but the process of using activities to develop the social and language skills of the whole child (Ward, 1947). It creates a pressure-free environment for the child to be guided to develop selfconfidence through artistic expressions. Creative dramatics begins with play, the natural way that a child learns (Ward, 1947). 
The importance of play for children is well documented in research. Play is not seen as a frivolous waste of time, but as critical to social and cognitive development of children (Bodrova \& Leong, 2005). Maria Montessori, an innovative physician and educator of the early $20^{\text {th }}$ century, developed the Montessori Method which is used in preschool curriculums around the world. Montessori saw play as work for children and central in their development. Montessori (2017) said: "Grown-ups think of play as a purposeless occupation that keeps children happy and out of mischief, but actually when children are left to play by themselves very little of their activity is purposeless" (p. 17). Montessori was an early advocate of including play in the education curriculum. She focused her curriculum on playful learning aspects in which the child has the independence to choose objects and activities and interact with peers or adults in an enjoyable and supportive way (Lillard, 2013).

Pestalozzi was a nineteenth century educational reformer who also believed in the importance of play and other educational changes (Gutek, 1968). In his book How Gertrude Teaches her Children: An attempt to help mothers to teach their own children and an account of the method (1894/1915), Pestalozzi portrayed the mother-child relationship as the exemplary model for education (Sellers \& Imig, 2021). Pestalozzi advocated that schools try to establish kind and loving environments He believed that students learn by observing their teachers just as children learn from their mothers (Gutek, 1968). He believed in a developmentally appropriate approach to aspects of education and to respect the child (Sellers \& Imig, 2021). He also emphasized sensory learning. He created the Anschauung Principle based on sensory learning or an "individual's capacity for obtaining knowledge and rationality by using his or her own innate ability, primarily, by means of the five senses" (Takaya, 2003, p. 78). He also believed in educating the whole child. Brühlmeier (2010) stated that Pestalozzi thought that it is important to 
educate with "head, heart, hands" (p. 47). Pestalozzi recognized the importance of unstructured play in education as well and how play could facilitate children's learning (Sellers \& Imig, 2021). Pestalozzi saw play as a "natural gift, a propensity, or inclination of children, and following its dictates would result in a free-play approach or delightful or playful activities" (Frost, 2009, p. 48). Children would learn more easily by engaging in playful educational activities rather than rigid, rote memorization.

Frederick Froebel studied under Pestalozzi and they both shared ideas of humanistic education and educating the whole child (Manning, 2005). Pestalozzi focused on student observation, but Froebel added activity (Cole, 1918). Froebel also expanded on this importance of free play in his book, The Education of Man (1887). He wrote of his belief in the importance of play as well: "Play is the highest phase of child development of human development — at this period." (p. 55).

The National Association for the Education of Young Children stated that "high-level dramatic play produces documented cognitive, social, and emotional benefits" (Copple \& Bredekamp, 2009, p. 15). Play is not just beneficial to young children, but to children of all ages. It is the basis for literacy and problem-solving skills (Zigler et al., 2004). It also is vital in emotional well-being and mental health in older children (Ginsburg, 2007). Play is a critical part of child development. Unfortunately, children are not getting enough play time in the school system (Frost, 2012; Miller \& Almon, 2009). Creative dramatics provides a much-needed outlet for play and creative exercises for children. Creative dramatics is essentially imaginative play (Pincotti, 1993). Winfred Ward (1947) described creative dramatics as not only imaginative play, but also dramatic play, playmaking, make believe play: "it is the play-living in which a child 
'tries on life"' (p. 3). Therefore, play is essential to creative dramatics. Pinciotti (1993) described the play roots of creative dramatics:

An encompassing learning medium, emerging from the spontaneous play of young children and utilizing the art of theatre to build and enhance the participants' artistic sensitivity, awareness of self, others, and the world and develop each child's dramatic imagination" (p. 24).

Thus, creative dramatics allows children to continue to develop and use critical play skills.

Creative dramatics is also a natural strategy for communication because students feel confident to speak free of pressure. Interestingly, oral language skills have even been enhanced through the use of pantomime as the success in physical response to story activities leads the child to focus on spoken language to communicate (Tubbs, 2008).

\section{History of Creative Dramatics in Education}

The roots of creative dramatics in the schools can be traced back to Friedrich Froebel's kindergarten in the United States (Wright, 2016). Froebel created the first kindergarten curriculum to use play as an integral part of learning, as indicated by Hensel (1977):

The Froebelian kindergarten had been introduced in the United States in the 1850 s and revolved around a series of highly structured play materials which were to be used in a predetermined way to lead the child toward discovery of the basic principles of life. (p. 5) Froebel believed in concrete, developmentally appropriate learning materials that he called "gifts." These were wooden blocks that the students could keep. He also introduced occupations or play materials that consisted of clay, paints, paper, shells, scissors. He believed these materials would promote naturalistic play (Park \& Yang, 2016). These ideas continue to be used in kindergarten curriculums today. 
Jean Piaget also recognized the importance of child's play as vital to a child's cognitive development (Garwood, 1982). His theory of development identified symbolic play as "an activity that children use naturally to assimilate new experience and to play with it in order to understand it better" (Siks, 1983, p. 8). Creative dramatics is one way to encourage symbolic play, as well as the power of imagining so important to Piaget. After early development of images, "the child develops the ability to give form to them through the abstract symbols of language and movement, evident in the child's symbolic play” (Siks, 1983, p. 42).

In the American movement toward progressive education in the early 20th century, the child-centered approach to education was also being developed (Reese, 2001). John Dewey, the most famous American educational theorist and philosopher, was the first to advocate the use of drama in his child-centered classroom in the United States. He saw art as an experience (Dewey, 1934). Dewey (1916) also believed that children learned by doing and not through passive experience, writing, "Give the pupils something to do, not something to learn; and the doing is of such a nature as to demand thinking; learning naturally results" (p. 154). Dewey viewed constructive thought, such as poetry or philosophy, as experience with the same aesthetic qualities as the fine arts. Experience, in both cases, "has an artistic structure because it possesses internal integration and fulfillment reached through ordered and organized movement" (1934, p. 416). Intellectual experience cannot be separated from artistic, since both must have aesthetic qualities to be complete. Thus, Dewey believed that movement in the classroom was important. Bolton (1985) wrote, "What excited the early progressives about drama was not innovation in terms of curricular content, but the learning process and expression. Children, it was argued, would enjoy learning facts if they were illustrated in this attractively active way" (p. 152). Drama was used as a tool to link what children do naturally in the classroom with what the child was 
studying. Dewey did not see art as an isolated function, but as "emphatic expressions of that which makes any education worthwhile" (1916, p. 238). With this perspective, educational drama was solidified as part of the progressive education curriculum.

The British seized upon these progressive ideas. In the 1930s and 40s, Peter Slade, a British educator, was one of the first theorists to see "child's play" as a critical skill for human development. Slade (1998) believed in the importance of children's natural expression. He encouraged teachers to feel more comfortable integrating creative dramatic and theater techniques in the classroom. His book, Child Drama (1955), was the result of twenty successful years using drama techniques with children. He believed that using drama in education was an essential way to bring children's natural play to schooling.

Brian Way, a contemporary of Peter Slade, also focused on the relationship between drama and teaching (Dillon \& Way, 1981). He introduced the notion that drama was concerned with the individual and individual experience. This focus on individuality "echoed the philosophy of progressive education. Once again drama was seen to epitomize a liberal education. In drama, each child could 'find himself,' to use a catchphrase from the American humanist movement" (Bolton, 1985, p. 154). Yet, Way did not see drama as a tool in education. Way introduced participation theater to drama. This allows the audience to become part of the play or activity. McCaslin (1990) expanded, "The line commonly drawn between creative drama and children's theatre disappears as the spectator becomes a participant" (p. 9). Participation, therefore, is an important aspect of educational drama.

British educator, Dorothy Heathcote, brought the idea of drama back into teaching in the 1950's. Heathcote believed that drama activities could be incorporated across many subjects to help students learn (McCaslin, 1990). She believed that educators could by "a conscious 
employment of the elements of drama to educate ... literally bring out what the children already know but don't yet know they know" (Wagner, 1976, p. 13). In her now-famous book in the field, Drama as a Learning Medium, Heathcote (1976) wrote a chapter about working with severely handicapped nonverbal students. She found that by using "nonverbal signals" during a drama activity about fairies, she was able to elicit verbal response (Wagner, 1976). Heathcote further explained that presenting universal material "in concretely graspable form ... is the massively untapped aspect of drama methods. By its nature it slows time down, forces attention.... It is essential in all learning” (Johnson \& O’Neill, 1984, p. 152).

Winifred Ward, an American educator and an expert in pedagogy, was the first to call educational drama, "creative dramatics," coining the term in 1930 (Shuman, 1978). She also was greatly influenced by Dewey's progressive movement. Ward wrote in Playmaking with Children (1947):

Most modern educationists ... agree with John Dewey that education is not merely preparing a child for his future life. It is giving him the chance to live richly now in the belief that this is the best preparation for the future. They believe that the whole child should be educated, not just his mind; that he should be developed to his highest potential both as an individual and as a social being; that he grows, not from having knowledge poured in by the teacher but rather from participating in activities that challenge his deepest interest and highest powers. (p. 17)

Ward formulated her views of creative dramatics through a special interest in children's personality development, stressing "that the greatest opportunity from creative dramatics was in the area of character development" (Hensel, 1977, p. 6). Thus, Ward believed that creative 
dramatics could foster self-confidence by allowing the child to pursue and develop preferred interests through dramatic exercises.

\section{Creative Dramatics Influence on Pedagogy}

Creative dramatics can be viewed from a critical pedagogical lens as found in the works of Paolo Freire. Gerbardt (1993) wrote that Freire was a Brazilian theorist, educator, and revolutionist in the 20th century. He worked with the illiterate poor in Brazil, who were oppressed by their social institutions because they could not vote due to not being able to read. He saw schools as oppressive institutions with educators constantly dictating to students what to do instead of giving students an opportunity to think for themselves or to have a voice in the learning process. He felt that educators controlled society by deciding what is taught to students and who is taught (Teodoro, 2003). Maxine Greene also agreed with Freire's views on pedagogical oppression (Lake, 2013). She believed that current curriculum laid in the hands of bureaucrats, not educators. In this way, students were still being told what to learn instead of being enabled to think for themselves. Greene (1977) believed that education needs to be liberated from bureaucratic domination and technology. Greene asserted that students have to start asking, "why?" An aesthetic curriculum encourages those important "why" questions (Greene, 1977). With creative dramatics, students are encouraged to express themselves in the classroom. Creative dramatics fosters the confidence in students that gives them the courage to challenge and express ideas. All students are encouraged to express themselves fully, regardless of disability (Wagner, 1976).

Augusto Boal, a contemporary of Freire, created the Theater of the Oppressed (TO), "an aesthetic education for liberation," based on Freire's ideas (Pitcher, 2007, p. 79). TO highlights theater not as spectacle, but rather as a learning process that fosters critical thinking. Specifically, 
TO is understood as a practice consistent with Paulo Freire's approach to liberal education, namely aesthetic education that promotes a transformative model of learning based on dialogue. Creative dramatics in the classroom can use some tenets from TO to help students become aware of their oppression (Pitcher, 2007, p. 79). "In TO, theory and practice form an integrated system; they constitute a praxis that is rooted in the struggle to change consciousness, and this struggle emerges as the art of organizing for direct democracy by using direct democracy" (Pitcher, 2007, p. 81).

TO, particularly Image Theater, is a form of creative dramatics that can be used in the classroom. Pitcher (2007), for example, wrote:

Image Theater is a repertory of games and techniques that emphasizes physical dialogues, nonverbal imagery, consensus-building, problem solving processes, and techniques for developing awareness of both objective and internalized forms of oppression. Here, the body is used to create images that help participants explore power relations and group solutions to concrete problems. (p. 82)

Not only do students develop communication skills, particularly language and social skills, but they also develop an ability to think for themselves, reflect, and question ideas with creative dramatics and TO methodology (Pitcher, 2007).

Unfortunately, many people with disabilities are oppressed in our society today. Even though there is legislation, such as No Child Left Behind, to protect students with disabilities in the schools, such students are still being marginalized. Some teachers routinely try to exclude them from their classroom. They feel overwhelmed by the amount of extra work and preparation needed to work with a child with disabilities and some feel that it takes away from their typically developing students (Horne \& Timmons, 2009). It is also even more poignant for students with 
ASD because they have difficulties expressing their wants, needs, and feelings and often cannot advocate for themselves (Keen, 2009). Kiernan Rose, the founder of The Autistic Advocate an online blog and resource website for individuals with ASD writes of his own difficult experiences having ASD in school. He writes that school was exhausting for a student with ASD because he was trying to fit into the neurotypical world as much as he could, despite educators who did not understand ASD. Also, he believes that schools should be safe sensory environments for students with ASD to learn, but they are not (Rose, 2018).

Many times, others presume to know how these students are feeling in spite of their limited ability to express themselves. Teachers or other students may assume that these students do not have feelings at all. They also may incorrectly minimalize their intellectual abilities based on their limited language skills (Courchesne et al., 2015). Therefore, it is important to help these students find "their voices" to express their wants and needs. Creative dramatics allows this in a non-pressured setting. For example, if a student is being bullied, he or she can express through improvisation what is going on and then come up with strategies to prevent this in the future (O’Toole \& O’Mara, 2007).

There are a number of advocacy centers for individuals with ASD. Autism Self Advocacy Network (ASAN), Autism Speaks, and Autism Society of America are national organizations devoted to providing education on ASD, as well as resources for individuals with ASD. There are also statewide and local advocacy and support resources. For example, the West Virginia Autism Training Center (WV ATC), affiliated with Marshall University. was established in 1984 by The West Virginia Legislature. The WV ATC provides education, information, and advocacy for not only individuals with ASD, but also their families and educators working with individuals with ASD. 


\section{Creative Dramatics Used with Students with ASD}

Despite the need for social language intervention in the burgeoning ASD population, support for creative dramatics has been slow to emerge as an effective approach to maximize language development. This is surprising because play experiences, especially symbolic play, are particularly lacking in students with ASD:

For many children with ASD, the various stages of play never truly develop, or occur in a fragmented fashion. Difficulties in motor planning, expressive and receptive communication, imitation, and fine and gross motor movements are just some of the many obstacles they encounter during play. (Mastrangelo, 2009, p. 34)

This is a particularly serious deficiency because play or make believe is an important component for children to establish their social competence. As Lewis (2003) points out, "Play, particularly when other people are involved, provides many opportunities for developing social, cognitive, and communication skills" (p. 391).

Creative dramatics offers an especially effective approach to counter these deficiencies through play and make believe. Structured classroom play activities allow children to facilitate important language skills in a positive and rewarding fashion. Peter (2009) asserts that "drama as narrative pedagogy can offer even the most remote, hard-to-reach, socially challenged children the opportunity to develop a sense of narrative identity and to move toward more effective participation within a social world" (p. 16).

While there is little research on creative dramatics as an effective therapy technique for students with ASD, there are some findings that report on particular components of creative dramatics used with children with ASD. Kempe and Tissot (2012) analyzed a high school senior year mixed classroom in England of 12 students, meaning that some students did not have any 
special education needs whereas others did have some special education needs. The study focused on two female students with ASD. The teacher guided the class through the drama process of creating and then performing a play. Kempe and Tissot (2012) aimed to analyze the social language skills of the two girls. Their study found that the drama process created a "safe space" for the students to have the opportunity to practice social skills that they might not otherwise have had. It also unexpectedly found imagination skills of the students that had previously not been identified. However, this study also uncovered challenges. The first was peer learning. It was difficult to nurture peer cooperation and learning among students on such different levels. The second challenge was having the teachers feel comfortable enough with their own backgrounds to fully participate in helping their students with the exercise.

Another study by Guli et al. (2013) analyzed the Social Competence Intervention Program (SCIP), an intervention program based on creative drama. This study investigated the use of SCIP with children diagnosed with ASD, Nonverbal Learning Disability (NLD), and Attention Deficit Hyperactivity Disorder (ADHA). It compared the performance of children in the SCIP with a control group with similar diagnoses and ability levels who did not receive this intervention. The children were between the ages of 8 and 14 . The results of this study found an increase in social interaction and a decrease in solitary play of participants who participated in SCIP compared with those who did not. It also found generalizability of social skills outside of the intervention setting.

Schrandt et al. (2009) also conducted a study using dolls and puppets to teach empathy and social language skills through dramatic play vignettes to four children with ASD, ages 4 to 6 . This study found that the students exhibited an increase in empathy skills, not only in therapy, but generalized outside of therapy. Interestingly, this study also found that some children were 
more comfortable expressing emotions through the use of puppets and dolls. This tool of expression was not intimidating and provided a safe way to express their emotions without the worry of judgment of others. It also allowed them to play out emotions in social situations and in a safe environment.

Corbett et al. (2011) investigated a pilot program called Social Emotional Neuroscience Endocrinology (SENSE) Theatre to improve the social and emotional skills of children with ASD, as well as to reduce stress. The study consisted of eight children ages 6 to 17 years of age. The program involved the children being part of a complete musical theater experience from rehearsals to production while paired with peers that modeled appropriate social interactions. The study tested aspects of socioemotional functioning such as face identification and theory of mind skills. It also studied the participants' stress cortisol levels throughout the program intervention. The researchers concluded that the children did have increased ability for face identification of emotions and expressions. Also, stress decreased over time in terms of the children's cortisol levels. However, this study found minimal improvement in theory of mind skills such as ability to understand others' perspectives and what others are thinking and feeling.

On the other hand, the research of Schrandt et al. (2009) found that children with ASD can develop important pragmatic language skills, including interaction with others, understanding nonverbal cues, and recognizing and practicing emotions. Paralinguistic communication skills, specifically prosody and rate, can be improved by creative dramatic exercises (Potter \& Whittaker, 2001). Difficulties with metalinguistic language concepts can also be identified and depicted through creative dramatics (Sherratt \& Peter, 2006). Overall, creative dramatics provides children with opportunities to generalize to different communication situations, rather than practice single-scripted communication behavior in a therapy setting 
(Tubbs, 2008). Peter (2009) found the under-functioning parts of the brains of children with ASD may be stimulated by playful activity that tends to provoke emotional responses. Lastly, creative dramatics provides an outlet for creativity and play.

Unfortunately, many students with ASD have few if any creative opportunities in the school system. With creative dramatics, students can express themselves while interacting with peers in a pressure-free situation to build self-esteem, as well as relationships with peers (Sherratt \& Peter, 2006).

\section{Conclusion}

This case study will explore the experiences of SLPs working with children with ASD. It is important to identify the strategies and treatment practices that are employed by SLPs. These experiences include not only what therapy techniques have been successful for them, but also to hear about the entire experience of being an SLP. Usually, there is just a single SLP servicing a school or multiple school. SLPs rarely get the chance to discuss their therapy practices with other professionals. This study will offer insights into that practice. It is also beneficial for other professionals to be aware of the treatment practices employed by SLPs. As mentioned in Chapter 1 , there are few case studies that have been conducted on this topic and none that has been conducted from the perspective of the SLPs. Therefore, this study will be groundbreaking in the sense that it simply has not been addressed previously in the context of the experience of the SLPs working with their students with ASD.

This study will also explore in depth the phenomenon of SLPs using creative drama in speech and language therapy for children with ASD. Not only is a study like this absent in the current literature, but it also seeks to determine if an innovative therapy technique such as creative dramatics is used by SLPs. The studies discussed previously provide preliminary 
evidence that creative drama methods can be effective with children with ASD. The limited empirical research confirms that not only have children's pragmatic social language skills increased, but imagination and self-confidence increased as well. Some of these studies have also documented the generalizability of communication skills; however, additional investigations need to be conducted. It is possible that this research will lead to an increase in the use of creative dramatic methods with children with ASD and further empirical scrutiny. 


\title{
CHAPTER 3: METHODS
}

\begin{abstract}
Aim of the Study
How might SLPs facilitate language development in children with ASD? SLPs and other educators in the school system are working with an increasing population of children diagnosed with ASD. As previously stated, the prevalence of ASD (CDC, 2020b) in the United States is currently 1 in 54 children. This reflected a 10 percent increase from 2014 when the prevalence of ASD was lin 59 (Autism Speaks, 2020). This case study was conceived from the belief that it is important that SLPs and educators have tools to help their students communicate their basic wants and needs to enable them to participate most effectively in the academic environment in the classroom with their peers, with the educator, and with the other academic staff. It is also critical that educators foster in their students a love of learning and creativity. The main purpose of this study was to investigate the experiences and perspectives of SLPs delivering speech and language therapy to children with ASD. This encompassed the techniques and methods SLPs describe to increase language skills with these children. This study also addressed a secondary research question that identifies what, if any, creative dramatic techniques SLPs are using in their practice; how they described these techniques; and if they found these techniques beneficial to language development.
\end{abstract}

This case study investigated SLPs' experiences of working with children with ASD during speech and language therapy sessions. While focused on the full range of experiences, I was interested in experiences that provide insight into the use of creative dramatics, using the lens of the Building Blocks Model. The SLPs described their "lived-through" memories during interviews. Focusing on SLPs' experiences of conducting language therapy for children with 
ASD will provided a deeper understanding of how language therapy is currently provided to students with ASD and ways to make it more successful in the future.

Using an exploratory single case study research design, two research questions were investigated:

- Primary Research Question: What are the experiences of speech language pathologists utilizing different treatment methods to improve the language skills of children with ASD?

- Secondary Research Question: To what degree do SLPs use creative dramatics in language therapy?

The primary research question investigated the phenomena of providing language therapy to children with ASD. This question explored multiple aspects of SLPs' experiences of the SLPs' experiences. This study attempted to understand the techniques or methods that SLPs used during their therapy sessions, as well as the outcomes of those techniques. In addition, this study identified aspects that were successful, those that were not, and why this was the case through qualitative analysis.

The secondary research question examined the experiences of SLPs providing language therapy to students with ASD, but focused specifically on that part of their experience that entailed creative dramatics in therapy. This was an exploratory research question to determine if creative dramatics was even present in therapy sessions. If the SLPs did use creative dramatics, this question guided the research to explore the way these experiences manifested in practice. These questions were investigated primarily through a semi-structured interview protocol with five SLPs who currently work with children with ASD in the school system, private practice, or 
Birth to Three settings. The interview format allowed the SLPs to discuss specific components of their work, but also enabled them to discuss particular experiences in depth.

\section{Exploratory Case Study}

This exploratory case study, a qualitative research design, focused on a holistic research approach. Grounded in the constructionist epistemological paradigm, the study focused on meaning constructed through experience as "reality is constructed by individuals interacting with their social worlds" (Merriman, 2009, p. 6). Qualitative inquiry is rooted in the work of anthropologists and sociologists going into "the field" to understand deeply a group of people, an event, and/or a situation. Thus, the qualitative research method emerged as a scientific process to observe a phenomenon (Merriman, 2009). Stake (1995), a prominent case study researcher, wrote that "Qualitative study capitalizes on ordinary ways of making sense. Each person has a great deal of experience encountering strange objects and phenomenon” (p. 72). Thus, a case study is a qualitative research approach that looks in depth at a single case, multiple cases or a group, a phenomenon or an event.

Yin (1984) coined the term exploratory case study as a category of case study research. "Exploratory case studies set to explore any phenomenon in the data which serves as a point of interest to the researcher" (Zainal, 2007, p. 3). Exploratory case study does not have a set outcome to the study. It is also conducted to see if further investigation in needed. Baxter and Jack (2008) cited Yin (2003) for the proposition that an exploratory case study "is used to explore those situations in which the intervention being evaluated has no clear, single set of outcomes" (p. 548). Exploratory case study research also lends itself to further research on the case study in the future. Exploratory case study is most appropriate to conduct research on the experiences of SLPs working with children with ASD because the research design allows the 
researcher to investigate a phenomenon in the context in which it occurs. It aims for an "in-depth understanding of the situation and meaning for those involved," and focuses on "process rather than outcomes, in context rather than a specific variable, in discovery rather than confirmation" (Merriam, 1998, p.19). Case study “enables the researcher to answer 'how' and 'why' type questions, while taking into consideration how a phenomenon is influenced by the context within which it is situated" (Baxter \& Jack, 2008, p. 556). Case studies are grounded in the constructivism epistemology. Constructivists counter the positivist claims to objective reality (and universal truths). Instead, constructivism posits that meaning is constructed through human experience, as well as situated in culture. Therefore, when using an underlying theoretical model such as constructivism in case study research, Crotty (1998) said it is important to remember: Description and narration can no longer be seen as straightforwardly representation of reality. It is not a case of merely mirroring 'what is there.' When we describe something, we are, in the normal course of events, reporting how something is seen and reacted to, and thereby meaningfully constructed, within a given community or set of communities. When we narrate something, even in telling our very own story, it is (again in the normal course of events) the voice of our own culture—its many voices, in fact—that is heard in what we say. (p. 64)

\section{Appropriateness}

Stake (2006) stated that "Qualitative case study was developed to study the experience of real cases operating in real situations" (p. 3). The main purpose of the study was to better understand the ways in which SLPs work with children with ASD. Therefore, case study allowed me to investigate the ways SLPs describe their individual and unique experiences of working with children with ASD. While there may be similarities among SLPs, each was unique in her 
practices and contexts, allowing a deeper understanding of the experiences of working with children with ASD in a language therapy setting.

The study looked at the phenomenon of SLPs in a language therapy setting. There were no specific limitations imposed on what the SLPs chose to talk about during the interviews. There were guiding questions, but the SLPs had the freedom to divert to whatever they felt was appropriate and important to convey the experience of working with children with ASD (see Appendix C for interview questions). Stake (2006) described the goal of case study research:

The researcher tries to capture the experience of that activity. He or she may be unable to draw a line marking where the case ends and where its environment begins, but boundness, contexts, and experience are useful concepts for specifying the case. (p. 3) Thus, this study attempted to understand the experience of SLPs providing therapy to students with ASD in the hope that it will help SLPs who are currently working with students with ASD in their therapy practices, as well as leading to future research on more creative alternatives to traditional language therapy.

\section{Boundary of the Investigation}

Stake (2006) noted "that a case has an outside and an inside. Critical components lie within the system, within the boundaries of the case; certain features lie outside. A few of the outside features help define the context or environment of the case" (p. 3). The research completed for this dissertation necessarily made it difficult to "draw a line marking where the case ends, and the environment begins" (Stake, 2006, p. 3). This difficulty in defining what was outside and inside the case is revealed due to the very nature of the research - outreach to SLPs to determine their experiences working with children with autism. Because of the differing environments in which they operate and their different experiences, clear and concise boundaries 
for the case were difficult to define. However, to the extent that information was utilized that was outside the case, it strengthens, rather than weakens the overall impact of the information synthesized for this dissertation as it begins to form the basis for potentially larger and more in depth study of the subject matter in the future, utilizing an even more refined and targeted approach to further explore this important area of study, which has yet to be thoroughly examined in great detail. The parameters of the case can certainly be defined through experiences and input provided by the SLPs that engaged in interviews. As Stake (2006) asserted, "boundedness, contexts and experiences are useful concepts for specifying the case" (p. 3). The boundedness of SLPs working with children with autism, irrespective of actual job setting, confirms a baseline for their ability to provide input for this dissertation. While their "contexts" in the form of job setting may differ, their "experiences" provide additional parameters within which I was able to explore these experiences and the results they obtained working with children with ASD.

Stake (2006) sees the case as a noun. He wrote, "We can use the case as an arena or host or fulcrum to bring many functions and relationships together for study" (p. 2). The case investigated in this study was the phenomenon of five SLPs' working with children with ASD. The phenomenon included not only the SLPs current practice of working with children in a therapy setting, but also their impressions and insights over years of working with these children, interacting with parents and peers, and observing the advantages and disadvantages of therapy approaches and materials. The phenomenon of SLPs' experiences working with students with ASD was the boundary of the case. As Stake (1995) stated, the case does have boundaries and is an "integrated system" (p. 2). There were also five sub-cases of each individual SLP in this study. 


\section{Research Design}

As noted briefly above, this dissertation study used an exploratory single case study research design. Exploratory single case study design was the most appropriate methodology to utilize, compared to other qualitative method research designs, such as ethnography, heuristic inquiry, ecology psychology, constructionism/constructivism, and reality testing (Patton, 2002). Unlike studies seeking a cure or resolution on an issue, this study sought to determine what techniques, including creative drama, were being utilized to help children with ASD. Another aim of this study was to determine whether SLPs used creative dramatics with their students with ASD and if it was successful. The purpose of this study was not to find an answer concerning which specific approach was the best or which type of approach to ASD and language was the best approach based on formally tested student outcomes. That is another area of study that will need to be completed in the future if creative dramatics is more widely used in the classroom and there are larger number of students who have been exposed to this type of instruction.

This study aimed to better understand the phenomena of SLPs working with children with ASD in an in-depth, personal, individual way. Each child comes to school from a unique family setting and culture with variant life experiences, physical characteristics, and social skills. The SLP must analyze and treat the whole child to be successful at speech therapy, including the unique characteristics that inevitably influence outcomes. This is especially true for children with ASD because each of these children presents an individual symptomology. There is not one language therapy technique that has been found to be the "gold standard" technique for helping children with ASD. In fact, a wide range of treatment modalities are utilized. Because each child with ASD presents a unique set of symptoms, differing treatment methods are used. Whereas issues such as Attention Deficit Disorder (ADD) and Behavioral Disorder (BD) offer relatively 
uniformed symptomology, the characteristics of ASD can differ significantly depending on the individual child. Therefore, studying the phenomenon of SLPs working with children with autism is pertinent and important.

\section{Participants}

I chose purposive sampling to select my participants. Patton believed this is one of the most valuable types of sampling to gain the greatest amount of in-depth information for a study. Patton (2002) argued, "The logic and power of purposeful sampling lies in selecting informationrich cases for study in-depth. Information-rich cases are those from which one can learn a great deal about the issues of central importance to the purpose of the inquiry, thus the term purposeful sampling” (p. 230). I chose convenience sampling as the subset of purposive sampling for my study (Merriam, 2009), selecting five SLPs who work with children with ASD in a variety of settings (see Appendix D for Recruitment Letter). I also chose these SLPs on the basis that I had studied with them in graduate school at The University of Virginia or had worked or currently work with them through the Marion County Board of Education in West Virginia. I did not work with or professionally interact with any of these individuals on a daily basis. However, our shared educational experiences and the commonality of the population of students we worked with allowed me to evaluate the results of this study while accommodating for the implicit bias that arises from shared educational and professional experiences. I worked to reflect and examine the information provided by the participants from the standpoint of similar educational and professional experiences. Although, my experience as an SLP may have influenced my analysis in this study, it also is a strength because it allowed me to better see the nuances of SLP practice. Lastly, all the participants were willing to share details of therapy sessions with their children with ASD. At the time of this study, three of the SLPs were working in the school system, one 
owned her own private practice, and the other worked for a therapy company, but limited her therapy to children with ASD. Table 3.1 is a summary of the background of the participants. Table 3.1

Background of Participants

\begin{tabular}{|c|c|c|c|c|}
\hline Pseudonym & Position & Workplace & $\begin{array}{l}\text { Background } \\
\text { (Years } \\
\text { Practicing) }\end{array}$ & $\begin{array}{c}\text { Level of } \\
\text { Severity of } \\
\text { Students }\end{array}$ \\
\hline Amber & $\begin{array}{l}\text { Birth to Three } \\
\text { SLP }\end{array}$ & $\begin{array}{c}\text { Students' } \\
\text { homes }\end{array}$ & 21 years & All Levels \\
\hline Denise & $\begin{array}{c}\text { Private } \\
\text { Practice } \\
\text { SLP/Owner } \\
\text { and Clinician } \\
\end{array}$ & Private Clinic & 13 years & All Levels \\
\hline Erin & School SLP & $\begin{array}{l}\text { Elementary } \\
\text { Schools }\end{array}$ & 25 years & All Levels \\
\hline Nina & $\begin{array}{c}\text { Private } \\
\text { Practice } \\
\text { SLP/Owner } \\
\text { and Clinician }\end{array}$ & $\begin{array}{c}\text { Students' } \\
\text { Homes }\end{array}$ & 13 years & All Levels \\
\hline Sara & School SLP & $\begin{array}{l}\text { Elementary and } \\
\text { Middle Schools }\end{array}$ & 23 years & All Levels \\
\hline
\end{tabular}

\section{Data Sources}

Approval to initiate this investigation was obtained from the Office of Integrity and Compliance (Approval Number 1602997313). The data consisted of interviews with the SLPs and field notes taken during the interview process and a journal kept by the researcher. I personally contacted potential participants via email and inquired about their willingness to participate in the study. Due to distance, I set up arranged times to collect data via phone contact or in person to discuss the requirements of the study, answer any questions about the study the participants may have had, and set up a time for the upcoming interview. Participants signed a written consent to participate in the study. No identifying information was included that would allow the participants to be identified. 


\section{Interviews}

This study utilized a case study research design approach with interviews as the primary data source. Similar studies have been conducted (Houghton et al., 2012; Karli et al., 2009; Kraft and Gilmour, 2016). They also used this case study methodological approach with interviews as the primary data source.

Firsthand interviews were used as the primary data source for this study. The goal of an interview is to "find out those things we cannot directly observe" (Patton, 2002, p. 340). Conducting an interview also allows the researcher "to enter into the other person's perspective" (p. 341). Therefore, interviewing five SLPs who work with children with ASD was incredibly valuable in this study. As noted previously, I chose five SLPs for the purpose of this study. This is appropriate for this case study design, as a case study can have one participant or many participants. However, studies including multiple participants allow the researcher to not only look at each participant's experience individually, but also across the collective participants' experiences as a whole (Yin, 2003).

This study utilized the semi-structured interview approach. Merriman (1998) described the semi-structured interview as "guided by a set of questions and issues to be explored" (p. 93). The interviewer needs to be familiar with the phenomenon and spend time reflecting on this phenomenon before and after the interview process. Therefore, the researcher prepared questions in advance, as a semi-structured interview guide (see Appendix C). This interview guide included questions such as, "Describe a typical session with a child with ASD and describe the activities that you have seen as the most successful in terms of facilitating language development for children with ASD." The prompt "tell me more" was used if it appeared that the SLP wanted to discuss in further detail a topic. The follow up questions varied dependent on the nature of the 
conversation. Overall, the natural discussion of the interview shaped the conversation. The interviews were conducted in person privately in closed rooms. There was not a set time limit to the interviews. They lasted as long as the participant wanted to discuss the topics. The length of the interview varied among the participants. One interview was approximately an hour in length, three were approximately two hours, and one was approximately three hours. The participants all appeared at ease during the interviews. Each interview was recorded using a tape recorder with the interviewee's permission. I also took notes during the interview and immediately after the interview. The note taking process also continued in the weeks following the interviews in the form of reflections upon the interviews. Lastly, the participants were given a transcript of their interview to review and make any revisions needed. I contacted them through phone calls during this interview review process. None of the participants chose to make revisions.

\section{Researcher Journal}

A researcher journal was kept as a data source for this study. A research journal is "research-focused reflective writing by researchers" (Borg, 2001, p. 157) that is kept during the research process. Janesick (1998) wrote, “Journal writing allows one to reflect, to dig deeper if you will into the heart of the words, beliefs, and behaviors, we describe in our journals. It allows one to reflect on the tapes and interview transcripts from our research endeavors" (p. 11). Thus, a research journal promotes reflection and reveals new observations that can lead to critical observation and thinking (Patton, 2002). A research journal was kept for this study during the interview and data analysis processes. Researcher journals have been found to promote reflections that lead the researcher to be more mindful of "our own epistemological position; our thoughts and feelings about how the research is progressing; exploring how we experienced the research situation as a social encounter and what influence that had on the interpretations 
produced" (Nadin \& Cassell, 2006, p. 216). Personally, keeping a research journal allowed me to become more reflective and engaged in every part of the research process.

\section{Thematic Analysis}

This study utilized thematic analysis as its data analysis procedure. Thematic analysis was the most appropriate procedure because one of the research questions of the study was an investigation on how SLPs conduct therapy with students with ASD. Therefore, the themes that emerged throughout the interviews were central to analyses of the SLPs' impressions of the types of therapies and their effectiveness. In addition, a secondary question pertained to the study of SLPs' use of creative dramatics and what themes emerged on that issue from the interviews. Specifically, what types of creative therapies had these SLPs utilized in their respective practices. Maguire \& Delahunt (2017) emphasized, "The goal of a thematic analysis is to identify themes, i.e. patterns in the data that are important or interesting, and use these themes to address the research or say something about an issue" (p. 3353). The SLPs' interviews were analyzed for themes related to each personal interview. Additionally, themes across all the interviews were examined.

Thematic analysis involved not only organizing and summarizing the data, but interpretation as well (Maguire \& Delahunt, 2017). Thematic analysis is a method to organize data in terms of themes or patterns in qualitative research (Braun \& Clarke, 2006). Thematic analysis emphasizes the recurrent idea or theme: "A theme captures something important about the data in relation to the research question and represents some level of patterned response or meaning within the data set" (Braun \& Clarke, 2006, p. 82). There are two levels of themes in thematic analysis created by Braun \& Clarke (2006). These levels are semantic themes and latent themes. Braun \& Clarke (2006) discussed the difference between semantic and latent themes as 
follows: Semantic themes are the obvious surface themes that deal with the whole; latent themes deal more with the analysis. Braun \& Clarke (2006) describe semantic themes as "within the explicit or surface meanings of the data and the analyst is not looking for anything beyond what a participant has said or what has been written" (p. 84). Conversely, latent themes go in depth beyond semantic themes. These themes deal with a deeper analysis. Braun \& Clarke (2006) describe latent themes as "...start[ing] to identify or examine the underlying ideas, assumptions, conceptualizations and ideologies that are theorized as shaping or informing the semantic content of the data" (p. 84). Thematic analysis was utilized in this study to look at patterns in interviews to capture the experiences of five SLPs working with children with ASD.

This dissertation utilized Braun \& Clarke's (2006) six step framework as a guide for completing thematic analysis. This framework, listed below in detail, provided a comprehensive guide for thematic analysis. Table 3.2 outlines Braun and Clarke's (2006) Thematic Analysis Framework.

Table 3.2

Braun and Clarke (2006) Thematic Analysis Framework

\begin{tabular}{lc}
\hline \multicolumn{1}{c}{ Step } & Description \\
\hline $\begin{array}{l}\text { 1. Familiarizing yourself } \\
\text { with your data }\end{array}$ & Reviewing the data \\
\hline $\begin{array}{l}\text { 2. Generating initial } \\
\text { codes }\end{array}$ & $\begin{array}{c}\text { Highlighting sections of data, taking notes, and assigning } \\
\text { broad codes }\end{array}$ \\
\hline $\begin{array}{l}\text { 3. Searching for themes } \\
\text { 4. Reviewing themes }\end{array}$ & $\begin{array}{c}\text { Review the codes and look for patterns in the codes that form } \\
\text { themes }\end{array}$ \\
$\begin{array}{l}\text { Checking that themes are accurate representations of the data } \\
\text { and pertinent to the study. Themes can be stand alone, be } \\
\text { combined or discarded. }\end{array}$ \\
\hline $\begin{array}{c}\text { Refining and reviewing the themes. Assigning names to the } \\
\text { themes and defining them. }\end{array}$ \\
\hline
\end{tabular}




\section{Step 1: Familiarizing Yourself with Your Data}

The initial step consisted of reviewing all the data in order to become familiar with it. Saldaña (2016) calls this step precoding and suggested reviewing the data by laying it out. The coding process in this dissertation began with Saldaña's suggestion of laying out the data. This entailed rereading the interview transcripts. Therefore, I read the SLP transcripts five times, attempting to assure that each potentially relevant piece of information was identified and incorporated into the broader analysis. I read each SLP's interview individually and I also read them consecutively all together. As part of the preliminary process related to the analysis, it has been suggested "to make notes and jot down early impressions" (Maguire \& Delahunt, 2017, p. 3355). As part of this analysis, I printed interview transcripts with my field notes double spaced on the left two thirds (2/3) portion of the paper. The right one-third (1/3) of the paper was left blank. This space is where I made codes and notes. Precoding was also utilized by highlighting and underlining words, phrases, and/or entire quotes that were important and useful for later coding. Table 3.3 shows one such example of the initial data review.

Table 3.3

Initial Data Review

\begin{tabular}{l|l}
\hline \multicolumn{1}{c|}{ Excerpt from Interview Transcript } & \multicolumn{1}{c}{ Codes and Notes } \\
\hline So our students -- first let's do the more severe, a more severe & severe \\
that is more or less nonverbal, maybe with a few words, but & Nonverbal student \\
with prompting, but with little spontaneous speech. Usually & Little spontaneous speech \\
with those kids early on, when I first start to see them, we just & \\
do a lot of rapport building, because a lot of times if I'm their & Rapport building \\
first point on contact in the therapy world. They don't know & First time in therapy \\
\hline
\end{tabular}




\begin{tabular}{|c|c|}
\hline what to do. They don't interact. They don't want to sit down & \\
\hline and do activities. So a lot of it is just establishing interaction, & Establishing interaction \\
\hline just getting them at the table. We might do super simple & Simple activities \\
\hline activities, like putting pennies in a jar or just super simple turn- & Pennies in jar \\
\hline taking games, just to establish either coming to the therapy & Turn taking games \\
\hline table or the floor, and working with someone else, you know, & Table/floor \\
\hline in a one-on-one situation. & One-on-one \\
\hline
\end{tabular}

Additionally, I kept a research journal to document my thoughts regarding the review of each interview transcript after the initial reading of the interview transcripts. This research journal was used during the data analysis process as well.

\section{Step 2: Generating the Initial Codes}

Generating the initial codes started with the meaningful organization of data. The purpose of initial coding was to become familiar with data and begin to make broad codes and take notes. Maguire and Delahunt (2017) described coding as reducing "lots of data into small chunks of meaning” (p. 3355). Coding was an essential part of this study's data analysis. Saldaña (2016) asserts that coding is so important that it is a form of analysis: "Coding is deep reflection about and, thus, deep interpretation of data's meanings. In other words, coding is analysis" (p. 63). The data was coded for patterns, which Saldaña stated "is repetitive, regular, or consistent occurrences of action/data that appear more than twice" (p. 5). A researcher does not code for themes, but a theme may be a result of coding. Saldaña (2016) recommended that "a theme can be an outcome of coding, categorization, or analytic reflection" (p. 15). Thus, the themes emerged from the codes. 
The codes began to emerge through the rereading of the data during Step 1 and were defined in this step. I used an open coding strategy which involved an iterative process. Initial codes were modified during multiple readings of the data. In open coding, there are not "pre-set codes, but [codes are] developed and modified" (Maguire \& Delahunt, 2017, p. 3355). The chart below illustrates an example of coding that was drawn from the interview. The left-hand side of the chart includes information that was directly provided by the SLP during the interview. The SLP is describing how a particular student with ASD is often presented with food-based rewards for participating in therapy. On the right-hand side of the page are my notes that form the basis of the coding for this particular interview. In the notes, I draw out the key components and takeaways from the interview, focusing on those specific issues and facts that are germane to my research questions. Table 3.4 includes examples of open coding from the data. 
Table 3.4

Open Coding

\begin{tabular}{c|c}
\hline Excerpt from Interview Transcript & Open Coding \\
\hline So my typical session with my severe kiddo involves... & severe student session \\
I usually have his parents bring in food that's desirable & food reinforcement (parents \\
for him because he's usually very motivated by food. & provided in reward) \\
For example, McDonald's french fries, and he knows he & \\
has a comprehension... like I'll tell him if we are doing & has ability to comprehend \\
an activity, if you do this, you get french fries, and he & \\
does. But we also use them for communication & \\
purposes. So we are trying to work on instead of just I & \\
want, I want, I'm trying to get him to use a verb and a & Basic grammar skills using food \\
\end{tabular}

Next, I engaged in line-by-line coding. Line-by-line coding requires an examination of each line of data, or in this case, the interview transcript, in an effort to locate and extrapolate as much information as possible. Table 3.5 includes examples of line-by-line coding from the data. Table 3.5

Line by Line Coding

\begin{tabular}{c|c}
\hline Excerpt from Interview Transcript & Line-by-Line Coding \\
\hline I recently did a very great therapy activity using the ${ }^{1}$ & ${ }^{1}$ movie Inside Out \\
movie Inside Out, and the characters for emotions and & ${ }^{2}$ video clips \\
using the ${ }^{2}$ small video clips and having the children ${ }^{3}$ & \\
\hline
\end{tabular}




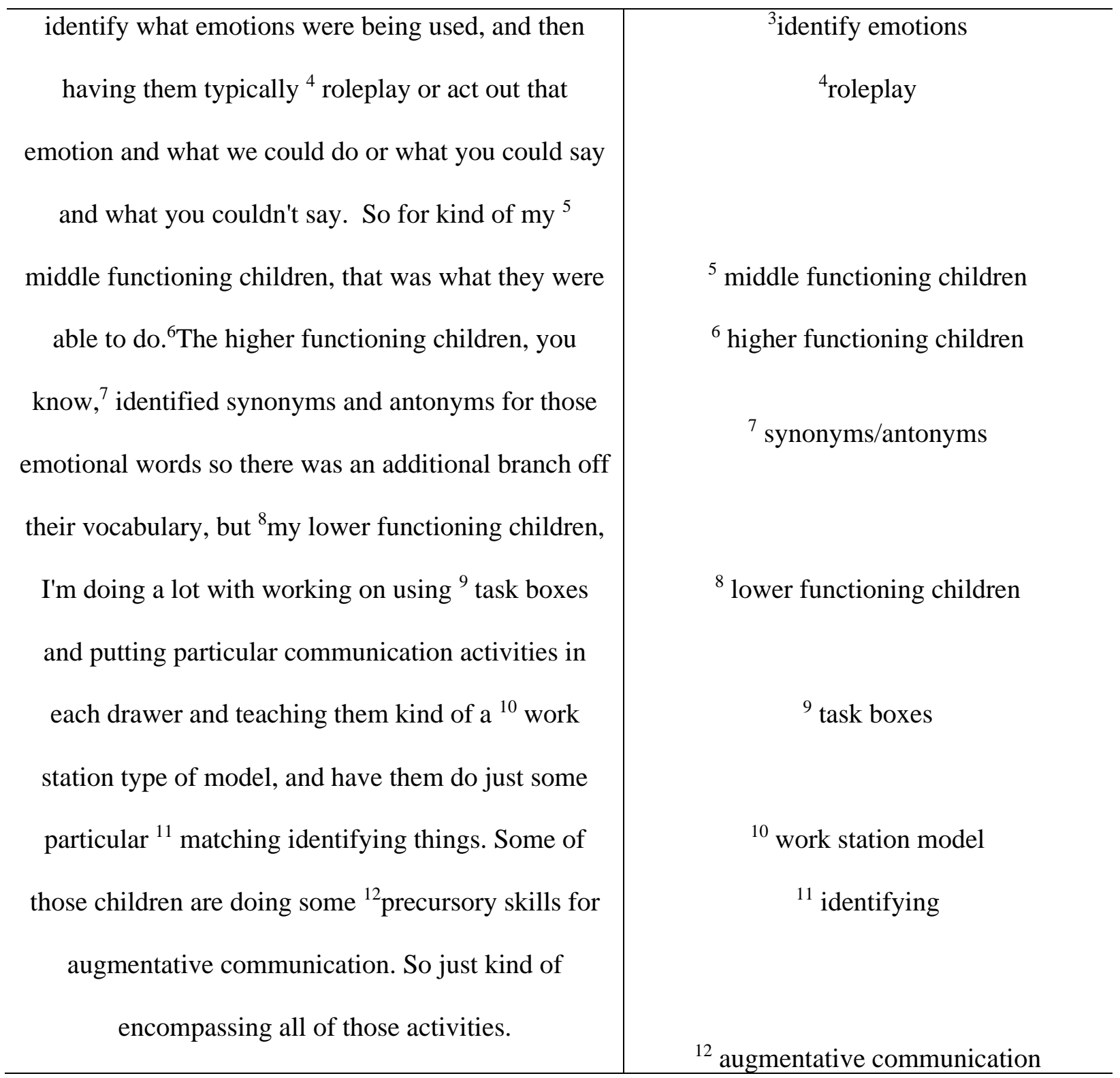

\section{Step 3: Searching for Themes}

Building from the codes generated, I examined the data to identify and notate emerging themes. Maguire and Delahunt (2017) describe themes as "a pattern that captures something significant or interesting about the data and/or research question” (p. 3356). There is usually more than one theme throughout the data in case studies. Similarly, this study had multiple themes emerge from the interviews. Analyzing the SLP interviews not only resulted in themes 
related to the individual SLP interviewed, but also in themes across all the interviews. The code that occurred most frequently across all the interviews was individualized therapy. The words individual, each, every, unique, single, special were frequently used by the SLPs to indicate individualized therapy. Therefore, the main theme was individualized therapy based on the frequency and various ways that the SLPs expressed it.

Within-case analysis and cross-case analysis were both utilized, meaning that each SLP's interview was analyzed individually, as well as across all five participants. This provided a basis for larger patterns and themes to emerge. Table 3.6 includes an example of cross-case analysis for the code of Creative Dramatics.

Table 3.6

Cross Case Analysis

\begin{tabular}{|c|c|c|}
\hline Pseudonym & Coded as Creative Dramatics (Interview) & Other Codes \\
\hline Amber & $\begin{array}{l}1 .{ }^{1} \text { The high functioning students, I try to get more of the }{ }^{2} \text { pretend } \\
\text { play and those kinds of thing, because usually they are into the } \\
\text { numbers and the shapes and stuff like that. So, I try to draw away } \\
\text { from that memory kind of thing, and talking on the telephone, } \\
\text { pretending to cook, loving the babies, those kind of things, do a lot } \\
\text { of that. }\end{array}$ & $\begin{array}{c}{ }^{1} \text { high functioning } \\
{ }^{2} \text { pretend play }\end{array}$ \\
\hline \multirow[t]{3}{*}{ Erin } & $\begin{array}{l}\text { 1. I recently did a very great therapy activity using the movie Inside } \\
\text { Out, and the characters for emotions and using the small }{ }^{3} \text { video clips } \\
\text { and having the children identify what emotions were being used, and } \\
\text { then having them typically }{ }^{4} \text { role play or act out that emotion and } \\
\text { what we could do or what you could say and what you couldn't say }\end{array}$ & $\begin{array}{l}{ }^{3} \text { video } \\
{ }^{4} \text { role play }\end{array}$ \\
\hline & $\begin{array}{l}\text { 2. I also have the children do a really great activity on this same } \\
\text { theme with } 5 \text { acting out an emotion, kind of like a }{ }^{6} \text { charade, and the } \\
\text { other children have to identify it. So, you know, those sessions } \\
\text { typically take a lot of }{ }^{7} \text { planning to be able to have children } \\
\text { effectively meet their goals and get their }{ }^{8} \text { specific needs met. }\end{array}$ & $\begin{array}{l}{ }^{5} \text { acting } \\
\quad{ }^{6} \text { charades } \\
{ }^{7} \text { temporality issues } \\
{ }^{8} \text { individualizing } \\
\text { therapy }\end{array}$ \\
\hline & $\begin{array}{l}\text { 3. You know, just typical things that take just that }{ }^{7} \text { extra time to } \\
\text { make sure you have enough for }{ }^{8} \text { every child, and that it's going to } \\
\text { work. Again, it has to be very well thought out, and you can't just } \\
\text { take a bunch of stuff and kind of there. It has to be scripted and well } \\
\text { thought out. }\end{array}$ & $\begin{array}{c}\text { 8individualizing } \\
\text { therapy }\end{array}$ \\
\hline
\end{tabular}


4. They immensely, immensely ${ }^{9}$ enjoy standing up, talking with each other, acting things out, more or less playing the ${ }^{6}$ charades, ${ }^{5}$ acting out scenarios or ${ }^{10}$ identifying the particular behaviors that we are trying to find in short ${ }^{3}$ video clips or in stories that we've read, and then they like to pretend to be those characters, and you know, often times I'll have ${ }^{11}$ props for them to do that, and they always enjoy the ${ }^{11}$ props, always. Sometimes a little too much.

5. We'll have different types of ${ }^{11}$ hats for different roles. We've had different sports equipment we've brought in. We've done a lot of different things with like different stories. Oftentimes, I'll have a stuffed animal or a puppet or something that represents the main character. I'm trying to think. We did Pete's Magic Sunglasses, and that one was really fun. so, they all had sunglasses.

Sara 1. It's been a while since I've done a lot of ${ }^{4}$ role playing. I had some character trait springboard things, you know, that we would do a lot that this is the way we might act to be a helpful person, and that we might act out things like that. I didn't do as many --- I know you would -- I wish I would get ${ }^{12}$ motivated and do some things like that dramatic scenes where you could really try to simulate a certain type of environment. So, we sometimes will go on ${ }^{13}$ journeys. I mean, we will sometimes do things like that where we just take we think of someplace we would like to go, and then we roleplay through all the things that we are going to need to get with us before we take ... this trip, and then how we are going to get there, and then maybe we might pretend that we are a family that are doing this. So, the trips is one thing that I have done with kids that kind of stands out in my mind. But taking a trip somewhere and using -- not creating the environment necessarily, but using some ${ }^{14}$ pictures of places and some ${ }^{3}$ videos and things like that so that they get some exposure to different things, but then making up a situation that when we get there-- this is what happens, and then what are we going to do. So, those kinds of things. I guess more than anything has been the real trying to ${ }^{4}$ role play through typical day-to-day situations.

2. I think even though it's ${ }^{15}$ difficult for them, that they do like to roleplay and things, and I think it's because whether it's on any kind of conscious level because they need it, you know, because they don't function well, and when you give them a situation that's not as unexpected what's going to happen. When you give them a ${ }^{16}$ contrived situation to try to use socialization in, that they respond to it better, and I think some of them do like ${ }^{5}$ acting out stories and trying to ${ }^{5}$ act out small talk.
${ }^{9}$ enjoyed activities ${ }^{6}$ charades 5 acting ${ }^{10}$ identifying behaviors
${ }^{3}$ videos
${ }^{11}$ props
${ }^{11}$ props
${ }^{11}$ props

${ }^{4}$ role play

${ }^{12}$ motivation

${ }^{13}$ journeys

${ }^{14}$ pictures

${ }^{3}$ videos

${ }^{4}$ role play

${ }^{15}$ difficult

${ }^{16}$ contrived situation

5 acting 


\section{Step 4: Reviewing Themes}

The fourth step entailed reviewing the themes that emerged from the generated codes. The themes should differ from each other and each theme should be able to stand on its own. Stake (1995) discussed looking for patterns in the codes. These patterns become themes. Stake (1995) emphasized the importance of these patterns. "Often, the patterns will be known in advance, drawn from the research questions, serving as a template for the analysis. Sometimes, the patterns will emerge unexpectedly from the analysis" (p. 78). Maguire and Delahunt (2017) outlined suggestions for reviewing themes from the data which was utilized as a guideline for deciphering themes in this study. They suggest asking the following questions while reviewing themes: "Do the themes make sense? Does the data support the themes? Am I trying to fit too much into a theme? If themes overlap, are they really separate themes? Are there themes within themes (subthemes)? Are there other themes within the data?" (p. 3358). Themes do not have to come from repeated codes. A single powerful code can become a theme. Stake (1995) emphasized: "Sometimes, we will find the significant meaning in a single instance, but usually the important meanings will come from reappearance over and over" (p.78). An example of this step in this study was the major theme of individualized therapy. The SLPs discussed this so frequently and broadly that I decided it required minor themes. These became severity of students with ASD, special interests, and incentives. Another example of this step was that only two SLPs brought up temporality issues related to their practices. However, because they powerfully described these time issues, it warranted elaboration as a theme.

\section{Step 5: Defining and Naming Themes}

Defining and naming themes consisted of studying each theme from the generated codes. This entailed making sure that the themes were accurate representations and useful to the study. 
The themes were modified at this stage, some being combined and others discarded. Braun and Clarke (2006) explain this step as "identify[ing] the 'essence' of what each theme is about” (p. 92). In this dissertation study, the SLP interviews were studied extensively, focusing on the themes through which SLPs described their experiences of working with children with ASD. In this context, the issue was whether there were major, common themes among their experiences and whether their experiences related or did not relate to each other. Similarly, the examination focused on whether there were minor, individual themes.

The codes of individualizing therapy, severity of students, special interest, incentives, food rewards, YouTube reward, toy reward, and iPad reward emerged during the analysis process. The chart shows that individualizing therapy was a common theme among the SLPs. Therefore, this became a major theme. During this defining theme step, it is noted four of the SLPs discussed incentives. The chart also showed that only Nina and Sara mentioned YouTube video reward, toy reward, and iPad reward, so those codes were not as prominent as food reward for four SLPs mentioned. However, those SLPs emphasized food reward as a very powerful incentive in their interviews. Therefore, I decided to place a theme of incentives as a sub theme of individualizing therapy focusing on food reward, but also mentioning the other types of rewards that were discussed inside this subtheme. A toy reward mentioned by Amber was not a prominent pattern or useful enough as a piece of information in this study for it to be considered a theme or sub theme. Table 3.7 indicates a summary of themes from the SLP interviews. 
Table 3.7

Themes from Interviews

\begin{tabular}{lcccccccc}
\hline Pseudonym & $\begin{array}{c}\text { Individualizing } \\
\text { Therapy }\end{array}$ & $\begin{array}{c}\text { Severity } \\
\text { Level of } \\
\text { Student }\end{array}$ & $\begin{array}{c}\text { Special } \\
\text { Interest }\end{array}$ & Incentive & $\begin{array}{c}\text { Food } \\
\text { Reward }\end{array}$ & $\begin{array}{c}\text { You } \\
\text { Tube } \\
\text { Video } \\
\text { Reward }\end{array}$ & $\begin{array}{c}\text { Toy } \\
\text { Reward }\end{array}$ & $\begin{array}{c}\text { iPad } \\
\text { Reward }\end{array}$ \\
\hline Amber & $\mathrm{X}$ & $\mathrm{X}$ & $\mathrm{X}$ & $\mathrm{X}$ & $\mathrm{X}$ & & & \\
\hline Denise & $\mathrm{X}$ & $\mathrm{X}$ & $\mathrm{X}$ & $\mathrm{X}$ & $\mathrm{X}$ & & & \\
\hline Erin & $\mathrm{X}$ & $\mathrm{X}$ & $\mathrm{X}$ & & & & & \\
\hline Nina & $\mathrm{X}$ & $\mathrm{X}$ & $\mathrm{X}$ & $\mathrm{X}$ & $\mathrm{X}$ & $\mathrm{X}$ & $\mathrm{X}$ & \\
\hline Sara & $\mathrm{X}$ & $\mathrm{X}$ & $\mathrm{X}$ & $\mathrm{X}$ & $\mathrm{X}$ & & & $\mathrm{X}$ \\
\hline
\end{tabular}

\section{Step 6: Producing the report}

The final step of thematic analysis was producing the report (Braun \& Clarke, 2006).

This step must take place after themes have been identified. Braun and Clarke (2006) suggested, "It is important that the analysis (the write-up of it, including data extracts) provides a concise, coherent, logical, non-repetitive and interesting account of the story the data tell / within and across themes" (p. 93). This step was included in both Chapters 4 and 5 of this dissertation.

\section{Actions to Ensure Quality of Research Conclusions}

There were several measures utilized in this study to ensure the quality of conclusions, as well as measures to ensure that the study was of high quality and rigor. Guba (1981) described four naturalistic terms to represent criteria that need to be outlined to ensure trustworthiness of qualitative research. These terms were credibility, transferability, confirmability, and dependability. Each is detailed below as it related to this study.

\section{Credibility}

The first, credibility is known as internal validity or authenticity. Miles et al. used the term "truth value" (p. 306) to describe this standard. To ensure credibility, I worked to provide substantive and meaningful descriptions of the interviews and the interview process. This was 
reinforced in the researcher journal as "reflective commentary" (Shenton, 2004, p. 68). The participants were also given the opportunity not to participate in the study at any time. Thus, the participants provided information free from coercion. Another step taken to ensure internal validity/authenticity, specifically that the conclusions were authentic, was the participants' subsequent review of their interview transcripts and conclusions to assess accuracy. This allowed the SLPs who were interviewed to undertake a reflective analysis of their previous interviews and add any additional thoughts and ideas that may have escaped them during the actual interview. This further allowed for additional exchange with the speech SLPs concerning the entire process and their specific experiences. Lastly, I engaged in what Silverman (1994) terms “frequent debriefing sessions" with my dissertation advisor, Dr. Keri Valentine (p. 57). These provided invaluable assistance concerning my research, which supported credibility. We met to discuss the research in-depth, analysis of the research, and conclusions drawn from the analysis. She guided me during this process.

\section{Confirmability}

The second measure was confirmability. Miles et al. (2020) defined confirmability "as relative neutrality and reasonable freedom from unacknowledged researched bias...explicitness about the inevitable biases that exist" (p. 305). Confirmability was achieved in this study by providing detailed methods and procedures sections. Also, as the researcher, I attempted to explicitly outline any biases or personal assumptions that may have influenced the study in both my research journal and in the write up of the study's findings.

\section{Dependability}

Miles et al. (2020) described dependability as focused on, "whether the process of the study is consistent, reasonably stable over time and across researchers and methods" (p. 305). In 
this way, dependability considers the question: can a study be repeated with like results? To ensure dependability, the researcher questions his or her role in the study. The researcher also describes all aspects of the study in detail. Shenton (2004) referenced Guba's suggested research provision for dependability as, "In-depth methodological description to allow the study to be repeated" (p. 73). The study provided detailed descriptions in order to establish dependability.

\section{Transferability}

The last measure to confirm the quality of the research undertaken was transferability or external validity/fittingness and this was accomplished by identifying the limitations of this study. These limitations included researcher bias, the sample size, and unique demographic data of the participants. These are discussed in the next section in detail. This step is important to inform considerations when using the results of this study to other contexts (Miles et al., 2020). It is the intention of this researcher that SLPs hearing experiences of other SLPs who provide treatment services to children with ASD will benefit from the data generate herein, despite the identified limitations.

\section{Limitations of the Study}

SLPs in the public-school system work daily with children with ASD. I have used creative dramatics in my practice for years. I formulated the Building Blocks Model, utilizing the design first articulated by Way, through working with my students and have repeatedly applied every step of the Model. I believe in its effectiveness to increase language skills with children with ASD. I personally think children with ASD need to have more exposure to drama and all other creative outlets as part of their education. I have personally witnessed my students' language skills increase as a result of creative dramatics. Thus, my influence as the researcher could be seen as a limitation since my position certainly influenced the follow-up questions I 
asked during interviews, as well as analysis of the data. Therefore, I may unintentionally biased the data (Merriman, 1998). While I made every attempt to avoid any bias in this study, it was not possible to limit my subjective influence in this study. The fact that I am an SLP I believe helped me interpret my data, particularly with technical aspects of the field. I am not taking an objective position in this study.

A second limitation of this study would be the limited demographic data of the participants, such as gender, location, educational background, experience with children with ASD, experience with creative dramatics, and experience using creative dramatics in speech and language therapy. All of my participants were female. Consequently, the selection of my participants may have skewed the results.

A further limitation of this study is that I used convenience sampling. The participants knew that I was also an SLP. They may have been aware that I used creative dramatics exercises with my students. This could have potentially influenced their interviews.

Lastly, the sample size was small. Therefore, there is a limit of transferability. However, this is an exploratory study and was not intended to generalize to a larger population. This study focused on the experiences of five SLPs. There may be future studies that can reanalyze the data generated from this study and draw patterns from it to investigate.

\section{Conclusion}

This study used the exploratory single case study research design method and analysis. It aimed to study the experiences and perspectives of five SLPs working with children with ASD. The purpose was to record the experiences of a small group of SLPs who provide services to children with ASD and to identify what they have found successful in therapy that may help other SLPs, educators, and parents. It is also the hope that this study will lead to 
additional empirical studies with this population of children and improve language treatment services. The analysis of the study and conclusions are presented in the following chapters. 


\section{CHAPTER 4: FINDINGS \\ Introduction}

This study examined the speech therapy practices of five SLPs who worked in different therapy settings, but they all provided speech and language therapy to children with ASD. Amber worked with Birth to Three Students after working in the school system for 17 years specifically with students with ASD. Denise and Nina owned their own private practices. Erin and Sara worked in the public schools.

An SLP assumes responsibility for the communication development of a child. This is accomplished in association with parents, classroom teachers, psychologists, educational theorists, and the assortment of supervisory, medical, and legal agencies concerned in the process. Consequently, an SLP must be able to assimilate the varying considerations and responsibilities that all stakeholders bring with them in order to maximize the positive outcomes for the child. With these complexities at the forefront, this study is guided by two case study research questions:

- Primary Research Question: What are the experiences of speech language pathologists utilizing different treatment methods to improve the language skills of children with ASD?

- Secondary Research Question: To what degree do SLPs use creative dramatics in language therapy?

I investigated these questions through interviews with five SLPS working in different settings with their own backgrounds and therapy experiences. Analyzing the collective interviews, a range of major and minor themes emerged, most concerned with practical issues of language therapy with students with ASD within the inherent constraints of the time and tools 
allocated for the job. The overall major theme identified in this study turned out to be individualizing therapy. Individualizing therapy was also associated with a number of minor themes that included severity of student issues, special interests, and incentives. Other major themes were counseling caregivers, temporality issues, successful therapy activities, student perspective, traditional verses creative therapies, and creative dramatics. Table 4.1 indicates prominent themes from the interviews.

Table 4.1

Prominent Themes from Interviews

\begin{tabular}{lcccccc}
\hline Pseudonym & $\begin{array}{c}\text { Individualizing } \\
\text { Therapy }\end{array}$ & $\begin{array}{c}\text { Counseling } \\
\text { Caregivers }\end{array}$ & $\begin{array}{c}\text { Temporality } \\
\text { Issues }\end{array}$ & $\begin{array}{c}\text { Successful } \\
\text { Activities }\end{array}$ & $\begin{array}{c}\text { Enjoyed } \\
\text { Activities }\end{array}$ & $\begin{array}{c}\text { Creative } \\
\text { Dramatics }\end{array}$ \\
\hline Amber & $\mathrm{X}$ & $\mathrm{X}$ & & $\mathrm{X}$ & $\mathrm{X}$ & $\mathrm{X}$ \\
\hline Denise & $\mathrm{X}$ & $\mathrm{X}$ & & $\mathrm{X}$ & $\mathrm{X}$ & \\
\hline Erin & $\mathrm{X}$ & $\mathrm{X}$ & $\mathrm{X}$ & $\mathrm{X}$ & $\mathrm{X}$ & $\mathrm{X}$ \\
\hline Nina & $\mathrm{X}$ & & & $\mathrm{X}$ & $\mathrm{X}$ & \\
\hline Sara & $\mathrm{X}$ & $\mathrm{X}$ & $\mathrm{X}$ & $\mathrm{X}$ & $\mathrm{X}$ & $\mathrm{X}$ \\
\hline
\end{tabular}

\section{Individualizing Therapy}

The major theme emerging from each interview was individualizing therapy. All the SLPs interviewed stressed the need for the SLP to be sensitive to the students' needs and to be flexible in arranging therapy programs. Individualizing therapy was such a common theme in the SLP interviews that it contained the three sub-themes of student severity, special interests, and incentives. All the SLPs emphasized that students with ASD had different levels of severity. This level of severity affected every aspect of therapy. Thus, therapy had to be tailored to the specific severity levels. They also recognized that their students had unique special interests that motived them. Lastly in terms of individualizing therapy, they discussed the importance of incentives and 
that, again, these incentives were specific to each child. Children were motivated by different incentives. While the overarching theme was individualizing therapy, other themes emerged as well. These themes were identified as counseling caregivers, temporality issues, successful therapy activities, student perspective of most enjoyed therapy activities, traditional verses creative therapies, and creative dramatics. This chapter discusses in detail each of these themes and how they were conveyed. Table 4.2 summarizes therapy activities used with children with ASD.

Table 4.2

Therapy Activities used with Children with ASD

\begin{tabular}{ll}
\hline SLP & Activities \\
\hline & Rapport Building \\
& Object Identification \\
Sensory Activities \\
Picture Based Communication System \\
Sign Language \\
Movement Activities \\
Creative Dramatics \\
Play Therapy (Toys) \\
\\
\\
Picture Based Communication System \\
One Step Directions \\
Labeling \\
Simple Questions \\
Conversation Activities \\
Social Thinking Program \\
iPad Activity: Social Express \\
Games: Socially Speaking \\
Get to Know Me Cards \\
Literature Activities \\
Play Therapy (Toys) \\
\\
Denise \\
\end{tabular}




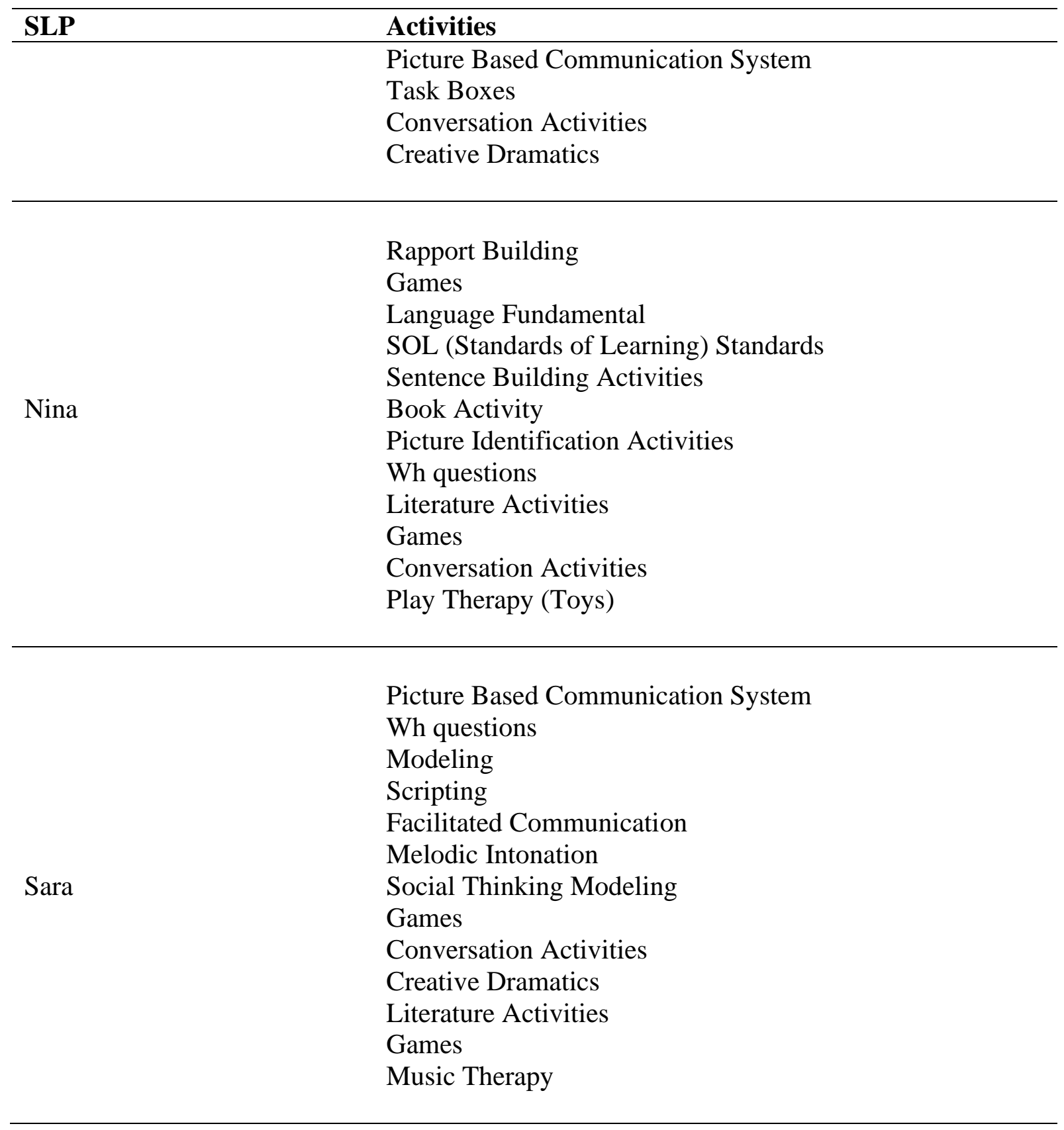

As mentioned previously, the major theme present in all the interviews was the importance of individual responsiveness to the child with ASD. The theme of individualizing therapy, specifically being responsive to the problems and personality of each child, was woven throughout the interviews with the SLPS in different ways. Obviously, an SLP must be aware of and speak to the special needs of the individual child. The SLPs interviewed for this study also 
focused on the importance of special interests to the child. The SLPs indicated that they must know the basic human desires and intrinsic motivations of each child. The SLPs also confirmed the importance of being creative and in exploring different types of therapy tools with a goal to finding the specific mechanism that triggers motivation in the child. A common refrain was the need to be flexible during therapy. The SLPs agreed that they must be innovative during therapy to find the right "tools" within the SLP toolbox, thereby facilitating maximum benefit for each child.

As discussed in Chapter 2, each student with ASD had a personalized, individual set of symptomologies. ASD is characterized by impairment in the areas of communication and social interaction. The symptoms may include repetitive behaviors; avoidance of eye contact; lack of apparent awareness of conversational partner; difficulty with maintaining a conversation; and lack of play skills (CDC, 2020a). Every child is different, so SLPs must tailor their approaches to the individual needs of every child. Therefore, there is no single, uniform approach to providing language therapy for students with ASD.

The SLPs discussed many aspects of individualizing therapy in the context of working with students with ASD, such as in therapy placement and arranging therapy groups according to the severity of ASD with individual children. After searching for special interests among the students with ASD, they chose appropriate therapy activities for the individual student. The SLPs discussed providing a range of therapy activities in sessions tailored to the needs of each student. This is essential because ASD affects everyone differently, so students need unique therapies for unique communication needs.

The idea of the importance of recognizing individual needs in students is not a new concept. As mentioned earlier, The Progressive Educational Movement of the late nineteenth 
century, led by Dewey, throughout the early twentieth century also highlighted the individual needs of each child and child centered education (Reese, 2001). While Dewey forged the idea for a child centered curriculum, he also advocated for a curriculum that advanced society as well (Urban \& Wagoner, 2003). Similarly, The Montessori Method is based on an educational philosophy that also emphasizes the importance of individuality of each child. This idea of individuality is central to the Montessori Educational Method. Maria Montessori based the Montessori Method in the early 1900s on the idea that each child was a unique individual. Her concept of "follow the child," means that learning is based on the individual needs and interests of each child. Her ideas were catalysts of the individual instruction movement (Brehony, 2000). Like the Montessori Methods, the SLPs I interviewed emphasized that instruction had to be individualized for each student.

As discussed in Chapter 2, Autism is known as a spectrum disease: "Each person's experience with Autism presents unique challenges, as well as strength, which define the type of support needed to lead a fulfilling life" (Autism Speaks, 2018, p. 3). All the SLPs agreed that speech and language therapy had to be individualized based on the pattern of deficits within each individual student with ASD. Anyone working in the field can confirm that symptoms can range from mild to severe. Erin said, "Those typical sessions, of course, are based on what each individual child needs at that point." Likewise, Amber appeared dismayed when I asked her to describe a typical therapy session because there are no typical speech therapy sessions. Amber explained: "It's really hard to say exactly how I would see a kid because every kid is different."

\section{Severity of Student with ASD}

The SLPs collectively stressed that therapy had to correspond to the severity of a child's condition. Consequently, therapy goals and activities will be different for high functioning 
children with ASD compared to low functioning children with ASD. Every SLP emphasized that certain therapy activities seemed appropriate for high functioning children while other therapy activities may be more useful for low functioning children. Unfortunately, these activities can vary dramatically depending on the level of severity. Erin detailed therapy activities that she used for students at different levels. She was the only SLP to include a middle functioning group as well. Erin explained:

I recently did a very great therapy activity using the movie Inside Out, and the characters for emotions and using the small video clips and having the children identify what emotions were being used, and then having them typically roleplay or act out that emotion and what we could do or what you could say and what you couldn't say. So for kind of my middle functioning children, that was what they were able to do. The higher functioning children, you know, identified synonyms and antonyms for those emotional words so there was an additional branch off their vocabulary, but my lower functioning children, I'm doing a lot with working on using task boxes and putting particular communication activities in each drawer and teaching them kind of a work station type of model, and have them do just some particular matching identifying things. Some of those children are doing some precursory skills for augmentative communication. So just kind of encompassing all of those activities.

Erin demonstrated how speech and language activities are tailored to meet the needs and ability levels of her students. Her higher and middle functioning students learned about identifying emotions by watching movie clips and then discussing them. They also acted out the scenes in order to further understand emotions in depth. The higher functioning students were also asked to work on figurative language skills to assist in the development of metalinguistic awareness. 
While her lower functioning students had task boxes or compartments with materials with visual support that they attended to independently, she also began to work on skills that they may need to use AAC devices. Erin described how therapy can be structured to fit a variety of students' needs.

Interestingly, the SLPs used the specific terms "high functioning" and "low functioning" to describe their students' severity level on the spectrum. They also used the terms "verbal" with more high functioning children and "nonverbal" with low functioning children. However, The Diagnostic and Statistical Manual of Mental Disorders (5th ed.; DSM-5; American Psychiatric Association, 2013) does not use these differentiations. The DSM-5 has just one diagnostic category, Autism Spectrum Disorder, with three increasing severity levels: level 1 "requiring support"; level 2 - "requiring substantial support"; and level 3 - "requiring very substantial support.” Previously, The Diagnostic and Statistical Manual of Mental Disorders (4th ed.; DSM-4; American Psychiatric Association, 2000) had four distinct diagnostic categories: Autistic Disorder, Asperger's Disorder, Childhood Disintegrative Disorder, and Pervasive Developmental Disorder Not Otherwise Specified (PDD-NOS). There were no severity levels. Asperger's was commonly considered high functioning Autism. None of the SLPs used the severity terms as outlined in the DSM-5 throughout their interviews. This may be typical because SLPs do not diagnose ASD. SLPs diagnose language disorders such as a pragmatic language disorder associated with ASD. Therefore, SLPs often may not use DSM-5 terminology or may alter it as the interviewees did. It also makes sense that they would categorize verbal ability with functioning levels because, typically, high functioning students with ASD have better verbal skills. However, high functioning is often used to describe a person with ASD who has normal intellectual ability. Yet, recent research advocates not to use the term 
high or low functioning because it seems to diminish the struggles and challenges that these individuals still may have every day with their functional abilities (Alvares et al., 2020).

\section{Special Interests}

All SLPs discussed the importance of appealing to the individual special interests of their students with ASD. Typically, students with ASD not only have varying severity and symptomatology of the disease, but different life interests, as discussed in Chapter 2. These interests vary from objects the students like to work with or topics that individuals with ASD pursue with focus and intensity -- for example, demonstrating a fascination with hurricanes -that can restrict engagement with other objects or topics (Mancil \& Pearl, 2008 as cited in Gunn \& Delafield-Butt, 2016, p. 209). These special interests are often used in therapy among the SLPs. As Nina explains:

For kids on the spectrum, a lot of times they have a special interest, which is something that they are just almost obsessed with. Like they love Pokémon, or they love Mickey Mouse Club or whatever it happens to be. So, when it comes to the [expression of] special interest, it can be almost any material. It can be stickers. It can be a picture. It can be a stuffed animal. It can be a toy.

Identifying and using a child's special interests is essential in our effort to improve his or her communication, emotional, and sensory development (Winter-Messiers, 2007). I have had students who have special interests which range from spiders, Peppa Pig, and Thomas the Train to the song, "Let It Go" in Frozen. A dramatic study of a person with an obsessive interest is the character of Raymond Babbitt depicted in the movie Rain Man. His obsession was watching Judge Wapner on the television show The People's Court. He not only loved to watch it, but watching it gave him a sense of calm, security, and stability. As we see, the special interest may 
have a profound psychological effect on the subject. The therapist may use it to motivate or try to introduce other interests to minimize the special interest if too obsessive.

\section{Incentives}

The SLPs described using special interests of their students in terms of individual responsiveness, specifically student motivation. Considering special interests naturally led to how SLPs motivated students in therapy. All agreed that appealing to personal interests motivated students to work harder for an incentive. Three of the SLPs discussed food as reward for their students. They found food rewards among the most motivating. Sara discussed a student who was only motivated by a food reward. This student only "loved pop and potato chips, and he would never fail to give me a picture or hit the switch that requested pop or potato chips." Amber said that she uses a lot of food rewards in typical therapies. Denise also talked of using food rewards generally, but specifically with one student. She discussed how food is typically used as an incentive to communicate in a speech session:

So, my typical session with my severe kiddo involves having his parents bring in food that's desirable for him because he's usually very motivated by food. For example, McDonald's french fries, I'll tell him if we are doing an activity, if you do this, you get french fries, and he does. But we also use them for communication purposes. So, we are trying to work on instead of just "I want, I want," I'm trying to get him to use a verb and a noun, so i.e., "french fry." So, like I said, use food for reinforcement, but I'll also just for the communication encourage the parts of speech.

There is controversy in the field of speech language pathology over whether food is a suitable reward for children with ASD due to health concerns with weight management (Bandini et al., 2013). While not universal, there is some criticism of SLPs who use food as a reward. 
However, food rewards are used in Applied Behavior Analysis therapy, specifically in speech therapy when using PECS. I have used food as a reward for years with PECS and it has proven beneficial as a reward in a therapy session when used with parental permission if it motivates a child to communicate. Although the three SLPs talked positively of using food as a reward, only Sara suggested the stigma of it, along with its effectiveness:

I'm ashamed to say the one individual loved pop and potato chips, and he would never fail to give me a picture or hit the switch that requested pop or potato chips. Now, anything else, he wasn't too interested in.

Examined in its totality, it all comes down to balancing the effectiveness of the tool against a potentially negative reaction, such as unnecessary weight gain.

Electronics were also a reward that SLPs were somewhat reluctant to embrace in their interviews. Among therapy activities that students most enjoyed, electronics were high on the list. Nina said electronics were what her students collectively enjoyed the most, though she appeared apprehensive with that stimulus. Nina said:

Like if I'm looking at my whole career, I would say electronics [is the therapy activity that students enjoy the most], and I kind of hate to say that because I try to use that as a last resort. Like letting them work for a video on YouTube or time on the iPad or something like that.

Sara found the iPad to be such a powerful motivator that she had one student who spoke only to demand the iPad. Sara stated, "I'm thinking of one of those severe individuals, that the one picture I could get her to use was that computer or that I-Pad picture. That the one spontaneous utterance that she had on a consistent basis was, 'I want iPad."' 
Electronics were described by the SLPs as not only a reward, but also as a therapy activity. There are iPad apps, videos, and programs to help with communication. Throughout her entire interview, Denise repeatedly discussed the iPad app of Social Express as being one of the most successful therapy tools for her students with ASD. Denise was excited to use Social Express because her students loved it. One advantage she pointed out was that it was interactive, giving her the ability to engage in meaningful dialogue with her students:

It's not something that they are just staring at this. It's something that is interactive and then we have a discussion about it. They watch the two minutes of whatever it is, and then we talk about that actual interaction. You know, how would you do it differently or what are they doing wrong? What was good in that interaction?

Opportunities for social interaction are a cornerstone to learning appropriate social language skills. Students are able to watch appropriate social interaction, as well as to make choices giving them the opportunity to practice social language skills. The student may notice an inappropriate social language choice and learn exactly why the choice was not appropriate through discussion and have multiple opportunities to try again. Erin discussed the value in practicing social skills by acting out situations in terms of long-term progress. Erin said:

They are able to also apply it at different times, which is how you really see true carryover when you are able to see that child out of that setting in a different environment and they are able to either identify the emotion, the vocabulary, the intonation, the proper pragmatic skills, the turn-taking in conversation. Those are tangible things that you are able to see when you are outside of that therapy setting that demonstrate growth and progress. 
While emphasizing the love children have for electronics, Sara debated the value of electronics. Do these tools help the child with ASD? Sara noted:

They like their screens. I tend to stay away from them now more with my autistic students than with others. I don't know if that's right or not. I mean, those are the cues and some other communication systems on there. I feel like the computer programs and the apps, I think they do more for us than they do for the communication. I think that they can be a good evaluative tool, and a way to have insight into the concepts that that individual might really have, but I don't find it an effective tool for helping them communicate. But, again, they love it.

I was surprised that the majority of the SLPs mentioned using certain iPad apps, such as Proloquo2Go, as a communication device for their students. I use Proloquo2Go with some nonverbal students as their main tool for communication. It is a symbol-based communication app that provides text to speech. It is beneficial because it allows students to choose from many pictures to express their wants and needs. It is also convenient to carry. It can be easily adapted to accommodate different situations and changing interests. It also is not stigmatizing to a child as other AAC devices may be. Their peers understand the iPad and often think that it is "cool" for a child to have one and communicate with it. As our society increasingly becomes more reliant on technology, we may find more options to adapt our therapy tools and utilize the many technological advancements that seem to emerge each day. Other studies have found that Proloquo2Go and other iPad apps are beneficial for some people with ASD (Alzrayer et al., 2014).

An emerging technological therapy is Robot Assisted Therapy (RAT). Children practice social skills with the robot as the SLP moderates. The robots can even offer important hints 
about social cues during the interactions that simulate a natural social communication environment with a peer or adult. Even though it is a new and evolving therapy tool, it has already shown success with improving communication for students with ASD (Thill et al., 2013). However, at this time there needs to be more research using a greater number of participants. Cost effectiveness needs to be addressed as well. Unfortunately, many of these robots are cost prohibitive for school systems and private practices. Also, each robot needs to be specifically programmed for individual student's needs and SLPs need to have the knowledge and training to do this (DiPietro et al., 2019). Yet, there are exciting therapy treatments on the horizon.

\section{Counseling Caregivers}

Another theme that emerged during the interviews was related to extensional dimensions or themes (Van Manen, 2014) connected to the practice of SLPs. Van Manen (2014) proposed that the state of being or experience may be viewed through certain existential themes. These are "lived relation (relationality), lived body (corporeality), lived space (spatiality), lived time (temporality), and lived things and technology (materiality)" (p. 302). Therefore, when the SLPs discussed what it was like for them to be a working SLP, this study viewed the experience through these existential themes. The interviews unmasked the role of being an SLP in terms of everyday pressures. SLP's services may extend beyond the therapy setting. In fact, SLP responsibilities take on many different roles beyond diagnostician and therapy provider. As SLPs work closely with students and families of their students, their jobs have evolved into more family-centered practices by collaborating with parents or guardians and becoming counselors and support systems to them as well. Sara discussed how she uses her role as an SLP to guide parents to seek further help for their children. A speech or language problem may have been evident, but as she worked with a particular child, she realized that the child needed more help 
than just dealing with speech and language: "You have your kids that you suspect who are not talking, not communicating, and not showing any signs of engagement, and that's when you get concerned." Also, it is common that an SLP is the first person to notice and recognize the symptoms of ASD, very often before caregivers, whether parents, guardians, or professional support, particularly in situations, such as with a preliminary assessment. Denise said:

There's a lot of little kids that we work with that you are kind of the first professional that they see, and then you are the one who is trying to have to tell the parent that you need to go to a pediatrician.

\section{Caregiver Interaction}

The existential theme of relationality or lived self-other, how people are connected, emerged in the role of being an SLP with caregiver interaction (Van Manen 2014).

Unfortunately, there is a lack of research on how SLPs should undertake professional interactions with caregivers and others. Most of the studies that could be located did not specifically analyze SLPs only, but conducted a group analysis of the therapy team (Pappas et al., 2008). It is obvious that parents and other caregivers play a vital role in the communication development of a child. Children spend significantly more time with their caregivers than with teachers or SLPs. Therefore, it is critical for SLPs to collaborate with caregivers to facilitate potential development in communication skills. Collaboration can be key for success. Erin discussed the inclusion of her students' parents to not only witness success in therapy, but also engage in appropriate social interactions that they may have never observed in the past:

I will video the children if I have their parents' permission, for the parents to see it later, and that is always very touching for them to be able to know that. They like to be able to see their children participating in something like that and have the participation from the 
other children. They really enjoy seeing their child communicating with others. They like to see that reciprocity between that child and their classmates.

Denise also discussed parental interactions as being positive for the students in speech therapy. Denise saw the parents as helpful to success. She encourages her students' parents to bring reinforcements, such as food and toys, that may motivate the students in therapy. Caregivers may know the most effective rewards, as they are closest to the child. She believed that such cooperation strengthens her entire therapy session because the student genuinely wanted that reinforcement and would work harder to get the desired item. She provided an example: "So my typical session with my severe kiddo, I usually have his parents bring in food that's desirable for him because he's usually very motivated by food." Denise also talked about recommending books to her students' parents to reinforce social language carryover at home. She has had success by recommending Julia Cook's Social Story Books that she uses with her students: "I have had a few parents buy some of those books and go over them with their kids at home."

There is an anecdotal phrase used in the SLP community in Marion County, West Virginia: "Do not work harder than the parent." This suggests that reinforcement by the parent or guardian is the most essential part of therapy. This is especially true for language therapy with children who are nonverbal or who have nonfunctional speech and use Augmentative and Alternative Communication (AAC) systems to communicate. If a child has a communication device that generates speech and is only being used at school and turned off when that child gets home, that device loses most of its potential and is essentially ineffective. The child's development of effective communication must extend outside of the school environment to the home where he/she spends most of his or her time. Research has shown that children can only 
become successful AAC users with the help of their caregivers (Parette \& Angelo, 1996). It has also been shown that parents' frustration in communicating with SLPs, as well as parents' lack of understanding their child's communication device, impacted their children's success with AAC devices (Angelo, 2000). Clearly, SLPs have an important role with encouraging caregivers to use the device with their child at home.

Unfortunately, not all caregivers are willing to collaborate with SLPs. Parents can be overwhelmed, disinterested, or even intimidated by communication issues brought to their attention. Sometimes when there is collaboration, it is not positive. It has been well documented that caregivers have to cope with increased stress when they have a child with ASD (Benson, 2006). This stress can lead to anxiety and depression that can manifest itself in a variety of ways (Sharpley et al., 1997). However, caregiver involvement is critical. Bennett (2012) found that lack of parental involvement in early intervention programs with children with ASD had far reaching implications of negatively affecting their growth and development. In my experience, rarely do caregivers attend Individualized Education Meetings. I have also found difficulty with persuading parents to attend meetings to discuss how to maximize communication in the home environment, even though I stress to them how important this is for nonverbal students with communication devices. Unfortunately, it is increasingly becoming a struggle to obtain satisfactory participation. This is especially frustrating as I have worked with exceptional caregivers in the past. I have even had situations where parents asked to attend therapy sessions, so they could see exactly how communication was being encouraged and fostered. In an attempt to improve this, the special education teacher and I currently share a communication notebook for each student with ASD. This includes weekly documentation concerning the child's progress, focusing on the activities completed with the child and suggestions on how to encourage home 
reinforcement. This communication has proven to be valuable because it has helped develop a longitudinal understanding of the students. For example, a parent wrote that her child stayed up late one night because family came to visit. That information explained why that student was tired and easily became upset during difficult activities the next day. It also has helped that parents or caregivers indicate when they suspect that a child becoming ill. Many children with ASD do not have the verbal capacity to tell you when they are sick. Therefore, this information can clue the special education teacher or the SLP to monitor how the child is feeling. It has been especially beneficial because it promotes sharing with the parents exactly what has been completed in therapy and further assists in providing advice on how that can be expanded at home.

Interestingly, the responses from the SLPs studied differed significantly concerning their interactions with parents. Nina who works in private practice did not mention it at all, while Denise and Erin mentioned it positively. Though Denise worked in private practice as well and Erin worked for a school system, both had positive caregiver interactions in different settings. Amber broached it briefly in a negative way in the context of discussing PECS with parents needing to help their children establish basic language. She does not use PECS because it has such strict guidelines. Amber said, "Some parents can take the direction and follow the protocol, but most can't. So, I usually don't call it PECS. I do a picture exchange system, and I modify it to work for the family." Amber works with Birth to Three with her students in their homes. It appeared that location of service delivery did not make a difference in this study. Sara has a son with ASD. Therefore, she has a unique perspective. She mentioned a touching story in which a parent thought that her child was communicating, but the child was not: "The parent really thought he was communicating. It broke my heart because I could never really get him to say 
anything that meant anything with me. He was able to move around, but he never made any words."

ASHA (2006) stated that it is critical for SLPs to provide support to families and caregivers who are taking care of individuals with ASD "through counseling, education and training, coordination of services, and advocacy" (p. 6). Therefore, the interaction between SLP and the caregiver is critical. Parents with children with ASD have higher levels of stress and depression than parents who do not have children with ASD (Bitsika \& Sharpley, 2004; Totsika et al., 2011). A study conducted by Boyd (2002) found that mothers receiving support, even informal support, were more likely to be emotionally engaged with their children with ASD. SLPs have a unique opportunity to support caregivers by providing information and resources. SLPs have the capability to not only help the child with ASD communicate more effectively, but to also help caregivers learn to communicate more effectively with their child and increase their child's communication skills.

\section{Temporality Issues}

Temporality issues, issues relating to time, emerged in the interviews, especially time constraints upon planning effective therapy. In discussing role playing therapy activities, Erin talked of how her students loved this activity and how successful it was. However, she emphasized several times that it must be well-planned and thought out before the activity:

I also have the children do a really great activity on this same theme with acting out an emotion, kind of like a charade, and the other children have to identify it. So, you know, those sessions typically take a lot of planning to be able to have children effectively meet their goals and get their specific needs met. So, a lot of things need to be scripted and very well thought out. 
Erin also mentioned her use of prompts during the role-playing activities. Again, she emphasized that significant planning was essential:

You know, just typical things take extra time to make sure you have enough for every child, and that it's going to work. Again, it has to be very well thought out, and you can't just take a bunch of stuff and kind of be there [such aspects as the uses of props]. It has to be scripted and well thought out.

Unfortunately, time constraints are a major issue that SLPs, especially school SLPs, must juggle with ever-increasing caseloads. Some states have caseload caps, meaning that SLPs can only serve so many students, while other states have none at all. Connecticut, Delaware, Indiana, Florida, Montana, and New Hampshire are examples of states that do not currently have caseload limitation. Some states have caseload caps so high as to be virtually useless. Pennsylvania, Kentucky, and New York all have 65 students as maximum. West Virginia has a limit of 50 students on a caseload. Arizona has the lowest maximum number of students at 45 . Therefore, some SLPs must drastically restrict their time to service all the students on their caseloads, resulting in sacrificing effectiveness and, also, usually taking up the therapist's personal time. Sara discussed the sacrifices she made during her beginning years as an SLP: "I have no idea how I pulled off some of the stuff. All I know, I was young and full of energy and had no family that I had to take care of. So, I just did therapy, didn't have planning, didn't have lunch."

Sara also talked of the time issues with the role of SLPs with picture communication systems and AAC devices and how SLPs must find time to organize carefully those communication systems to be successful. She discussed how she used to see students every day. However, she pointed out that today it is very difficult to schedule a student for that much therapy: 
I did speak of cases where I saw someone every day for a certain number of years; that's not typical, I mean, because the logistics of scheduling that just doesn't pan out very well. For those kind of systems to be successful, it has to be going on everywhere, and usually that doesn't happen.

The SLPs discussed temporal issues in their interviews. They emphasized the amount of time it took to plan therapy activities for students with ASD. Caseload size also caused time constraints. Many SLPs in the school system have significantly high caseloads which can negatively impact speech therapy planning and delivery.

\section{Successful Therapy Activities}

The SLPs who were interviewed were asked to identify the most successful language therapy activities that they employed in their practices. The answers were varied. The therapy activities most mentioned were social stories, book activities, iPad apps, simple therapy activities such as wind-up toys, and creative dramatic activities. Table 4.3 includes a summary of the most successful therapy activities.

Table 4.3

Most Successful Therapy Activities

\begin{tabular}{ll}
\hline SLP & Activities \\
\hline Amber & Picture Communication System \\
& Sign Language \\
\hline Denise & Social Games \\
& iPad App (Social Express) \\
& Toys \\
\hline Erin & Drill and Practice \\
& Creative Dramatics \\
\hline Nina & Literature \\
Sara & Social Stories \\
& Literature \\
& AAC \\
\hline
\end{tabular}


Sara found that reading Social Stories and practicing social skills, particularly social modeling, have been the most successful for her students. While she emphasized the importance of modeling overall, she specifically mentioned students with echolalia being unsuccessful with social modeling. Echolalia is the continuous repetition of a word or phrase (Prizant \& Ducan, 1981). Echolalia is common in students with ASD. Overall, Sara pointed out the power of social modeling and the success she has had with it:

This is the information that you need to give back or the information that you need to comprehend this in your brain. Here is what you really can say. I think that's been very effective. I think that the social modeling is probably one of the most effective tools, and for those individuals that really, really struggle with comprehension.

Sara also has a unique perspective because she has a son with ASD, as mentioned previously. She emphasized several times how powerful social stories have been not only with her students, but also her son. Sara said:

[Social Stories] proved to be very effective for a couple of students through the years, very effective for my own son. Social stories have been very, very effective for him. So, that's a therapy technique that I know I will continue to go back to.

Literature activities were also mentioned as among the most successful. Literature provided both meaning and a passive learning mechanism for the students. Sara emphasized the importance of context and not just working on individual skills:

I would say [there were] a couple of those cases that the use of literature was pretty successful; that it helped by creating a bridge; that it required so many of those skills that we know are often at deficit: the comprehension, the ability to formulate responses, and I think that's just huge. And then the context where you are going to have some multi- 
meaningful vocabulary and figurative language. I think that having the context where it's all pooled together, where you can work on all those things from that springboard is pretty effective; I mean, instead of just trying to have isolated activities, maybe, that work on those skills.

The majority of the SLPs actually named specific books and book series that they used in therapy. Nina talked of using the Little Critter book series by Mercer Mayer. Nina said: "I use a lot of the Little Critter books, because they are very concrete.... It's not like, oh, he thinks this, and she feels this, and he's going to pull a trick on her. It's very early level reading books." Nina also mentioned that she had a student who loved the Scaredy Squirrel book series by Melanie Watt. Sara mentioned that she used Little House in the Big Woods by Laura Ingalls Wilder with a student. Sara said, "I remember the one girl that I was talking about that we did Little House in the Big Woods, and that was just like, that was just the neatest thing for her." Denise also talked about books, specifically, two authors, Julia Cook and Cheri Meiners, who wrote books to specifically help with social skills. Denise explained:

There's a book called Talk and Work it Out. This one is by Cheri Meiners and she has a few books. Yeah, another one by Sherry Minors is Cool Down and Work Through Anger. Then, Julia Cook is like my favorite. She's amazing. She has so many books. One is called Wilma Jean, the Worry Machine. You know what, if I do this, I might be able to get to more of the books. Yeah, But It's Not My Fault, Attitude, What to do When Life Stinks, Lying Up a Storm. But again, it's all social stuff. I love her.

Nina also said that literature activities were successful for communication development with her students. She emphasized the importance of repetition in a story. She also mentioned pairing literature with AAC: 
I think the visual combined with the repetitive story that they can go back and read over and over again is very helpful. The same thing with the kids where they are more nonverbal or verbal output devices, or they are just pressing a button and they are hearing like "cookie." I think like the visual, hearing the same voice over and over again saying the word, maybe the multi-sensory, really helps it click there.

Not only did Nina mention using AAC devices with literature activities, but she also was the only SLP to discuss using digital books. Nina described why she used digital books: "I really use the digital books, just because it is just so practical for me," Nina travels to her student's homes so it is easier for her to use digital books with them. Currently, there are many digital books and stories that are free to access online. There is even a free online site for digital stories to explain the experience of attending school during the Covid 19 Pandemic for children with ASD. These books can be accessed at https://www.autismlittlelearners.com/2020/07/covid-19related-stories-for-schools.html.

Successful therapies have varied among this researcher's students. Like Sara, I have had success with AAC paired with literature with nonverbal students. These devices give students who may not have a "voice" a means to express themselves and participate with others. When one nonverbal student started using a simple BIGmack Communicator during an activity with the book Brown Bear Brown Bear, she learned to hit her device that was programmed to say, "What do you see?" She was thrilled to be able to participate in the therapy group with the other children. She exhibited fewer avoidance behaviors and smiled when the other children looked at her as she participated. Amber felt that the traditional therapies of Picture Exchange and Sign Language were the most successful activities for her Birth to Three students. Amber said, 
"picture exchange. That and sign language are usually the two best ways to facilitate communication."

Denise found that games facilitate communication skills. She talked about interactive social language games like Socially Speaking. She also explained that the previously discussed iPad app, Social Express, was the most successful for her older students. Denise emphasized that it is important that children did not just watch the Social Express App on the iPad. She had an actual discussion with them throughout the time that the children were on the app. She also said that simple toys were among the most successful therapy activities for her younger students:

But again, it's [Social Express], not something they are just staring at this. It's something that is interactive and then we have a discussion about it. They watch the two minutes of whatever it is, and then we talk about that actual interaction. You know, how would you do it differently or what are they doing wrong? What was good in that interaction? So yes, social express is something that's been really helpful for me. It's also working on games, but it's in a game format we are working on their social skills. So, I would say if I am going to repeat, just to kind of reiterate, socially speaking, which is that game; the social express, which is the app; and then for my little ones, like the basic toys that allow for imagination communication, like the bubbles and the ball and the food and potato head.

Denise found that not only the Social Express app that SLPs may or may not have, but inexpensive and accessible therapy materials such as balls and bubbles also promote language development. Therefore, therapy materials do not have to be complicated or expensive in her opinion. 
Though I have heard complaints about difficulty in locating activities, my professor, Dr. Goldberg, in a speech and hearing clinic class at the College of Wooster, provided an assignment to create two language therapy activities using just a paperclip. He said the point of this exercise was to show that language activities can be created from simple materials. While this was an extreme example of a simple tool used in therapy, there are therapy materials in most homes. As any parent can attest, children often gravitate towards simple objects that may not originally be children's toys. Pots and pans beaten with a wooden spoon, can easily take the place of a complex and expensive drum kit for a small child. My son initially enjoyed playing with the wrapping paper and the box that a gift came in more than the gift.

As stated previously, Denise mentioned several times that simple toys are especially powerful tools with young students and lead to communication success. She mentioned the effectiveness of using bubbles in a speech therapy setting:

From like my little ones, anything that -- like simple stuff literally. I don't know if this is silly to say, but bubble, wind-up toys, a ball. Those are like the best things in the world. Potato Head... and I mean, my autistic kids love bubbles. It's amazing what kind of language you can get out of just bubbles or even communication.

Denise also named wind-up toys specifically as the best therapy tools that she has for young children. She pointed out that not only are wind-up toys effective in instruction, but students enjoy them as well:

I know that sounds really simple, but honestly, those are the best tools that I have. I have wind-up toys. I have this wind-up frog, and wind-up monkey that jumps, and then you know how are you going to get communication? Well, they want more of that. So they love the wind-up toys. 
Simple toys are especially powerful tools in early intervention settings. SLPs in Birth to Three, like Amber, often show parents how they can interact with their child to stimulate language skills by using toys that the child already may have in the home environment. A study by Sosa (2016) found that the type of toy had an impact on quality and quantity of communication interactions between parents and children. It found that traditional toys such as puzzles, blocks, and stacking cups yielded greater communication than electronic toys.

Erin found that the traditional therapy of drill and practice along with creative dramatic exercises, such as acting out stories or role playing, were the most successful therapy activities. Specifically, she found that using both activities helped her students. Erin commented, "The interplay of both I really see as being important.” Thus, her students were able to practice social skills in a more natural interactive way through role play activities after first learning them during drill activities. A study by Abdoola et al. (2017) found that role playing helped to increase generalization of social skills in children with language learning difficulties.

\section{Student Perspective}

The interviewed SLPs discussed which therapy activities children appeared to enjoy most. They mentioned a variety of activities. In fact, few mentioned the same activity. However, three of the SLPs said their students enjoyed technology the most. The other therapy activities that were judged as most popular were toys, outside activities, games, and conversation/question activities. They especially enjoyed the creative dramatics activities of role playing/acting and music. Table 4.4 summarizes the reported most enjoyed therapy activities. 
Table 4.4

Most Enjoyed Therapy Activities

\begin{tabular}{lccccc}
\hline & Games & Technology & Toys & $\begin{array}{c}\text { Creative } \\
\text { Dramatics }\end{array}$ & Other \\
\hline Amber & & & & $\mathrm{X}$ & $\begin{array}{c}\text { Outside Play } \\
\text { Sensory Activities }\end{array}$ \\
\hline Denies & $\mathrm{X}$ & $\mathrm{X}$ & $\mathrm{X}$ & & \\
\hline Erin & & & & $\mathrm{X}$ & \\
\hline Nina & $\mathrm{X}$ & $\mathrm{X}$ & $\mathrm{X}$ & & \\
\hline Sara & $\mathrm{X}$ & $\mathrm{X}$ & & $\mathrm{X}$ & Music \\
\hline
\end{tabular}

Technology was discussed by Nina, Sara, and Denise. Nina talked of how her students enjoyed electronics more than any other activity: "If I'm looking at my whole career, I would say definitely electronics." Sara also said that students "like their screens." Denise said that her student enjoyed The Social Express App that was previously mentioned: "They love that. I think because a lot of kids love the iPad."

The SLPs found that their students also liked play activities and toys. As previously reported, Denise said that her students liked windup toys and bubbles. Nina mentioned that, also, especially mechanical type toys. Amber said that her Birth to Three students enjoy having speech therapy outside and doing outside activities: "Almost all of them love to be outside." Amber added that her students like sensory activities, too, like manipulating beans and rice. Nina also mentioned that while her students enjoy playing any type of game, especially building games or games with gears, they also love common games, such as Pop up Pirate and Scattegories. Denise also agreed that her students love to play games: "They love games.... Socially Speaking is a really fun game for them, and again, it totally works on social skills, but it's like in a game form." Sara mentioned that her students greatly enjoyed games: "They love games. I mean, anytime you can make a game out of something." 
Erin said that her students enjoyed creative dramatic activities the most: “They immensely, immensely enjoy standing up, talking with each other, acting things out, more or less playing the charades." Erin emphasized that her students enjoyed doing creative activities, especially working with the props, to the point that they enjoyed the props "sometimes too much" to the point of distraction from the therapy activity. Amber also said that her students enjoyed movement activities which can be seen as play, but also creative dramatics exercises. Amber pointed out, "Once you get them past the initial fear, they like a lot of movement, swinging, whether it's on a swing or in a blanket or in my arms."

Sara said specifically that her students greatly enjoy using music in speech therapy. After all, music is also a form a language expression. She thought that music was especially effective for students with ASD: "Some of them seem to have even more enjoyment of music than maybe your average kid does." Music therapy has been documented as beneficial for children with ASD (Gold, 2011). However, there is little research on using music with children with ASD in speech and language therapy, yet, Sara found that it increased her students' language skills as well.

\section{Traditional verses Creative Therapies}

It is interesting to note that although both traditional and creative therapies are judged as enjoyable and effective by the SLPs in the field, there is pressure in some school systems to downplay the creative. As mentioned in Chapter 2, evidence-based traditional therapies in speech therapy have been used by SLPs for years. Evidence-Based Practice is "conscientious, explicit and judicious use of current best evidence in making decisions about the care of individual patients." (Sackett et al., 1997, p. 2) In a clinical setting, evidence-based interventions are effective treatments that are based on peer reviewed data (Wong et al., 2005). Examples are Discrete Trial Training, Functional Communication Training, Video Modeling, PECS, Voice 
Output Communication Aid Devices, Peer Mediated Instruction and Intervention, Naturalistic Language Strategies, Joint Action Routine, Social Narratives, and Imitation and Modeling (Lofland, 2014). Erin alluded to the pressure that SLPs feel to use traditional therapies and avoid creatives ones; however, she believed that both are useful and important to use with students. Erin remarked:

I think there is a place for pretty much a lot of what we would do traditionally, as our drill, our practice, but there is that much of a place as well for the use of the creativity, the creative dramatics, the incorporation of the stories. There is just that much of an importance for them as well, because we are trying to make these children be more independent, functional learners, functional members of society, and to be able to have one piece doesn't necessarily mean you will have the other. So, the interplay of both really see as being important

Erin discussed the tug between creative and traditional therapies. One problem hampering creative activities is lack of research. As mentioned in Chapter 2, there have been few studies that measure creative dramatics as a treatment for children with ASD. When starting to use creative dramatics with my pragmatic language group at Jayenne Elementary, I felt a need to locate research articles on the effectiveness of creative dramatics as well as to find guides on how to use creative dramatics with children with ASD. There was very little information available, aside from the research mentioned in Chapter 2. There also was not a single therapy guidebook on how to use alternative approaches, like creative dramatics, for children with ASD. However, it was clear to me that my practice revealed significant improvement with the communication development of students responding to creative dramatic exercises, especially the carryover of social skills outside the language group. Also, and most important, the students 
were excited about language therapy. They enjoyed coming to language group. This was evident because the negative behaviors, especially avoidance behaviors, stopped. They could focus on the task more because they enjoyed the activities. There was less time dedicated to reminding them and redirecting them to pay attention. There was also a significant reduction in time spent warning the children against negative behaviors such as hitting, getting out of their seats, etc. They were engaged in the tasks and wanted to be there.

\section{Creative Dramatics}

The secondary question that guided this study was how do SLPs describe using creative dramatics during language therapy sessions? The SLPs were not directly asked about creative dramatics. I wanted to determine if SLPs would bring up creative dramatics and how they would talk about creative dramatics in their respective practices. Throughout their interviews, Erin, Sara, and Amber independently mentioned using creative dramatics during their therapy sessions. However, all the participants in the study were aware that not only was I also an SLP, but that I had often used creative dramatics with my own students. This may have influenced their discussing creative dramatics in their interviews.

Creative dramatics in not intended to be performed in front of an audience, but to be used for self-expression and personal growth (Ward, 1947). As discussed in Chapter 2, the SLPs used creative dramatics as an effective device for developing their students' communication skills. Erin found that pragmatic skills could especially be taught by directly interacting with other students through creative means. Erin used creative dramatics with her students frequently in her speech and language sessions. She described a useful role playing/acting activity that she did with her students: "I also have the children do a really great activity on this same theme with 
acting out emotion, kind of like a charade, and the other children have to identify it." Erin further discussed an acting activity that she did with her students:

I recently did a very great therapy activity using the movie Inside Out, and the characters for emotions and using the small video clips and having the children identify what emotions were being used, and then having them typically roleplay or act out that emotion and what we could do or what you could say and what you couldn't say.

Erin found that not only do students have the ability to naturally work on pragmatics in an interactive situation with peers, but they also responded to these creative activities:

They immensely, immensely enjoy standing up, talking with each other, acting things out, more or less playing the charades, acting out scenarios or identifying the particular behaviors that we are trying to find in short video clips or in stories that we've read, and then they like to pretend to be those characters, and you know, often times I'll have props for them to do that, and they always enjoy the props, always. Sometimes a little too much.

Erin discussed the value in using objects or props with her students. Not only do her students enjoy them, especially hats, but props helped with them role play:

We'll have different types of hats for different roles. We've had different sports equipment we've brought in. We've done a lot of different things with like different stories.

Oftentimes, I'll have a stuffed animal or a puppet or something that represents the main character. I'm trying to think. We did Pete's Magic Sunglasses, and that one was really fun. so, they all had sunglasses.

Another SLP, Sara, discovered that students were successful in working on social language skills in natural settings where they have the opportunity to practice skills, such as turn taking or 
topic maintenance, through spontaneous conversation. Sara said: "When you give them a contrived situation to try to use socialization in, they respond to it... and I think some of them do like acting out stories and trying to act out small talk."

Sara discussed specifically how she has used role playing exercises in her speech therapy. She and her students take pretend "journeys" to places that the students frequently visit in their communities which leads to discussing other places that they would like to visit. It is important for students to practice social skills that they need to navigate social situations in familiar places in order to prepare themselves for unfamiliar ones:

We sometimes will go on journeys. We roleplay all the things that we are going to need to get with us before we take this trip, and then how we are going to get there, and then maybe we might pretend that we are a family doing this. [These] trips [are] one thing that I have done with kids that kind of stands out in my mind. But taking a trip somewhere and using - not creating the environment necessarily - but using some pictures of places and some videos and things like that so that they get some exposure to different things, but then making up a situation that [might happen] when we get there: this is what happens, and then what are we going to do? Trying to roleplay through typical day-today situations.

Amber, who works with the younger children in Birth to Three, also used acting/role playing activities with her students. She expands their expressive language through pretending play: With the high functioning students, I try to get more of the pretend play and those kinds of things, because usually they are into the numbers and the shapes and stuff like that. So, I try to draw away from that memory kind of thing, and talking on the telephone, pretending to cook, loving the babies, those kinds of things. [I] do a lot of that. 
As the driving theme in this dissertation, my interest in creative dramatics came from direct experience of working with students with ASD in a pragmatic language group with students of varying language abilities in their classroom. The group included students who were nonverbal with limited functional language, and others that had very high functioning verbal skills. There was a recognition that the task involving finding activities that would not only expand their collective language skills, but also that would promote engagement within a 30minute period, twice a week. It was hard to play traditional games or do craft activities with these students due to their varying abilities. Therefore, the approaches to using creative drama activities had to emerge out of expedience and necessity. This started with singing and rhyming, then expanded to using puppets, then role playing ... and finally acting out a narrative or story.

Observing the reactions of the language group, all students, regardless of severity level, became excited about the activities which genuinely engaged them. One nonverbal student, "Sarah," had difficulty attending to tasks. She exhibited avoidance behaviors to most of the activities in school. In a short time after attending language group, however, she started independently going to a box of props stored in her special education classroom as soon as the session began and offering a puppet. She would repeatedly poke the puppet at me until I accepted it and used it in a small puppet activity. She initiated a strong interest in wanting to interact and participate in this activity. For a child with such severe initiation difficulty, this was significant. Through the creative exercises, it became apparent that many students possessed more language abilities than had previously been realized. These activities provided the children an opportunity to practice appropriately their language skills in a natural way that was closer to play than just drill. One of the students, "Aaron," who had difficulty with problem solving while interacting with others, but was able to express himself in complete sentences. However, one day 
while acting out the story The Three Little Pigs, his character was the little pig who lived in the house of straw. When the wolf began trying to blow it down, he suddenly broke in: "Stop! I am going to call 911 and take care of this." There was a profound recognition that he could independently arrive at an appropriate solution which led into a discussion, and later, to an activity on what to do if he was in danger. Aaron was ultimately able to lead our language group in an exercise about calling 911.

\section{Building Blocks Model}

One of the objectives of this study was to determine if SLPs were integrating components of the Building Blocks Model in their treatment regiments. Three of the SLPs used components of the Building Blocks Model in their treatments and in a variety of ways. They used creative dramatics through different techniques to enrich and engage their students in language therapy.

Amber talked of the importance of teaching concentration skills to her student in therapy. Concentration is the first and foundational building block in the Model. The target skill of the concentration building block is joint attention. Joint attention skills are crucial in the role of language development, particularly social language development (Jones \& Carr, 2004). During her interview, Amber emphasized the importance of this foundational building block during her interview along with the need to teach it to students with all levels of ASD. Amber explained, "You have to teach regard .... Focusing on joint attention was a big thing with some of the more severe individuals, and most of them, even though they were very severe, did have some impetus to interact."

Sara mentioned, the third building block, movement to sound. This building block includes using music and singing. Music and movement to sound have been studied to help improve social skills of children with ASD (Srinivasan \& Bhat, 2013). Sara used music with her 
students. She believed that it is a powerful tool, especially for students with severe ASD. Sara said, "Kids do love music and love songs, but I like using music. I think they respond to music well.” As discussed earlier, she stated that children with ASD respond more than typically developing children to music.

The fourth building block, moods and emotions/role playing, was the most popular building block according to the SLPs in this study. Erin, Sara, and Amber mentioned using role play as part of their language treatment with their students. Erin not only named role playing as one of her most successful therapy activities for increasing language skills with her students, but explained that it was the activity that her students enjoy the most. There is limited, but some preliminary evidence that role playing can help increase social skills of students with ASD (Iswari et al., 2019). Erin gave the example of a role-playing speech therapy activity using the characters from the movie Inside Out.

Sara talked of using role play with her students. She termed it "going on journeys." Sara used role play scenarios of day-to-day situations to expand the expressive language of her students and to teach them how to interact in an appropriate social manner. Sara said: "We roleplay through all the things that we are going to need to gather before we take this trip, and then how we are going to get there.” Lastly, Amber, who works with younger children in Birth to Three, discussed how she engaged in pretend play with them. She says she encouraged her students to role play "pretending to cook, loving the babies, those kinds of things."

Sara talked about using the fifth building block, voice and diction (using appropriate vocal qualities and the manner of sound for your communication). Specifically, Sara used Melodic Intonation Therapy with her students in the past which fits into the voice and diction building block criteria. Melody Intonation Therapy focuses on the suprasegmental features of 
speech commonly referred to as prosody and features tone, stress, and rhythm by singing (Lee et al., 2019). An examination of research on Musical Therapy (MT) including Melodic Intonation Therapy by Accordino et al. (2007) found it to be successful for patients with ASD. They explained:

The preceding critique of the current literature shows that MT has been used to address and alter activities in areas where individuals with Autism are particularly deficient including behavior; sensory and motor skills; language and communication; interpersonal skills and abilities to express themselves; and self-help and survival skills. (p. 112) Sara also found melodic intonation therapy successful for her students. Sara said, "They went from direct intonation to maybe starting the phrase, and then being able to do it themselves when they saw the pictures that were associated with the phrases." However, Sara noted that her students still were reliant upon a cue to communicate. Sara relayed her experiences: "We practiced upon picture cue, but never really generalized it to become more effective communicators."

While the SLPs did discuss most of the building blocks, they did not mention every building block. They did not report on using the third building block, pantomime (imitating movement without sounds), or the sixth building block, storytelling (telling a story, also known as an oral narrative). However, they did talk about using most of the building blocks in their language treatments with their students.

\section{Conclusion}

Individualizing therapy was the major theme that the SLPs relayed in their experience working with children with ASD during therapy sessions. This major theme of individualizing therapy was supported by minor themes involving the severity of the child with ASD, special 
interests of the student, and incentives for communication. SLPs in this study were influenced by existential themes of interacting with caregivers. They discussed temporality constraints of planning therapy activities and caseload numbers. The SLPs discussed their most successful therapy activities involving social stories, book activities, iPad apps, and creative dramatic activities. However, their students enjoyed technology and games the most. Their practices also involved creative dramatics in speech therapy. The SLPs who mentioned creative dramatics found it to be successful at increasing communication skills. This was particularly true with role playing and acting. In conclusion, the SLPs emphasized that therapy had to be uniquely tailored to each of their students with ASD and that there were benefits in both evidence-based and creative therapies for these students. 


\section{CHAPTER 5: CONCLUSIONS}

Not being able to speak was utter frustration. If adults spoke directly to me, I could understand everything they said, but I could not get my words out. It was like a big stutter. If I was placed in a slight stress situation, words would sometimes overcome the barrier and come out. My speech therapist knew how to intrude into my world. She would hold me by my chin and made me look in her eyes and say "ball." At age 3, "ball" came out "bah," said with great stress. If the therapist pushed too hard, I threw a tantrum, and if she did not intrude far enough, no progress was made. My mother and teachers wondered why I screamed. Screaming was the only way I could communicate. Often, I would logically think to myself, I am going to scream now because I want to tell somebody I don't want to do something. (Autism Research Institute, 2021, para. 4.) Temple Grandin, a prominent advocate for the ASD community, discussed her own childhood frustration with attempting to communicate with others, along with her experience in speech and language therapy. Though Grandin is now a respected professor of animal science at Colorado State university, much of her research detailed her experiences in dealing with ASD. In such books as Thinking in Pictures (1995), she described her struggles to communicate her basic wants and needs while being completely aware of her communication issues. Grandin wrote: "I think in pictures. Words are like second language to me. I translate both spoken and written words into full-color movies, complete with sound, which run like a VCR tape in my head" (1995, p. 3). Her present goal is to educate observers on what it is like to have ASD and inspire those with the disorder to realize that they too can overcome the challenges of their condition. She credits much of her success in overcoming her communication difficulties associated with ASD to others who encouraged her, treated her, and gave her opportunities in her life. She 
believes that one-on-one speech therapy was tremendously beneficial for her communication skills (Raymond, 2010). Its influence was so significant in her own experience that she believes it can truly help other children with ASD learn to appropriate communicate.

This case study dissertation explored the perspectives of five SLPs working with their students with ASD through interviews. It looked in depth at the experience of these SLPs working with children with ASD in their therapy practices. I particularly investigated if and how SLPs used creative dramatics during their language therapy sessions. This study was guided by two questions:

- Primary Research Question: What are the experiences of speech language pathologists utilizing different treatment methods to improve the language skills of children with ASD?

- Secondary Research Question: To what degree do SLPs use creative dramatics in language therapy?

\section{Methods and Procedures}

This was an exploratory single case study. Five SLPs were interviewed by the researcher regarding their experiences working with students with ASD. These interviews were semistructured interviews with open-ended questions. This allowed the SLPs more spontaneous discussion. They were recorded on tape in order to promote a flow of ideas. The interviews were then transcribed. Another data source was a research journal kept by the researcher during the entire research process. This journal served to promote reflection throughout the research experience.

This study used thematic analysis to analyze the data. This dissertation specifically utilized Braun and Clarke's (2006) six step framework as a guide for conducting thematic 
analysis. These steps are: familiarizing yourself with your data; generating initial codes; searching for themes; reviewing themes; defining and naming themes; and producing the report. The process of coding unveiled the themes that would become the findings of the study.

\section{Major Findings}

Multiple themes found in this study from the SLPs' interviews reflected their experiences of working with children with ASD. The first research question addressed many aspects of working with children with ASD. This experience included not only actually working in therapy sessions, but also planning for therapy and interacting with caregivers. This study found that individualizing therapy was the most prominent discussion point in each interview and across all interviews as a whole. The SLPs emphasized that there is no "one size fits all" model for speech and language therapy for children with ASD. Therapy has to be tailored to meet the needs of each student. This also reflected the unique symptomology of ASD that each student exhibited, as well as the unique preferences of each student. These preferences shaped therapy and contributed to therapy success.

The importance of individualizing therapy was the major theme that the SLPs relayed from their experience of working with children with ASD during speech language therapy sessions. Amber pointed out that there were no typical language sessions for children with ASD because each child is different. She said, "Those typical sessions, of course, are based on what each individual child needs at that point." All SLPs emphasized that they needed to be flexible to the unique therapy needs of each of their students.

This major theme of individualizing therapy was supported by minor themes involving the severity of the child's ASD, special interests of the student, and incentives for communication. The SLPs all worked with children with different levels of severity with ASD. 
The severity of the child's disorder greatly affected therapy from the treatment interventions to the student's progress. Even the structure of a therapy session was impacted. As Amber stated, when asked to describe a typical speech and language therapy session with a student with ASD: "It depends on the severity of the child." The SLPs also described the difficulty of having students with ASD of varying severities on their caseloads at the same time. Another minor theme was appealing to the special interests of the students. SLPs talked about using those special interests to tailor speech therapy for a particular child. Nina said that she would work on conversation skills with a child by discussing topics of interest to that child. She gave the example of Pokémon that interested some children. Discovering the special interests of a child was part of the therapy experience for SLPs.

The last minor theme under individualizing therapy was using incentives to help foster and increase communication in therapy. These incentives were described by the SLPs as being highly motivating for a child to reinforce communication with children. The SLPs discussed using special interests mostly as reward in therapy. Sara emphasized that the reward has to be a "highly desired item" that motivated that particular child. Denise told of her student who loved French fries, so she used them as a reward in speech therapy. SLPs mentioned other rewards such as iPads, electronics, and potato chips. These rewards were all varied and dependent on the individual desires of the child.

This study also found that the experiences of SLPs in treating students with ASD in this study were influenced by existential dimensions (Van Manen, 2014) of interacting with parents and caregivers. SLPs did not work with children in a bubble, but interacted with their caregivers as well. Ideally, the caregivers would have a collaborative role with the SLPs and help provide therapy materials, such as preferred items for picture exchange activities. They also would 
carryover therapy activities at home to increase generalization of skills. In reviewing social language books, Denise recommended Julia Cook books to caregivers that focus on the specific social skills that she had been working with her student in therapy. Having the caregivers read and review the books with the child effectively reinforces those social skills. Thus, counseling caregivers was also a theme. Most of the SLPs discussed their interactions with parents. While two of the SLPs, Erin and Denise, discussed this interaction in a positive way, Amber mentioned that parents had difficulty implementing treatment methods and procedures, specifically, following the strict directions for PECS. She had to modify the treatment in order for the parents to be able to help the children. On the other hand, Erin mentioned that it was rewarding for caregivers to see their children's language improvement during speech therapy sessions.

The SLPs also discussed temporality, specifically temporality constraints that impacted them. These temporality issues were mainly regarding the time required to plan effective therapy activities. The SLPs pointed out that therapy activities, especially creative dramatic activities, took much time to plan. Sara explained that when she was younger, she had more energy for the extensive planning that some of these activities required. She willingly gave up her lunch to meet the needs of her students. Erin emphasized that her student therapy activities required a substantial amount of time. Erin said in regard to speech therapy that "sessions typically take a lot of planning to be able to have children effectively meet their goals." Time constraints were an issue for some of the SLPs in this study.

The SLPs described the activities that they use with their students. These were Rapport Building, Object Identification, Sensory Activities, Picture Based Communication System, Sign Language, Movement Activities, Creative Dramatics, Play Therapy (Toys), One Step Directions, Labeling, Simple Questions, Conversation Activities, Social Thinking Program, iPad Activity: 
Social Express, Games: Socially Speaking, Get to Know Me Cards, Literature Activities, Drill and Practice, Wh Questions (who, what, when, where, or why questions), Video Modeling Activity, Task Boxes, Games, Language Fundamental, SOL (Standards of Learning) Standards, Sentence Building Activities, Book Activity, Picture Identification Activities, Modeling, Scripting, Facilitated Communication, Melodic Intonation, Social Thinking Modeling, and Music Therapy. The SLPs also discussed their most successful therapy activities. These activities were Social Stories, book activities, iPad apps, and creative dramatic activities. They also discussed therapy activities that their students enjoyed the most. These activities used technology and games. They also enjoyed creative dramatics, music, outside play, sensory activities, and toy activities. Therefore, the most successful therapy activities and most enjoyed by the children were a mixture of traditional therapies and creative ones. One SLP, Erin, discussed the tug between creative and traditional therapies. This emerged as a theme. She believed that it is most beneficial to be open to both areas with students.

The second research question of the study was how SLPs described creative dramatics during therapy sessions if they did indeed use creative dramatics. This study found that the majority of SLPs interviewed did use creative dramatics. Specifically, all but one of the SLPs said that they use creative dramatics with their students. They also discussed a variety of creative dramatic techniques that they incorporated into therapy. The SLPs described using role playing, charades, singing, rhyming, acting out stories, and pretend play with props and puppets. Creative dramatics was found by the SLPS to be effective at increasing communication skills with their students. One SLP, Erin, judged it among the most successful therapy activities that she used with her students. Erin said role playing and acting in particular were the most beneficial. Also, two SLPs said that creative dramatics was the most enjoyable therapy activity. Whether it was 
the most enjoyed activity or not, all SLPS that discussed creative dramatic activities conveyed that their students enjoyed them to some degree. Erin described their enjoyment in the strongest terms: "They immensely, immensely enjoy standing up, talking with each other, acting things out, more or less playing the charades.” Interestingly, Sara noted that her students enjoyed creative dramatics even though the role playing activities were challenging for her students. Sara commented, "I think even though it's difficult for them, that they do like to roleplay and things, and I think it's because whether it's on any kind of conscious level because they need it." The SLPs who used creative dramatics with their students talked of how much enjoyment their students derived from creative dramatic activities.

\section{Discussion}

Since individualizing therapy was a major theme of this dissertation study, SLPs might consider being mindful of this while planning therapy in the future. Therapy should be customized towards each individual student with ASD (National Autism Center, 2015; National Research Council, 2001). In fact, SLPs need to individualize therapy for students with ASD more than for students with other speech and language issues, such as for children with articulation, language, and voice disorders, due to the unique symptomology of each student with ASD. This study is not the first to emphasize that individualized therapy is critical for improvement of communication needs (Stahmer et al., 2011). However, the SLPs interviewed in this study emphasized the importance of SLPs taking more time to investigate their students' preferences to have a successful therapy experience.

Caregivers have a critical role in the development of their child's communication and can help with their child's progress in speech therapy. It is considered best practice for working SLPs to take on the role of family centered practitioners while planning assessments and treatment 
(Beatson, 2006). Family centered practice means that SLPs work directly with caregivers in every aspect of service. It also recognizes caregivers as "key decision makers" (ASHA, 2021a). They can be useful in practicing speech and language skills learned in therapy and in generalizing those skills outside of the therapy setting. Not only can it help the progress of students' communication, but it is part of the responsibility of SLPs. ASHA has a position statement that promotes collaboration with students' caregivers as part of the roles and responsibilities of practicing SLPs (ASHA, 2010).

The majority of SLPs in this study suggested that interacting with caregivers was part of their experience working with children with ASD. They identified these interactions as an overall counseling role to educate the parents on how to carry over language therapy at home to increase communication. Within the counseling role, there is also a collaborative and coaching role for SLPs with caregivers as well. Through this collaborative and coaching role, the SLPs help caregivers extend therapy sessions at home and carry over language goals. This coaching role is important to the students' progress and generalizability of skills (Peterson et al., 2007; Rush et al., 2004). The caregivers would also help provide therapy materials, such as food as rewards for picture exchange programs. Therefore, caregivers were a multipurpose asset to helping with the speech-language experience. The SLPs also discussed the value of sharing language therapy experiences to demonstrate change to caregivers of their child's communication improvements. Erin would show parents video clips of students working on social skills with other special education students or with regular education peers. Erin explained that the caregivers enjoyed seeing their children interact and improve.

Connected to the theme of individualizing therapy was the temporal manifestation (e.g., time constraints). Therapy tailored to meet individual needs takes time to plan. SLPs also have 
increasing caseload numbers which impacts their time to plan therapy. Katz et.al. (2010) found that SLPs consider caseloads of 40 students or less to be manageable. Unfortunately, most states do not even have caseload caps. New Mexico and Alabama are the only states with caps at 40 or below. California also has a caseload cap at 40, but only if working with children ages 3-5 (ASHA, 2020). Other states have caseload caps of more than 40 or none at all.

ASHA has advocated that not only must caseloads be considered in the job requirements of school SLPs, but their workloads as well. They published a position statement (2002) that recommend states adopt a workload, instead of a caseload approach: “A workload analysis approach to setting caseload standards is necessary to ensure that students receive the services they need, instead of the services SLPs have time to offer or services based on administrative convenience "(p.1). SLPs have many tasks to complete beyond actual therapy time with their students. The SLPs in this study described not only working with students in therapy sessions, but also planning therapy, working with caregivers, collaborating with others, etc. A SLP's typical workloads may require the SLP to:

support students outside of sessions by planning evidence-based lessons and activities, communicating with parents and other educators, tracking session data, and participating in a multitiered system of supports (MTSS)and behavioral teams. SLPs also must attend student-centered meetings, consult, and collaborate with colleagues, and complete duties integral to the school community, such as bus and lunch duty. (Prasad, 2019, p. 57) ASHA (2021b) created a workload calculator as a tool for school systems that looks beyond caseload numbers in order to include all the other responsibilities and professional time constraints. This tool can help school systems decide how many students can be effectively treated on an SLP's caseload. However, despite ASHA's position on workloads in 2002 and the 
workload calculator, school systems are still generally using number of students or caseload approach as the main factor in determining caseloads (ASHA, 2020). An ASHA (2020) survey of SLPs in the schools found that $79 \%$ used a caseload approach with only $17 \%$ using a workload approach and $4 \%$ using a combined caseload approach and a workload approach. This survey also found that the median caseload was 47 students. A study by Ferney Harris et al. (2009) recognized this issue as a significant source of stress for school SLPs. Increased caseload has been an issue that has affected retention of school SLPs as well (Hutchins et al., 2010). SLPs in this study also found that caseload numbers affected the quality of their therapy, especially in terms of time needed to plan therapy. The caseload cap in WV is currently 50, but the number is not dependent on the type of population that an SLP may be servicing (ASHA, 2020). Some disorders require more planning time than others. As we have seen in the study, since students with ASD require especially challenging therapy, therefore, the planning time is greater. It may be beneficial in the future for caseload numbers to be lowered for SLPs working with children with ASD.

A secondary aim of this study was to determine if SLPs used creative dramatics with their students with ASD. The majority of SLPs interviewed in this study did use creative dramatics in their practices. They also found it successful and enjoyable for their students. Though there has been little research on creative dramatics in the field of speech-language pathology, it may be something SLPs naturally do with their students despite having little or no background or training on it. It is also noteworthy that they have found creative dramatics particularly successful in developing language skills. One SLP said it was one of the most successful therapy activities that she does with her students. As mentioned in Chapter 1, there are currently no formal studies on SLPs using creative dramatics with their children with ASD; 
however, there are some studies that have been conducted in the past. For example, Hahn (1955) and McIntyre \& McWilliams (1959) investigated creative dramatics in "speech corrections" or articulation therapy. The most recent speech-language pathology study is by Balyeat (1970) who studied creative dramatics used in speech therapy in a school setting. Balyeat found that creative dramatics increased articulation and language skills, and also increased positive attitudes towards speech therapy. Balyeat (1970) recommended, "further study of creative dramatics as a technique for use in speech therapy" (p. 26). This recommendation still holds true today. Bush (1978) outlined creative dramatic techniques to use with students who have speech and language disorders in a therapy setting. Lastly, an unpublished doctoral study by De la Cruz (1995) found that creative dramatics did increase oral language and social skills in a small sample of students who had been diagnosed with learning disorders.

However, as shown in this study, SLPS are using creative dramatics in their practices. They are also providing alternative sources on creative dramatics. There are speech-language pathology blogs on the internet such as Felice Clark's The Dabbling Speechie and Claudia Doan's Creative Speech Lab where SLPs are not only discussing using creative dramatic techniques with their students, but also providing examples and therapy lesson plans for other SLPs to use. Even with this sharing of practitioner knowledge, there is no empirical research on SLPs using creative dramatics working with students with ASD, aside from accounts referenced in personal blogs and web pages. However, my research shows that SLPs are using creative dramatics and finding it to be successful. It is a viable area for further research.

The SLPs in this study discussed the interventions that they use with their students with ASD. As mentioned previously, the SLPs discussed both creative therapy activities and traditional ones that they use in their practice. Erin stated that she thought both types of activities 
should be used to make students independent functioning members of society. Creative dramatics and evidence-based traditional therapies, such as PECS or Social Stories could be used together as part of a therapy plan for a student. However, there is no research on combining both traditional and creative dramatic interventions. There is simply a lack of research currently in this area, which accentuates the need for comprehensive research in the future.

There is, however, research on the benefits of using drama therapy with students with ASD. Drama therapy, as mentioned in Chapter 2, can help students identify emotions, increase social skills, and develop overall communication abilities (Chasen, 2011). There are drama programs across the USA for children with ASD that are helping to increase their social skills. The SENSE Theatre Research Program at Vanderbilt University and Theater Horizons in Philadelphia both have drama programs and drama experiences for children with ASD. The Spectrum Arts: The Autism Arts Network! is an online data base that includes current information on drama programs and experiences for both children and adults with ASD. The creator, Erica Meium, wanted to have a central database to make it easier to access information on these programs (Spectrum Arts, 2016). Drama has also been documented to help children with ASD (Kempe \& Tissot, 2012).

\section{Conclusions and Implications for Practice}

The major conclusion from this study was the importance of individualizing therapy in the experience of the five SLPs who were interviewed in this study. All recognized that effective treatment for children with ASD had to be based on individualizing therapy. This is particularly significant when the rates of ASD continue to rise in the United States. Even though more children continue to get diagnosed, it is critical to realized that each child with ASD is unique and thus needs a unique therapy program. 
Another theme that emerged from this study was the issue regarding time constraints. SLPs will likely need more planning time to organize therapies for children with ASD. This is particularly important since the population of children with ASD continues to increase, so SLPs will be gaining more of these students on their caseloads in the future. SLPs need to be given the support and time to adequately plan therapy, especially since therapy needs to be tailored for each individual student in this growing population.

Speech-language pathology in the school system can be an isolated profession. Aside from meeting other SLPs at conferences where SLPs gather to pursue continuing education opportunities, there are limited opportunities for SLPs to discuss professional issues. After all, there are usually only a few of SLPs to treat an entire school district, a few in a hospital, and one or two in private practices. Nicole Alison (2016) wrote an article on her speech-language therapist blog, Speech Peeps, entitled Dear Lonely SLP. She explained that she only sees other SLPs twice a year at professional developments. She started her blog as a way to reach out to other SLPs. It is critical that SLPs have a chance to compare their experiences. The studies that examined how SLPs feel toward the profession mainly deal with the subject of increased caseloads and burnout (Ewen et al., 2020; Ferney Harris et al., 2009). The ASHA Leader is an ASHA print and online newsletter that provides stories of professionals: Published ten times per year, The ASHA Leader is available to members of ASHA. It contains professional news and has a topics section entitled ASHA News and Member Stories. This section publishes "Member Voices" where SLPs, audiologists, and hearing scientists can share their personal experiences and their concerns to members within the speech and hearing community. Some comment on the efficacy of certain treatments, but few have investigated the qualitive perspective of the experience of the SLP. There obviously needs to be more opportunities for SLPs to share their 
perspectives with each other and have their voices heard to advance the profession, aside from The ASHA Leader.

There is no cure for ASD (Mayo Clinic Staff, 2018) and no single best communication intervention (Brignell et al., 2018). Particular interventions may be suitable for certain cases. Therefore, having a toolbox of intervention options is extraordinarily useful to practicing SLPs. This study found that both traditional research-based therapies and creative dramatics were used in the treatment of children with ASD. Evidence-based interventions for SLPs are Discrete Trial Training, Functional Communication Training, Video Modeling, PECS, Voice Output Communication Aide, Peer Meditated Instruction and Intervention, Social Narratives and Social Stories, and Imitation and Modeling Therapy (Lofland, 2014). The SLPs in this study reported positive results in using picture communication therapy systems similar to PECS, video modeling, and Social Stories with their students. They also described using effectively common SLP activities of Wh questions, scripting, play based therapy, and using literature activities in therapy. It would be beneficial in the profession to communicate what other activities other SLPs are finding the most successful activities and those that their students enjoy as a way to strengthen their service delivery model. There are many research-based articles that discuss therapy techniques, but it is powerful to hear therapy activities in the words of SLPs and not just conveyed through statistical interpretations. Professional communication coupled with continued treatment research would be especially beneficial given the importance of individualizing therapy and the increase of caseloads and incidences of ASD.

This study also discussed a friction between using traditional versus creative therapies. There is much more research on traditional evidence-based therapy (Lindgren \& Doobay, 2011). An SLP, Erin, interviewed in this study believed that there was a need for using both types of 
therapy. In her view, there needs to be more research on not only creative therapies in the speech-language pathology profession, but also approaches to combining both types of therapy. Traditional and creative therapies can support each other during therapy sessions if SLPs are trained how to do this or have the research to support them through their practice.

In conclusion, this dissertation has revealed that the SLPs interviewed are using creative dramatics in their practice. These SLPs found that creative dramatics helped to increase communication skills for children with ASD. The students also enjoyed the creative dramatic exercises. I created the Building Blocks Model and did a pilot study for this dissertation in May of 2011. I would like to continue to develop my Model and conduct a post dissertation study using it with students with ASD. It in my hope that the Building Blocks Model can become a tool for SLPs, caregivers, special educators, and regular educators to use with children with ASD to develop their communication skills.

\section{Suggestions for Further Research}

An emphasis of this study was to highlight what SLPs practicing every day are doing with their students with ASD, especially what they found successful in their daily treatment practice. They mentioned therapy activities that they found most successful. It was personally interesting and gratifying for me, as the researcher in the study, to learn how other SLPs approached working with their students with ASD. Moreover, my discoveries affected my own therapy. I was guided to Julia Cook's books and started using them with my students with ASD. I also was introduced to The Social Express iPad App and began using it in therapy. I have had success with both materials.

This study also identified the need for future research on temporal issues facing SLPs in the schools today. This is critical in order to support SLPs. With the current increase of students 
with ASD, SLPS may be overworked to the point that they lose their effectiveness. Since this study has revealed the importance of individualizing therapy of children with ASD, SLPs need the time and support to plan meaningful therapy activities for their students.

A further suggestion for research is also investigating the relationship between caregivers and SLPs and finding ways to make it more successful, particularly with the ASD population. There not only needs to be research and education on how the SLP can navigate interaction with caregivers to benefit their students with ASD, but also on how caregivers can be encouraged and helped to support speech and language therapy at home and work successfully with their child's SLP.

The SLPs' experiences in this study show that SLPs are already using creative dramatic techniques in their current practices. There needs to be further study on exploring these and other creative dramatic activities for children. Additionally, there is a need to determine best practices, better materials, and more effective training in creative dramatic techniques used in speech and language therapy. Lastly, there particularly needs to be research done on creative dramatics used with the ASD population. Studies need to focus on different creative dramatic techniques used by SLPs with students with ASD of varying verbal levels to determine what type of language skills improve. Studies should examine at how long creative dramatic techniques are utilized in therapy before progress is shown and if this progress is generalized outside of therapy. Studies may also focus the most useful ways for caregiver involvement with creative dramatics regarding their child's language therapy to carry over skills outside of therapy sessions. There are many different areas to research with creative dramatics and children with ASD because of the lack of previous research. The SLPs in this study found creative dramatics to be a successful 
intervention and I personally have found in successful too; however, very little research is being done on this topic.

\section{Conclusion}

The goal of this dissertation was to study the experiences of SLPs in their treatment practices of working with students with ASD. It found that while each SLPs had a unique treatment perspective there were similarities. Through interviews on the SLP experiences, several themes emerged. The conclusive theme was importance of individualizing therapy. The SLPs had to structure therapy for each of their students to meet their individual needs due to ASD. Their students also had unique motivators and incentives that guided therapy. The SLPs also discussed temporality issues that impacted their practices. They identified their most successful activities for their students and the activities their students enjoyed the most. The second goal of this study was to investigate whether SLPs were using creative dramatics with students with ASD. Most of the SLPs interviewed were successfully using creative dramatics in therapy. They were also using most creative dramatic techniques that make up the Building Blocks Model. The friction between creative therapy and traditional therapy was discussed, as well. Lastly, this study found a need for further research not only on the experiences of SLPs during speech therapy, but also exploring creative dramatics as a therapy tool.

I would like to continue to study SLPs working with children with ASD in the future. I would specifically like to expand my research on creative dramatics as a therapy tool for SLPs to use with their students with ASD. There is a need for additional in depth studies on creative dramatics in speech-language pathology. As shown in this study, SLPs are using it and reporting success with their students. I would like to conduct further research studies on the most effective ways to use creative dramatics with students with ASD. I also want to continue to develop my 
Building Blocks Model. I have enjoyed using it with my own students and sharing it with other educators over the years. I personally have seen my own students succeed with the development of their own communication abilities with the model. They have also enjoyed the creative dramatics techniques. They became excited about speech therapy and I was excited to see their progress. When I presented at The ASHA Conferences in 2010 and 2011, the professionals that I talked to appeared excited to see creative drama techniques as an option for students with ASD. I have also enjoyed encouraging educators, who I have worked with, to use components of the model with their own students. Ultimately, I want it to be a tool for SLPs, special educators, educators, and parents to use with children with ASD. I want to continue to expand creative dramatic techniques further in my own practice with students. Lastly, I want to continue to collaborate with special education teachers and caregivers using these techniques together in order to advocate for creative dramatics to be used. There are many exciting possibilities for creative dramatics to help children with ASD in the future. I look forward to exploring these with my students and the ASD community.

\section{Unstoppable: A Song for Autism}

I know you get frustrated trying to tell us what you want to say.

I know it's not easy for you, but that is ok.

We see the words in your smile.

We see the you right in your eyes.

When something in your world goes wrong.

Remember to stand up and be strong.

(Byrne \& Guerriero, 2018, track 1) 


\section{REFERENCES}

Abdoola, F., Flack, P. S., \& Karrim, S. B. (2017). Facilitating pragmatic skills through role-play in learners with language learning disability. The South African Journal of Communication Disorders, 64(1), e1-e12. https://doi.org/10.4102/sajcd.v64i1.187

Accordino, R., Comer, R., \& Heller, W. B. (2007). Searching for music's potential: A critical examination of research on music therapy with individuals with autism. Research in Autism Spectrum Disorders, 1(1), 101-115. https://doi.org/10.1016/j.rasd.2006.08.002

Alexander, J. L., Ayres, K. M., \& Smith, K. A. (2015). Training teachers in evidence-based practice for individuals with autism spectrum disorder: A review of the literature. Teacher Education and Special Education, 38(1), 13-27. https://doi.org/10.1177/0888406414544551

Allison, N. (2016, November 21). Dear lonely slp. Speech Peeps. http://speechpeeps.com/2016/11/dear-lonely-slp.html

Alvares, G. A., Bebbington, K., Cleary, D., Evans, K., Glasson, E. J., Maybery, M. T., Pillar, S., Uljarević, M., Varcin, K., Wray, J., \& Whitehouse, A. J. (2020). The misnomer of 'high functioning autism': Intelligence is an imprecise predictor of functional abilities at diagnosis. Autism: The International Journal of Research and Practice, 24(1), 221-232. https://doi.org/10.1177/1362361319852831

Alzrayer, N., Banda, D. R. \& Koul, R. K. (2014). Use of iPad/iPods with individuals with autism and other developmental disabilities: A meta-analysis of communication interventions. Review Journal of Autism and Developmental Disorders, 1, 179-191. https://doi.org/10.1007/s40489-014-0018-5 
American Psychiatric Association. (1980). Diagnostic and statistical manual of mental disorders (3rd ed.). American Psychiatric Association.

American Psychiatric Association (2000). Diagnostic and statistical manual of mental disorders (4th ed., Text Revision). American Psychiatric Association.

American Psychiatric Association. (2013). Diagnostic and statistical manual of mental disorders (5th ed.). American Psychiatric Association. https://doi.org/10.1176/appi.books.9780890425596

American Speech-Language-Hearing Association. (2002). A workload analysis approach for establishing speech-language caseload standards in the school: position statement [Position Statement]. https://doi:10.1044/policy.PS2002-00122

American Speech-Language-Hearing Association. (2006). Guidelines for speech-language pathologists in diagnosis, assessment, and treatment of autism spectrum disorders across the life span.

https://faculty.washington.edu/jct6/ASHAGuideLinesAutismAssessmentScreening.pdf American Speech-Language-Hearing Association. (2010). Roles and responsibilities of speechlanguage pathologists in schools [Position Statement]. https://doi:10.1044/policy.PS2010-00318

American-Speech-Language-Hearing Association. (2015, October 28). Autism (Autism Spectrum Disorders). http://www.asha.org/public/speech/disorders/Autism/.

American Speech-Language-Hearing Association. (2020, July 20). 2020 Schools survey report: SLP caseload and workload characteristics. www.asha.org/Research/memberdata/Schools-Survey/ 
American Speech-Language-Hearing Association. (2021a, March 10). Family-Centered Practice. https://www.asha.org/practice-portal/clinical-topics/autism/family-centeredpractice/

American-Speech-Language-Hearing Association. (2021b, March 20). ASHA Workload Calculator. https://www.asha.org/SLP/schools/Workload-Calculator/

Angelo, D. (2000). Impact of augmentative and alternative communication devices on families. Augmentative and Alternative Communication, 16, 37-47. https://doi.org/10.1080/07434610012331278894

Asperger, H. (1991). Autistic psychopathy in childhood. In U. Frith (Ed. \& Trans.), Autism and Asperger Syndrome (pp. 37-92). Cambridge University Press. (Original work published in 1944). https://doi.org/10.1017/CBO9780511526770.002

Autism Research Institute. (n.d.). Temple Grandin: Inside ASD. https://www.autism.org/templegrandin-inside-asd/\#lack-of-speech

Autism Society of America. (2012, May 22). About autism. http://www.autismsociety.org/about-autism/

Autism Speaks. (2018, July 16). Autism and health: A special report by autism speaks. https://www.autismspeaks.org/sites/default/files/2018-09/autism-and-health-report.pdf Autism Speaks. (2020, March 26). CDC estimate on autism prevalence increases by nearly 10 percent, to 1 in 54 children in the U.S. https://www.autismspeaks.org/press-release/cdcestimate-autism-prevalence-increases-nearly-10-percent-1-54-childrenus\#: :text=CDC\%20estimate\%20on\%20autism\%20prevalence,in\%20the\%20U.S.\%20\% 7C\%20Autism\%20Speaks 
Autism Task Force. (2011). Service guidelines for individuals with autism spectrum disorder/pervasive development disorder through the lifespan. Ohio: Ohio Disabilities Council.https://www.ocali.org/up_doc/Autism_Service_Guidelines.pdf

Ayres, A. J. (1972). Improving academic scores through sensory integration. Journal of Learning Disabilities, 5(6), 338-343. https://doi.org/10.1177/002221947200500605

Balyeat, S. L. (1970). An experimental study to determine the effect of creative dramatics upon a public school speech therapy program [Master's thesis, Central Washington University]. ScholarWorks@CWU. https://digitalcommons.cwu.edu/etd/1428

Bandini, L., Curtin, C., Anderson, S., Philips, S. and Must, A. (2013). Food as a reward and weight status in children with autism. Federation of American Societies for Experimental Biology Journal, 27, 1063-1111. https://doi.org/10.1096/fasebj.27.1_supplement.1063.11

Baxter, P., \& Jack, S. (2008). Qualitative case study methodology: Study design and implementation for novice researchers. The Qualitative Report, 13(4), 544559. https://doi.org/10.46743/2160-3715/2008.1573

Beadle-Brown, J., Wilkinson, D., Richardson, L., Shaughnessy, N., Trimingham, M., Leigh, J., Whelton, B., \& Himmerich, J. (2018). Imagining autism: Feasibility of a drama-based intervention on the social, communicative and imaginative behaviour of children with autism. Autism: The International Journal of Research and Practice, 22(8), 915-927. https://doi.org/10.1177/1362361317710797

Beatson, J. E. (2006). Preparing speech-language pathologists as family-centered practitioners in assessment and program planning for children with autism spectrum disorder. Seminars in Speech and Language, 27(1), 1-9. https://doi.org/10.1055/s-2006-932434 
Bennett, A. (2012). Parental involvement in early intervention programs for children with autism [Master's Thesis, St. Catherine University]. SOPHIA: St. Catherine University's Institutional Repository. https://sophia.stkate.edu/msw_papers/113

Benson, P. R. (2006). The impact of child symptom severity on depressed mood among parents of children with asd: The mediating role of stress proliferation. Journal of Autism and Developmental Disorders, 36(5), 685-695. https://doi.org/10.1007/s10803-006-0112-3

Berdik, C. (2014, October 14). Unlocking Emily's world: Cracking the code of silence in children with autism who barely speak. The Brink Boston University. https://www.bu.edu/articles/2014/autism/

Bernstein, L. (2014, May 27). U.S. autism rate surges, cdc reports. The Washington Post. https://www.washingtonpost.com/news/to-your-health/wp/2014/03/27/u-s-autism-ratesurges-cdc-reports/

Bitsika, V., \& Sharpley, C. F. (2004). Stress, anxiety and depression among parents of children with autism spectrum disorder. Australian Journal of Guidance and Counselling, 14(2), 151-161. https://doi.org/10.1017/S1037291100002466

Bleuler, E. (1950). Dementia praecox or the group of Schizophrenias. International Universities Press.

Blood, G.W., Ridenour, J.S., Thomas, E.A., Qualls, C.D., \& Hammer, C.S. (2002). Predicting job satisfaction among speech-language pathologists working in public schools. Language, Speech, and Hearing Services in Schools, 33(4), 282-290. https://doi.org/10.1044/0161-1461(2002/023)

Bodrova, E., \& Leong, D. J. (2005). The importance of play: Why children need to play. Early Childhood Today, 20(1), 6-7. 
Bolton, G. (1985), Changes in thinking about drama in education. Theory into Practice, 24(3), 151-157. https://doi.org/10.1080/00405848509543166

Bondy, A. S., \& Frost, L. A. (1998). The picture exchange communication system. Seminars in Speech and Language, 19(4), 373-424. https://doi.org/10.1055/s-2008-1064055

Bondy, A., \& Frost, L. (2001). The picture exchange communication system. Behavior Modification, 25(5), 725-744. https://doi.org/10.1177/0145445501255004

Borg, S. (2001). The research journal: a tool for promoting and understanding researcher development. Language Teaching Research, 5(2), 156-177. https://doi.org/10.1177\%2F136216880100500204

Boyd, B. A. (2002). Examining the relationship between stress and lack of social support in mothers of children with autism. Focus on Autism and Other Developmental Disabilities, 17(4), 208-215. https://doi.org/10.1177/10883576020170040301

Braun, V., \& Clarke, V. (2006). Using thematic analysis in psychology. Qualitative Research in Psychology, 3(2), 77-101. https://doi.org/10.1191/1478088706qp063oa

Brehony, K.J. (2000) Montessori, individual work and individuality in the elementary school classroom, History of Education, 29(2), 115-128. https://doi.org/10.1080/004676000284409

Brett, J. (1996). Goldilocks and the three bears. Putnam \& Grosset Group.

Brignell, A., Chenausky, K. V., Song, H., Zhu, J., Suo, C., \& Morgan, A. T. (2018). Communication interventions for autism spectrum disorder in minimally verbal children. The Cochrane Database of Systematic Reviews, 11(11), CD012324. https://doi.org/10.1002/14651858.CD012324.pub2 
Brock, S. E., Jimerson, S. R., \& Hansen, R. L. (2006). Identifying, assessing, and treating autism at school. Springer.

Brühlmeier, A. (2010). Head, heart and hand: Education in the spirit of Pestalozzi. Open Book Publishers.

Bush, C. S. (1978). Creative drama and language experiences: Effective clinical techniques. Language, Speech and Hearing Services in the Schools, 9(4), 254- 258. https://doi.org/10.1044/0161-1461.0904.254

Byrne, T., \& Guerriero, I. (2018). Unstoppable: A song for autism [Song]. Tommy Too Tall Productions.

Cardin, T. A., \& Wilcox, M.J. (2011). Promoting imitation in young children with autism: A comparison of reciprocal imitation training and video modeling. Journal of Autism and Developmental Disorders, 41(5), 654-666. https://doi.org/10.1007/s10803-010-1086-8

Carr, E. G., \& Durand, V. M. (1985). Reducing behavior problems through functional communication training. Journal of Applied Behavior Analysis, 18(2), 111-126. https://doi.org/10.1901/jaba.1985.18-111

Center for Disease Control and Prevention. (2020a, March 25). What is autism spectrum disorder? U.S. Department of Health \& Human Services. https://www.cdc.gov/ncbddd/autism/facts.html

Center for Disease Control and Prevention. (2020b, September 25). Data \& statistics on autism Spectrum Disorder. U.S. Department of Health \& Human Services. https://www.cdc.gov/ncbddd/autism/data.html 
Center for Disease Control and Prevention. (2020c, October 2). Executive summary. U.S. Department of Health \& Human Services. https://www.cdc.gov/ncbddd/autism/addmcommunity-report/executive-summary.html

Cerbo, S. N., \& Rabi, N. M. (2019). Drama activities as tool for socialization of learners with autism. International Journal of Academic Research in Business and Social Sciences, 9(6), 1250-1261. http://dx.doi.org/10.6007/IJARBSS/v9-i6/6102

Chan, J. M., Lang, R., Rispoli, M., O'Reilly, M., Sigafoos, J., \& Cole, H. (2009). Use of peermediated interventions in the treatment of autism spectrum disorders: A systematic review. Research in Autism Spectrum Disorders, 3(4), 876889. https://doi.org/10.1016/j.rasd.2009.04.003

Chang, Y. C., \& Locke, J. (2016). A systematic review of peer-mediated interventions for children with autism spectrum disorder. Research in Autism Spectrum Disorders, 27, 110. https://doi.org/10.1016/j.rasd.2016.03.010

Charlop-Christy, M. H., Carpenter, M., Le, L., LeBlanc, L. A., \& Kellet, K. (2002). Using the Picture Exchange Communication System (PECS) with children with Autism: Assessment of PECS acquisition, speech, social-communicative behavior, and problem behavior. Journal of Applied Behavior Analysis, 35(3), 213-231. https://doi.org/10.1901/jaba.2002.35-213

Chasen, L. (2011). Social skills, emotional growth and drama therapy: Inspiring connection on the autism spectrum. Jessica Kingsley Publishers.

Clark, F. (2019, November 1). What does play-based speech therapy look like? The Dabbling Speechie. https://thedabblingspeechie.com/2019/11/play-based-speechtherapy 
Cole, P.R. (1918). Froebel. In P. Monroe (Ed.). A cyclopedia of education (Vol. II, pp 718-723). The Macmillan Company.

Copple, C., \& Bredekamp, S. (2009). Developmentally appropriate practice in early childhood programs serving children from birth through age 8. National Association for the Education of Young Children.

Corbett, B. A., \& Abdullah, M. (2005). Video modeling: Why does it work for children with autism? Journal of Early and Intensive Behavior Intervention, 2(1), 2-8. http://dx.doi.org/10.1037/h0100294

Corbett, B. A., Gunther, J.R., Comins, D., Price, J., Ryan, N., Simon, D., Schupp, C.W., \& Rios, T. (2011). Brief report: Theatre as therapy for children with autism spectrum disorder. Journal of Autism Developmental Disorder, 41(4), 505-511. https://doi.org/10.1007/s10803-010-1064-1

Courchesne, V., Meilleur, A. A., Poulin-Lord, M. P., Dawson, M., \& Soulières, I. (2015). Autistic children at risk of being underestimated: School-based pilot study of a strengthinformed assessment. Molecular Autism, 6(12), 1-10. https://doi.org/10.1186/s13229015-0006-3

Crotty, M. (1998). The foundations of social research: Meaning and perspective in the research process. Sage Publications.

Czech, H. (2018). Hans Asperger, national socialism, and "race hygiene" in Nazi-era Vienna. Molecular Autism, 9, 29. https://doi.org/10.1186/s13229-018-0208-6

D'Amico, M., Lalonde, C., \& Snow, S. (2015). Evaluating the efficacy of drama therapy in teaching social skills to children with autism spectrum disorders. Drama Therapy Review, l(1), 21-39. https://doi.org/10.1386/dtr.1.1.21_1 
De la Cruz, R. E. (1995). The effects of creative drama on the social and oral language skills of children with learning disabilities [Unpublished doctoral dissertation]. Illinois State University.

Delprato, D. (2001). Comparisons of discrete-trial and normalized behavior language interventions for young children with autism. Journal of Autism and Developmental Disorders, 31, 315-325. https://doi.org/10.1023/a:1010747303957

Dewey, J. (1916). Democracy and education. The Free Press.

Dewey, J. (1934). Art as an experience. In D. Goldblatt, D., \& L.B. Brown (Eds.). (2010). Aesthetics: A reader in philosophy of the arts (3rd ed., pp. 414-418). Prentice Hall. Dillon, D., \& Way, B. (1981). Perspectives: Drama as a sense of wonder -- Brian Way. Language Arts, 58(3), 356-362. http://www.jstor.org/stable/41961309

DiPietro, J., Kelemen, A., Liang, Y., \& Sik-Lanyi, C. (2019). Computer- and robot-assisted therapies to aid social and intellectual functioning of children with autism spectrum disorder. Medicina (Kaunas, Lithuania), 55(8), 440. https://doi.org/10.3390/medicina55080440

Doan, C. (2020, February 12). Creative Speech Lab. https://creativespeechlab.com/2019/06/05/teaching-social-skills-with-drama-freebie Duffy, C., \& Healy, O. (2011). Spontaneous communication in autism spectrum disorder: A review of topographies and interventions. Research in Autism Spectrum Disorders, 5(3), 977-983. https://doi.org/10.1016/j.rasd.2010.12.005 
Ewen, C., Jenkins, H., Jackson, C., Jutley-Neilson, J., \& Galvin, J. (2020). Well-being, job satisfaction, stress and burnout in speech-language pathologists: A review. International Journal of Speech-Language Pathology, 1-11. https://doi.org/10.1080/17549507.2020.1758210

Feinstein, A. (2010). History of Autism: Conversations with the Pioneers. Wiley-Blackwell.

Flippin, M., Reszka, S., \& Watson, L. R. (2010). Effectiveness of the picture exchange communication system (pecs) on communication and speech for children with autism spectrum disorders: A meta-analysis. American Journal of Speech-Language Pathology, 19(2), 178-195. https://doi.org/10.1044/1058-0360(2010/09-0022)

Froebel, F., \& Hailmann, W. N. (1887). The education of man. Appleton

Frost, J. L. (2010). A history of children's play and play environments. Routledge.

Frost, J. (2012). The changing culture of play. International Journal of Play, 1(2), 117 - 130. https://doi.org/10.1080/21594937.2012.698461

Frost, L. A., \& Bondy, A. S. (2002). The picture exchange communication system training manual (2nd ed.). Pyramid Educational Products.

Garwood, S. G. (1982). Piaget and play: Translating theory into practice. Topics in Early Childhood Special Education, 2(3), 1-13. https://doi.org/10.1177/027112148200200305

Gerbardt, H.P. (1993). Paulo Freire. Prospects: The Quarterly Review of Comparative Education, (23), 439-458. https://doi.org/10.1007/BF02195128

Geschwind, D. H. (2011). Genetics of autism spectrum disorders. Trends in Cognitive Sciences, 15, 409-416. https://doi.org/10.1016/j.tics.2011.07.003 
Ginsburg, K. R. (2007). The importance of play in promoting healthy child development and maintaining strong parent-child bonds. Pediatrics, 119(1), 182-191. https://doi.org/10.1542/peds.2006-2697

Godfrey, E., \& Haythorne, D. (2013) Benefits of dramatherapy for autism spectrum disorder: A qualitative analysis of feedback from parents and teachers of clients attending roundabout dramatherapy sessions in schools. Dramatherapy, 35(1), 20-28, https://doi.org/10.1080/02630672.2013.773131

Goldstein, T. R., \& Winner, E. (2012). Enhancing empathy and theory of mind. Journal of Cognition and Development, 13(1), 19-37. https://doi.org/10.1080/15248372.2011.573514

Grandin, T. (1995). Thinking in pictures: My life with autism. Vintage Books.

Gray, C.A. (1998). Social stories and comic strip conversations with students with asperger syndrome and high-functioning autism. In E. Schopler, G. B. Mesibov, L.J. Kunce (Eds.), Asperger syndrome or high-functioning autism? Current issues in autism. Springer. https://doi.org/10.1007/978-1-4615-5369-4_9

Gray, C. A., \& Garand, J. D. (1993). Social stories: Improving responses of students with autism with accurate social information. Focus on Autistic Behavior, 8(1), 1-10. https://doi.org/10.1177/108835769300800101

Greene, M. (1977). The artistic-aesthetic and curriculum. Curriculum Inquiry, 6(4), 283-296. doi:10.2307/1179650

Guba, E. (1981). Criteria for assessing the trustworthiness of naturalistic inquiries. Educational Technology Research and Development, 29(2), 75-91. http://www.jstor.org/stable/30219811 
Guli, L. A., Semrud-Clikeman, M. E., Lerner, M. D., \& Britton, N. (2013). Social competence intervention program (scip): A pilot study of a creative drama program for youth with social difficulties. Arts in Psychotherapy, 40(1), 37-44. https://doi.org/10.1016/j.aip.2012.09.002

Guli, L. A., Wilkinson, A. D., \& Semrud-Clikeman, M. (2008). Social competence intervention program (scip): A drama-based intervention for youth on the autism spectrum. Research Press.

Gutek, G. L. (1968). Pestalozzi \& education. Random House.

Hahn, E. (1955). Role playing, creative dramatics and play therapy in speech correction. Speech Teacher, 4, 233-238.

Happé F. G. (1994). An advanced test of theory of mind: Understanding of story characters' thoughts and feelings by able autistic, mentally handicapped, and normal children and adults. Journal of Autism and Developmental Disorders, 24(2), 129-154. https://doi.org/10.1007/BF02172093

Ferney Harris, S., Prater, M. A., Dyches, T. T., \& Allen Heath, M. (2009). Job stress of schoolbased speech-language pathologists. Communication Disorders Quarterly, 30(2), 103 111. http://dx.doi.org.wvu.idm.oclc.org/10.1177/1525740108323856

Hendricks, D. (2011). Special education teachers serving students with autism: A descriptive study of the characteristics and self-reported knowledge and practices employed. Journal of Vocational Rehabilitation, 35, 37-50. https://doi.org/10.3233/JVR-2011-0552

Hensel, N. (1977). Evaluating children's development in creativity and creative drama. $\mathrm{R}$ and $\mathrm{E}$ Research Associates. 
Horne, P. E., \& Timmons, V. (2009). Making it work: Teachers' perspectives on inclusion. International Journal of Inclusive Education, 13(3), 273-286. https://doi.org/10.1080/13603110701433964

Houghton, C. E., Casey, D., Shaw, D., \& Murphy, K. (2012). Staff and students' perceptions and experiences of teaching and assessment in clinical skills laboratories: Interview findings from a multiple case study. Nurse Education Today, 32(6), e29-e34. https://doi.org/10.1016/j.nedt.2011.10.005

Hutchins, T. L., Howard, M., Prelock, P. A., \& Belin, G. (2010). Retention of school-based slps: Relationships among caseload size, workload satisfaction, job satisfaction, and best practice. Communication Disorders Quarterly, 31(3), 139-154. https://doi.org/10.1177/1525740109336870

Interagency Autism Coordinating Committee. (2017, October). 2016-2017 Interagency autism coordinating committee strategic plan for autism spectrum disorder. U.S. Department of Health and Human Services Interagency Autism Coordinating Committee. https://iacc.hhs.gov/publications/strategic-plan/2017/

Iswari, M., Efrina, E., Kasiyati, \& Mahdi, A (2019). Developing social skills of autistic children through role play. Non Formal Education International Conference (NFEIC 2018), 6468. https://doi.org/10.2991/nfeic-18.2019.14

Janesick, V. J. (1998, April 13-17). Journal writing as a qualitative research technique: History, issues, and reflections [Paper presentation]. Annual Meeting of the American Educational Research Association, San Diego, CA, United States.

Johnson, L. and O’Neill, C. (Eds.). (1984). Dorothy Heathcote: Collected writings on education and drama. Hutchinson. 
Jones, E. A., \& Carr, E. G. (2004). Joint attention in children with autism: Theory and intervention. Focus on Autism and Other Developmental Disabilities, 19(1), 1326. https://doi.org/10.1177/10883576040190010301

Jones, P. (Ed.). (2010). Drama as therapy: Clinical work and research into practice (Vol.2). Routledge.

Kalandadze, T., Norbury, C., Nærland, T., \& Næss, K.-A. B. (2018). Figurative language comprehension in individuals with autism spectrum disorder: A meta-analytic review. Autism, 22(2), 99-117. https://doi.org/10.1177/1362361316668652

Kanner, L. (1943). Autistic disturbances of affective contact. Nervous Child, 2, 217-250. http://mail.neurodiversity.com/library_kanner_1943.pdf

Karsli, F., Şahin, Ç., \& Ayas, A. (2009). Determining science teachers' ideas about the science process skills: A case study. Procedia - Social and Behavioral Sciences, 1(1), 890-895 https://doi.org/10.1016/j.sbspro.2009.01.158

Keen, D. (2009). Engagement in children with autism in learning. Australasian Journal of Special Education, 33(2), 130-140. http://doi.org/10.1375/ajse.33.2.13

Kempe, A., \& Tissot, C. (2012). Use of drama to teach social skills in a special school setting for students with autism. Support for Learning, 27(3), 97-102. https://doi.org/10.1111/j.1467-9604.2012.01526.x

Kraft, M. A., \& Gilmour, A. F. (2016). Can principals promote teacher development as evaluators? A case study of principals' views and experiences. Educational Administration Quarterly, 52(5), 711-753. https://doi.org/10.1177/0013161X16653445 
Lake, R. (2013). Landscapes of education. A curriculum of imagination in an era of standardization: An imaginative dialogue with Maxine Greene and Paulo Freire. Information Age Publishing.

LaRue, R., Weiss, M. J., \& Cable, M. K. (2009). Functional communication training: The role of speech pathologists and behavior analysts in serving students with autism. The Journal of Speech-Language Pathology and Applied Behavior Analysis, 3(2-3), 164-172. http://dx.doi.org/10.1037/h0100244

Lee, Y. S., Thaut, C., \& and Santoni, C. (2019). Neurologic music therapy for speech and language rehabilitation. In M. H. Thaut \& D. A. Hodges (Eds.), The Oxford Handbook of music and the brain (pp. 1-26). Oxford University Press. https://doi:10.1093/oxfordhb/9780198804123.013.28

Lerner, M. D., Mikami, A. Y., \& Levine, K. (2011). Socio-dramatic affective-relational intervention for adolescents with Asperger syndrome \& high functioning Autism: Pilot study. Autism: The International Journal of Research and Practice, 15(1), 21-42. https://doi.org/10.1177/1362361309353613

Lewis, V. (2003). Play and language in children with autism. Autism, 7(4), 391-399. https://doi.org/10.1177/1362361303007004005

Lillard, A. S. (2013). Playful learning and Montessori education. American Journal of Play, 5(2), 157-186. https://files.eric.ed.gov/fulltext/EJ1003949.pdf

Lindgren, S., \& Doobay. A. (2011, May). Evidence-based interventions for autism spectrum disorders. Iowa Department of Human Services (2011). http://www.interventionsunlimited.com/editoruploads/files/Iowa\%20DHS\%20Autism\%2 OInterventions\%206-10-11.pdf 
Lofland, K. (2014). Evidence-based practices for effective communication and social intervention. Indiana University Bloomington. https://www.iidc.indiana.edu/irca/articles/evidence-based-practices-for-effectivecommunication-and-social-intervention.html

Maglione, M. A., Gans, D., Das, L., Timbie, J., Kasari, C., Technical Expert Panel, \& HRSA Autism Intervention Research - Behavioral (AIR-B) Network (2012). Nonmedical interventions for children with asd: Recommended guidelines and further research needs. Pediatrics, 130(Suppl. 2), S169-S178. https://doi.org/10.1542/peds.2012-0900O

Maguire, M., \& Delahunt, B. (2017). Doing a thematic analysis: A practical, step-by-step guide for learning and teaching scholars. All Ireland Journal of Teaching and Learning in Higher Education, 8(3), 3351-33514. https://ojs.aishe.org/index.php/aishe$\mathrm{j} /$ article/view/335/553

Mancil, G., \& Pearl, C. (2008). Restricted interests as motivators: Improving academic engagement and outcomes of children on the autism spectrum. TEACHING Exceptional Children Plus, 4(6), 2-15. https://files.eric.ed.gov/fulltext/EJ967728.pdf

Manning, J. (2005). Rediscovering Froebel: A call to e-examine his life and gifts. Early Childhood Education Journal, 32(6), 371-376. https://doi.org/10.1007/s10643-005-00048

Manolitsi, M., \& Botting, N. (2011). Language abilities in children with autism and language impairment: Using narrative as a additional source of clinical information. Child Language Teaching and Therapy, 27(1), 39-55. https://doi.org/10.1177/0265659010369991 
Mastrangelo, S. (2009). Harnessing the power of play: Opportunities for children with autism spectrum disorders. Teaching Exceptional Children, 42(1), 34-44. https://doi.org/10.1177/004005990904200104

Maynard, K. (2018, August 10). Dramatherapy: History, applications and outcome measures. The Association for Child and Adolescent Mental Health. https://www.acamh.org/blog/dramatherapy-history-applications-outcome-measures/

Mayo Clinic Staff (2018, January 6). Autism spectrum disorders. Mayo Clinic. https://www.mayoclinic.org/diseases-conditions/autism-spectrum-disorder/diagnosistreatment/drc-20352934

McCaslin, N. (1990). Creative drama in the classroom. Longman.

McConnell, S.R. (2002). Interventions to facilitate social interaction for young children with autism: Review of available research and recommendations for educational intervention and future research. Journal of Autism Developmental Disorders, 32(5), 351-372. https://doi.org/10.1023/A:1020537805154

McIntyre, B.M., \& McWilliams, B.J. (1959). Creative dramatics in speech correction. Journal of Speech and Hearing Disorders, 24(3), 275-279. https://doi.org/10.1044/jshd.2403.275

Merriam, S. B. (2009). Qualitative research design: A guide to design and implementation. Jossey-Bass.

Miles, M. B., Huberman, A. M., \& Saldaña, J. (2020). Qualitative data analysis: A methods sourcebook. Sage Publications.

Miller, E., \& Almon, J. (2009). Crisis in the Kindergarten: Why Children Need to Play in School. Alliance for Childhood. 
Minne, E. P., \& Semrud-Clikeman, M. (2012). A social competence intervention for young children with high functioning autism and asperger syndrome: A pilot study. Autism, 16(6), 586-602. https://doi.org/10.1177/1362361311423384

Mirenda, P. (2009). Promising innovations in aac for individuals with autism spectrum disorders. Perspectives on Augmentative and Alternative Communication, 18(4), 112-113. https://doi.org/10.1044/aac18.4.112

Montessori, M. (2017). Maria Montessori speaks to parents: A selection of articles (Vol. 21). The Montessori Series. Montessori-Pierson Publishing Company.

Mpella, M. \& Evaggelinou, C. (2018). Does theatrical play promote social skills development in students with autism? A systematic review of the methods and measures employed in the literature. Preschool and Primary Education, 6(2), 96-118. https://doi.org/10.12681/ppej.16135

Myers, S. M., Johnson, C. P., \& American Academy of Pediatrics Council on Children with Disabilities (2007). Management of children with autism spectrum disorders. Pediatrics, 120(5), 1162-1182. https://doi.org/10.1542/peds.2007-2362

Nadin, S., \& Cassell, C. (2006). The use of a research diary as a tool for reflexive practice: Some reflections from management research. Qualitative Research in Accounting \& Management, 3, 208-217. https:// http://doi.org/10.1108/11766090610705407

National Autism Center. (2015, September 21). Evidence-based practice and autism in the schools (2nd ed.). The National Autism Center at May Institute. https://autismguidelines.dmh.mo.gov/documents/Interventions.pdf 
National Research Council. (2001). Educating children with autism. Committee on educational interventions for children with autism. In C. Lord \& J. P. McGee (Eds.), Division of behavioral and social sciences and education. National Academy Press.

http://www.nap.edu/catalog/10017.html

No Child Left Behind (NCLB) Act of 2001, Pub. L. No. 107-110, § 101, Stat. 1425 (2002).

O’Sullivan, C. (2015). Drama and autism. In F. Volkmar (Ed.), Encyclopedia of Autism Spectrum Disorders. Springer. https://doi.org/10.1007/978-1-4614-6435-8_102102-1

O'Toole, J. \& O'Mara, J. (2007). Proteus, the giant at the door: Drama and theatre in the curriculum. In L. Bresler (Ed.). International handbook of research in arts education (pp. 203-218). Springer. https://doi.org/10.1007/978-1-4020-3052-9_13

Pappas, N. W., McLeod, S., McAllister, L., \& McKinnon, D. H. (2008). Parental involvement in speech intervention: A national survey. Clinical linguistics \& phonetics, 22(4-5), 335344. https://doi.org/10.1080/02699200801919737

Parette, H. P., \& Angelo, D. H. (1996). Augmentative and alternative communication impact on families: Trends and future directions. The Journal of Special Education, 30(1), 77-98. https://doi.org/10.1177/002246699603000105

Park, Y. J., \& Yang Y. (2016). The continuing influence of Froebel's kindergarten system in current early childhood education in the USA and South Korea. Asia-Pacific Journal of Research in Early Childhood Education, 10(3), 125-140.

https://files.eric.ed.gov/fulltext/ED385386.pdf

Patton, M. Q. (2002). Qualitative research and evaluation methods. Sage Publications.

Pearce, J. M. (2005). Kanner's infantile autism and asperger's syndrome. Journal of Neurology, Neurosurgery, and Psychiatry, 76(2), 205. https://doi.org/10.1136/jnnp.2004.042820 
Pestalozzi, J. H. (1915). How Gertrude teaches her children: An attempt to help mothers to teach their own children and an account of the method. (E. Cooke, Ed \& L. E. Holland \& F. C. Turner, Trans.). Swan Sonnenschein. (Original work published 1894)

Peter, M. (2009). Drama: Narrative pedagogy and socially challenged children. British Journal of Special Education, 36, 9-17. https://doi.org/10.1111/j.1467-8578.2009.00414.x

Peterson, C. A., Luze, G. J., Eshbaugh, E. M., Jeon, H. J., \& Kantz, K. R. (2007). Enhancing parent-child interactions through home visiting: Promising practice or unfulfilled promise? Journal of Early Intervention, 29(2), 119-140. https://doi.org/10.1177/105381510702900205

Pezzei, C., \& Oratio, A.R. (1991). A multivariate analysis of the job satisfaction of public school speech-language pathologists. Language, Speech, and Hearing Services in Schools, 22(3), 139-146. https://doi.org/10.1044/0161-1461.2203.139

Pinciotti, P. (1993). Creative drama and young children: The dramatic learning connection. Arts Education Policy Review, 94 (6), 24-28. https://doi.org/10.1080/10632913.1993.9936938

Pitcher, M. (2007). Democratic process and the theater of the oppressed. New Directions for Adult and Continuing Education, 116, 79-88. https://doi.org/10.1002/ace.278

Plumb, A. M., \& Plexico, L. W. (2013). Autism spectrum disorders: Experience, training, and confidence levels of school-based speech-language pathologists. Language, Speech, and Hearing Services in Schools, 44(1), 89-104. https://doi.org/10.1044/0161-1461(2012/110105)

Potter, C., \& Whittaker, C. (2001). Enabling communication in children with autism. Jessica Kingsley Publishers. 
Prasad, A. H. (2019, August 1). Overloaded with tasks? Show them the numbers. ASHA Leader, 24(8). https://doi.org/10.1044/leader.FTR2.24082019.56

Preis, J., \& McKenna, M. (2014). The effects of sensory integration therapy on verbal expression and engagement in children with autism. International Journal of Therapy and Rehabilitation, 21(10), 476-486. https://doi.org/10.12968/ijtr.2014.21.10.476

Prelock, P., Paul, R., \& Allen, E. (2011). Evidence-based treatments in communication for children with autism spectrum disorders. In F. Volkmar \& B. Reichow (Eds.) Evidencebased treatments for children with asd (pp. 93-170). Springer.

Prizant B.M., \& Duchan, J.F. (1981). The functions of immediate echolalia in autistic children. Journal of Speech and Hearing Disorders, 46(3), 241-249. https://doi.org/10.1044/jshd.4603.241

Rabideau, L. K., Stanton-Chapman, T. L., \& Brown, T. S. (2018). Discrete trial training to teach alternative communication: A step-by-step guide. Young Exceptional Children, 21(1), 34-47. https://doi.org/10.1177/1096250615621357

Raymond, J. (2010, February 2). Temple Grandin on her struggles and 'yak yaks.' NBC News. https://www.nbcnews.com/health/health-news/temple-grandin-her-struggles-yak-yaksflna1c9442451

Reading, S., Reading J., Padgett R. J., Reading S., \& Pryor, P. (2016). The use of theatre to develop social and communication behaviors for students with autism spectrum disorders: A preliminary investigation. Journal of Speech Pathology \& Therapy, 1, 102. http://doi: 10.4172/2472-5005.1000102

Reese, W. (2001). The origins of progressive education. History of Education Quarterly, 41(1), 1-24. https://doi-org.wvu.idm.oclc.org/10.1111/j.1748-5959.2001.tb00072.x 
Rimland, B. (2015). Infantile autism: The syndrome and its implications for a neural theory of behavior. Kingsley Publishers.

Ronald, A., \& Hoekstra, R. A. (2011). Autism spectrum disorders and Autistic traits: A decade of new twin studies. American Journal of Medical Genetics Part B: Neuropsychiatric Genetics, 156, 255-274. doi:10.1002/ajmg.b.31159

Rose, K. (2018, May 18). An autistic burnout. The Autistic Advocate. https://theautisticadvocate.com/2018/05/an-autistic-burnout

Rudy, L.J. (2019, November 21). Overview of nonverbal autism. VeryWell Health. https://www.verywellhealth.com/what-is-nonverbal-autism-260032

Rush, D. D., Shelden, M. L., \& Hanft, B. E. (2003). Coaching families and colleagues: A process for collaboration in natural settings. Infants and Young Children, 16(1), 33-47

Sackett, D. L., Richardson, W. S., Rosenberg, W., \& Haynes, R. B. (1997). Evidence-based medicine: How to practice and teach EBM. Churchill Livingstone.

Saldaña, J. (2016). The coding manual for qualitative researchers. Sage Publications.

Schepis, M. M., Reid, D. H., Behrmann, M. M., \& Sutton, K. A. (1998). Increasing communicative interactions of young children with autism using a voice output communication aid and naturalistic teaching. Journal of Applied Behavior Analysis, 31(4), 561-578. https://doi.org/10.1901/jaba.1998.31-561

Schlosser, R. W., \& Blischak, D. M. (2001). Is there a role for speech output in interventions for persons with autism? A review. Focus on Autism and Other Developmental Disabilities, 16(3), 170-178. https://doi.org/10.1177/108835760101600305 
Schrandt, J. A., Townsend, D. B., \& Poulson, C. L. (2009). Teaching empathy skills to children with autism. Journal of Applied Behavior Analysis, 42(1), 17-32. https://doi.org/10.1901/jaba.2009.42-17

Schwartz, H., \& Drager, K. D. (2008). Training and knowledge in autism among speechlanguage pathologists: A survey. Language, Speech, and Hearing services in Schools, 39(1), 66-77. https://doi.org/10.1044/0161-1461(2008/007)

Sellars, M., \& Imig, D. (2021): Pestalozzi and pedagogies of love: Pathways to educational reform. Early Child Development and Care, 1-20. https://doi.org/10.1080/03004430.2020.1845667

Sennott, S.C., \& Bowker, A. (2009). Autism, aac, and proloquo2Go. Perspectives on Augmentative and Alternative Communication, 18(4), 137-145. https://doi.org/10.1044/aac18.4.137

Sharpley, C. F., Bitsika, V., \& Efremidis, B. (1997). Influence of gender, parental health, and perceived expertise of assistance upon stress, anxiety, and depression among parents of children with Autism. Journal of Intellectual and Developmental Disability, 22(1), 19-28. https://doi.org/10.1080/13668259700033261

Shenton, A.K. (2004). Strategies for ensuring trustworthiness in qualitative research projects. Education for Information, 22, 63-75. https://doi.org/10.3233/EFI-2004-22201

Sherratt, D. \& Peter, M. (2006). Developing play and drama in children with autistic spectrum disorders. David Fulton Publishers.

Shuman, R. B. (Ed.). (1978). Educational drama for today's schools. Scarecrow Press. Sicile-Kira, C. (2014). Autism spectrum disorder: The complete guide to understanding autism. Penguin Group. 
Siks, G. (1983). Drama with children. Harper \& Row.

Silverman, C. (2012). Understanding autism: Parents, doctors, and the history of a disorder. Princeton University Press.

Silverman, D., \& Gubrium, J. F. (1994). Competing strategies for analyzing the contexts of social interaction. Sociological Inquiry, 64(2), 179-198. https://doi.org/10.1111/j.1475682X.1994.tb00387.x

Slade, P. (1955). Child drama. University of London Press.

Slade, P. (1959). Drama therapy as an aid to becoming a person. Guild Lectures (No. 103). Guild of Pastoral Psychology.

Slade, P. (1998). The Importance of dramatic play in education and therapy. Child Psychology and Psychiatry Review, 3(3), 110-112. doi:10.1017/S1360641798001592

Smith, T. (2001). Discrete trial training in the treatment of autism. Focus on Autism and Other Developmental Disabilities, 16(2), 86-92. https://doi.org/10.1177/108835760101600204

Sng, C. Y., Carter, M., \& Stephenson, J. (2014). A review of video modelling and scripts in teaching conversational skills to individuals with autism spectrum disorders. Review Journal of Autism and Developmental Disorders, 1(2), 110-123. https://doi.org/10.1007/s40489-013-0010-5

Sosa, A. V. (2016). Association of the type of toy used during play with the quantity and quality of parent-infant communication. JAMA pediatrics, 170(2), 132-137. https://doi.org/10.1001/jamapediatrics.2015.3753

Spectrum Arts. (2016). The autism arts network. https://www.spectrumartsautism.org 
Srinivasan, S. M., \& Bhat, A. N. (2013). A review of "music and movement" therapies for children with autism: Embodied interventions for multisystem development. Frontiers in Integrative Neuroscience, 7, 22. https://doi.org/10.3389/fnint.2013.00022

Stahmer, A. C., Schreibman, L., \& Cunningham, A. B. (2011). Toward a technology of treatment individualization for young children with autism spectrum disorders. Brain Research, 1380, 229-239. https://doi.org/10.1016/j.brainres.2010.09.043

Stake, R. E. (1995). The art of case study research. Sage Publications.

Stake, R.E. (2006). Multiple case study analysis. The Guilford Press.

Stone, W. L. (1987). Cross-disciplinary perspectives on autism. Journal of Pediatric Psychology, 12(4), 615-630. https://doi.org/10.1093/jpepsy/12.4.615

Takaya, K. (2003). The method of Anschauung: From Johann H. Pestalozzi to Herbert Spencer. The Journal of Educational Thought / Revue De La Pensée Éducative, 37(1), 77-99. https://doi.org/10.11575/jet.v37i1.52692

Teodoro, A. (2003). Reading Freire and Habermas: Critical pedagogy and transformative social change/reinventing Paulo Freire: A pedagogy of love/the Freirean legacy: Educating for social justice. Essay review. Comparative Education Review, 47(3), 321-328. https://doi.org/10.1086/378250

Thill, S., Pop, C., Belpaeme, T., Ziemke, T., \& Vanderborght, B. (2013). Robot-Assisted therapy for autism spectrum disorders with (partially) autonomous control: Challenges and outlook. Paladyn, Journal of Behavioral Robotics, 3(4). https://doi.org/10.2478/s13230013-0107-7 
Tien, K. C. (2008). Effectiveness of the picture exchange communication system as a functional communication intervention for individuals with autism spectrum disorders: A practicebased research synthesis. Education and Training in Developmental Disabilities, 43(1), 61-76. http://www.daddcec.com/etadd.html

Totsika, V., Hastings, R. P., Emerson, E., Lancaster, G. A., \& Berridge, D. M. (2011). A population-based investigation of behavioural and emotional problems and maternal mental health: Associations with autism spectrum disorder and intellectual disability. Journal of Child Psychology and Psychiatry, and Allied Disciplines, 52(1), 91-99. https://doi.org/10.1111/j.1469-7610.2010.02295.x

Tricomi, L. P., \& Gallo-Lopez, L. (2012). The act project: Enhancing social competence through drama therapy and performance. In L. Gallo-Lopez \& L. C. Rubin (Eds.), Play-based interventions for children and adolescents with autism spectrum disorders (p. 271-291). Routledge/Taylor \& Francis Group.

Tubbs, J. (2008). Creative therapy for children with autism, add, and asperger's: Using artistic creativity to reach, teach, and touch our children. Square One Publishers.

Urban, W. J. \& Wagoner, J. L. (2003). American education: A history (3rd ed.). McGraw-Hill.

Van Manen, M. (2014). Phenomenology of practice: Meaning-Giving methods in phenomenological research and writing. Left Coast Press.

Verhoeff, B. (2013). Autism in flux: A history of the concept from Leo Kanner to DSM-5. History of Psychiatry, 24(4), 442-458. https://doi.org/10.1177/0957154X13500584

Wagner, B. (1976). Dorothy Heathcote: Drama as a learning medium. National Education Association.

Ward, W. (1947). Playmaking with children. Appleton-Century-Crofts. 
Way, B. (1967). Development through drama. Humanities Press International.

Weaver, B. (1996). A golden moment: Dramatherapy and Peter Slade. Dramatherapy, 18(3), 1521. https://doi.org/10.1080/02630672.1996-1997.9689427

Wilkinson, L. E. (2014). Autism spectrum disorder in children and adolescents: Evidence-based assessment and intervention in Schools. American Psychosocial Association.

Winter-Messiers, M. A. (2007). From tarantulas to toilet brushes: Understanding the special interest areas of children and youth with asperger syndrome. Remedial and Special Education, 28(3), 140-152. https://doi.org/10.1177/07419325070280030301

Wong, C., Odom, S. L., Hume, K. A., Cox, A. W., Fettig, A., Kucharczyk, S., Brock, M. E., Plavnick, J. B., Fleury, V. P., \& Schultz, T. R. (2015). Evidence-based practices for children, youth, and young adults with autism spectrum disorder: A comprehensive review. Journal of Autism and Developmental Disorders, 45(7), 1951-1966. https://doi.org/10.1007/s10803-014-2351-z

World Health Organization. (2001, May 22). International classification of functioning, disability and health. https://apps.who.int/iris/bitstream/handle/10665/42407/9241545429.pdf

Wright, M. H. (2016). Creative dramatics. In F. Gruber (Ed.), Teaching in America (pp. 137144). University of Pennsylvania Press. https://doi.org/10.9783/9781512802115-017

Yin, R. K. (1984). Case study research: Design and methods. Sage Publications.

Yin, R.K. (2003). Case study research: Design and methods (3rd ed.). Sage Publications.

Zainal, Z. (2007). Case study as a research method. Jurnal Kemanusiaan, 9,1-6. https://core.ac.uk/download/pdf/11784113.pdf 
Zhang, J., \& Wheeler J. J. (2011). A meta-analysis of peer-mediated interventions for young children with autism spectrum disorders. Education and Training in Autism and Developmental Disabilities, 46, 62-77. https://core.ac.uk/download/pdf/233574272.pdf

Zigler, E., Singer, D., \& Bishop-Josef, S. (Eds.). (2004). Children's play: The roots of reading. Zero to Three Press. 


\section{APPENDIX A}

\section{Pilot Study Creative Dramatic Therapy Plans}

September 26, 2011

Jayenne Elementary School

Building Blocks Model

Dissertation Pilot Study

\section{Activity 1: Building Block 1 Concentration}

Porridge Activity - Three different sized bowls (big, medium, and small) filled with different consistencies of porridge (dry, wet, sticky). Students will touch each consistency and discuss how it feels.

Goal: Gain attention and focus through sensory activities and to expand vocabulary and oral language skills

Materials: Porridge/oatmeal, water, three different sized bowls

\section{Activity 2: Building Block 2 Pantomime}

A. Bear Activity -- Pretend to be a bear (show facial expressions, how bears walk, noises bear makes etc.). Speech language pathologist will lead activity "you are a bear and you are wading through deep water, walking through mud, climbing a tree, tiptoeing quietly through a house, sticking your paw into a beehive."

Goal: Imitation of facial expression and actions to increase receptive language knowledge

Materials: None

B. Facial Expression Activity--Sorting bear and Goldilocks emotion cards and making paper bag bear puppet to reinforce bear movements and emotions

Goal: Receptive and expressive understanding of facial expression and actions

Materials: Bear and Goldilocks emotion cards, paper bag, glue or tape, cut out bear puppet components

\section{Activity 3: Building Block 3 Movements to Sound}

Song Activity - Song: "Five Little Bears Song" and have students color with markers the gloves to make bear paws and wear the gloves to sing the song 
Goal: Following directions, repeating sentences or phases, increasing vocabulary skills, understanding spatial language concepts

Materials: Brown and Black Markers and Gloves

\section{"5 Little Bears"}

5 little bears were dancing on the floor one fell down and that left 4 4 little bears climbed up a tree, one found a beehive that left 3 .

3 little bears were wondering what to do, one chased a bunny rabbit that left 2 2 little bears were looking for some fun, one took a swim that left 1

1 little bear sitting all alone he looked all around then ran home. 
September 28, 2011

Jayenne Elementary School

Building Blocks Model

Dissertation Pilot Study

\section{Activity 1: Building Block 4 Moods and Emotions}

Stick puppet activity: Students will assemble simple stick puppets. They will pretend with bears puppets what they would do at school: on the playground and in the lunchroom. SLP will inquire about lunchroom routine and how to solve various lunchroom conflicts (ex. Asking to go to the bathroom, asking for help in opening lunch items, choosing what foods to be placed on their trays, and telling the teacher the lunch is too noisy) and to solve playground conflicts (ex. Asking to take turns on swings, asking to share basketball, understanding when recess is over, etc.). The SLP and students will draw a model of the lunchroom and playground on a dry erase board.

Goals: Generalizing emotions, identifying and expressing the emotions and needs of others, and solving social problems

Materials: Stick puppet pattern, tape, popsicle sticks, dry erase board, dry erase marker

\section{Activity 2: Building Block 5 Voice and Diction}

"Teddy Bear/Teddy Bear" Rhyme: Have students stand up, say the rhyme several times with the SLP, and act out the words.

Goals: Increase appropriate speech suprasegmentals of prosody, rate, and stress and following directions

“Teddy Bear/Teddy Bear"

Teddy bear, teddy bear, Turn around.

Teddy bear, teddy bear, Touch the ground.

Teddy bear, teddy bear, Shine your shoes.

Teddy bear, teddy bear, Skidoo.

Teddy bear, teddy bear, Go upstairs.

Teddy bear, teddy bear, Say your prayers.

Teddy bear, teddy bear, Turn out the light. 
Teddy bear, teddy bear,

Say good night

Materials: None

Activity 3: Building Block 7 Storytelling

SLP will read Goldilocks and Three Bears book to students while asking wh questions about the story and encouraging predicting events.

Goals: Introduce story of Goldilocks and Three Bears, increase receptive and expressive vocabulary skills and language concepts with wh questions, increase language skills of sequencing events, increase metalinguistic language skills of predicting events and outcomes.

Materials: Goldilocks and Three Bears Book 
September 30, 2011

Jayenne Elementary School

Building Blocks Model

Dissertation Pilot Study

\section{Activity 1: Goldilocks Felt Board Story Building Block 6 Storytelling}

SLP will read Goldilocks and the Three Bears with students using felt board characters to act out the story as it is being read. The SLP will ask students questions through the story. The SLP will encourage the students to collaboratively retell the story using the felt board puppets.

Goals: Pragmatic language skills of following rules of conversation-introducing the topic, staying on topic, rephrasing when misunderstood, using verbal and nonverbal cues to tell the story, and receptive and expressive language skills of sequencing events, producing grammatically appropriate sentences, increasing vocabulary skills, and comprehending language concepts

Materials: Goldilocks Felt Board by Little Folk Visuals

Activity 2: The Three Little Bears go Camping Building Block 7 Playmaking and Improvisation

SLP will encourage students to tell their own version of Goldilocks and Three Bears. The scenario will be the three bears are going camping with Goldilocks. The students will wear bear masks. The SLP will be Goldilocks camping with the bears and will wear the Goldilocks mask. The SLP will encourage such interactions through questions as... what would they need to prepare for camping? What would they see going camping? What will they do while they are camping? Will Goldilocks go camping with them? They pretend together all the camping activities and may change roles or introduce new characters to the story. They will also solve problems and conflicts that arise while camping especially since Goldilocks and the 3 bears are camping together (ex. Will Goldilocks want to camp with the 3 bears? What would bears do if they see other animals while camping? The bears could tell Goldilocks what it is like to be a bear).

The scenario improvisation will be "Let's go camping together."

Goals: Pragmatic language skills of changing language according to the needs of the listener and situation, increase peer interacting, and problem solving skills in social situations

Materials: Goldilocks and the 3 Bears Masks, Sheet for Tent, Sleeping bag, Legos for pretend fire, coat hangers for pretend smores 
October 19, 2011

Jayenne Elementary School

Building Blocks Model

Dissertation Pilot Study

\section{Activity 1: Building Block 1 Concentration}

Touch Activity- Three little pigs play dough activity. Students will make play dough pigs and play with pop up wolf.

Goal: Gain attention and focus through sensory activities (rolling out the play dough and forming the play dough into pigs) and expand vocabulary and oral language skills

Materials: Play dough 3 little pigs set

Activity 2: Building Block 2 Pantomime

A. Pig Activity -- Pretend to be a pig (show facial expressions, how bears walk, noises bear makes etc.). Speech language pathologist will lead activity "you are a pig and you are walking through mud, snorting, running through the grass, eating, climbing a tree, picking up sticks, making a house."

Goal: Imitation of facial expression and actions to increase receptive language knowledge

Materials: None

B. Pig Paper Bag Activity-- making paper bag pig puppet to reinforce pig movements and emotions

Goal: Receptive and expressive understanding of facial expression and actions

Materials: Paper bag, glue or tape, cut out pig puppet components

Activity 3: Building Block 3 Movements to Sound

Song Activity - Song: "Six Little Pigs Song" and have students sing and act out song.

"Six Little Pigs"

Six little pigs rolled in the mud, Squishy, squashy, felt so good. The farmer took one pig out. Oink, Oink, Oink, the pig did shout.

Five little pigs rolled in the mud, 
Squishy, squashy, felt so good.

The farmer took one pig out.

Oink, Oink, Oink, the pig did shout.

Four little pigs rolled in the mud,

Squishy, squashy, felt so good.

The farmer took one pig out.

Oink, Oink, Oink, the pig did shout.

Three little pigs rolled in the mud,

Squishy, squashy, felt so good.

The farmer took one pig out.

Oink, Oink, Oink, the pig did shout.

Two little pigs rolled in the mud, Squishy, squashy, felt so good.

The farmer took one pig out.

Oink, Oink, Oink, the pig did shout.

One little pig rolled in the mud, Squishy, squashy, felt so good.

The farmer took one pig out.

Oink, Oink, Oink, the pig did shout.

No little pigs rolled in the mud,

They all looked clean and good.

The farmer turned his back and then,

Those pigs rolled in the mud again!

Goal: Following directions, repeating sentences or phases, increasing vocabulary skills, understanding spatial language concepts

Materials: None 
October 20, 2011

Jayenne Elementary School

Building Blocks Model

Dissertation Pilot Study

\section{Activity 1: Building Block 4 Moods and Emotions}

Three Little Pigs finger puppet and coloring activity: Students will share 3 little pigs finger puppets to explore the story. Each student will be one of the pigs and take turns being the wolf. They will identify and discuss the emotions of the pigs and wolf. They also will solve various problems that arise in the story (ex. how to build a safe house and how to work together to solve a problem). The SLP will also lead a discussion on safety (ex. not talking to strangers, not opening the door to strangers related to the story, and what to do if you are in trouble [tell your mom or dad, yell help, dial 911]).

Goals: Generalizing emotions, identifying and expressing the emotions and needs of others, and solving social problems

Materials: The Three Little Pigs Finger Puppet Pack.

Activity 2: Building Block 5 Voice and Diction

"This little piggy" Rhyme: Have students say the rhyme several times with the SLP.

This little piggy went to market

This little piggy stayed home

This little piggy had roast beef.

This little piggy had none.

And this little piggy cried, "Wee, wee, wee!

All the way home. (tickle him all over)

Goals: Increase appropriate speech suprasegmentals of prosody, rate, and stress and following directions

Materials: "This little piggy" picture cards

\section{Activity 3: Building Block 6 Storytelling}

SLP will read Three Little Pigs book to students while asking wh questions about the story and encouraging predicting events. There will also be illustrated pages for the students to color or look at as reinforcement of the story.

Goals: Introduce story of Three Little Pigs, increase receptive and expressive vocabulary skills and language concepts with wh questions, increase language skills of sequencing events, increase metalinguistic language skills of predicting events and outcomes. 
Materials: Three Little Pigs Book and Coloring Pages 
October 21, 2011

Jayenne Elementary School

Building Blocks Model

Dissertation Pilot Study

\section{Activity 1: Three Little Pigs Felt Board Story Building Block 6 Storytelling}

SLP will read Three Little Pigs with students using felt board characters to act out the story as it is being read. The SLP will ask students questions through the story. The SLP will encourage the students to collaboratively retell the story using the felt board puppets.

Goals: Pragmatic language skills of following rules of conversation-introducing the topic, staying on topic, rephrasing when misunderstood, using verbal and nonverbal cues to tell the story, and receptive and expressive language skills of sequencing events, producing grammatically appropriate sentences, increasing vocabulary skills, and comprehending language concepts

Materials: Three Little Pigs Felt Board by Little Folk Visuals

Activity 2: The Three Little Pigs go on a journey to build their own home Building Block 7 Playmaking and Improvisation

SLP will encourage students to tell their own version of the Three Little Pigs. The scenario will be the three pigs are going on a journey to build their own home. The students will use stick pig masks. The SLP will hold the wolf mask at one point during the improvisation.

To being the improvisation the SLP will encourage such interactions through questions as...where are we going to find a new house? (ex. in a city, in the woods, on a mountain, by an ocean). How will we get there (ex. by plane, by boat, by train)? What will we see during their journey to find a place to build our home? Once we get to where we want to build our own home. What will we need to put in our book bag to put in our homes and to build our homes? What will they need to build their own home? What do we want in their own home (ex. a swimming pool, a toy room, etc.)? The wolf will see the homes that they have built. Will the wolf be nice or mean? Will the wolf go on the journey with them? It will end with we all lived happily ever after.

They pretend together through all the traveling and building the homes' activities and may change roles or introduce new characters to the story. The SLP and the students will pretend together. They will also solve problems and conflicts that arise while traveling and building the homes.

The scenario improvisation will be "Let's go on a trip to build a house." 
Goals: Pragmatic language skills of changing language according to the needs of the listener and situation, increase peer interacting, and problem solving skills in social situations

Materials: The Three Little Pigs 


\section{APPENDIX B}

\section{Note on Hans Asperger}

While beyond the scope of this doctoral thesis, there has been significant literature and research devoted to Hans Asperger, including his ties to National Socialism, or acquiescence to tenants of Nazi ideology in the 1930's. Czech (2018) published a compelling article in Molecular Autism titled "Hans Asperger, National Socialism, and 'race hygiene' in Nazi-era Vienna." The article advocates the re-evaluation of the narrative that Mr. Asperger was an active opponent of National Socialism. All aspects of Nazi Socialism were and are abhorrent and deserve condemnation in the strongest possible terms. By inclusion or mention of Mr. Asperger, this author in no way condones any aspect of that stain on history. 


\section{APPENDIX C}

\section{Interview Questions}

1. How long have you been a speech language pathologist?

2. How many years have you worked with children with Autism Spectrum Disorders?

3. Describe the levels of severity of Autism the children have that you have worked with or are currently working with in speech and language therapy.

4. Describe a typical session with a child with Autism Spectrum Disorders; tell me everything.

(I may follow up with questions about what the interview describes to get more details, as well as the phase "tell me more").

5. Describe therapy activities that children with Autism Spectrum Disorders enjoy the most.

6. Describe the activities that you have seen as the most successful in terms of facilitating language development for children with Autism Spectrum Disorders. 


\section{APPENDIX D}

\section{Participant Recruitment Letter}

Dear

I am in the process of organizing a study for my dissertation as part of my doctorate requirements at West Virginia University. Dr. Joy Saab, West Virginia University Professor of Curriculum and Instruction, Literacy Studies, is the Principal Investigator of this study. I am researching the experiences of speech language pathologists working with children with Autism Spectrum Disorders in speech and language therapy.

I am requesting your voluntary participation in this study because of your experience and knowledge of working with children with Autism Spectrum Disorders. Your involvement would entail a one-on-one interview with me. You may choose the time and date of this one-onone interview at your convenience. I will be providing you with a transcript from the interview for you to review and make any changes that you deem necessary. I may also ask for a follow-up one-on-one interview for further information. This follow-up on-on-one interview would also be at your convenient location, time, and date. There is no obligation for you to be part of the study. Your participation is completely voluntary, and you can choose to end your participation at any time. Your participation in the study will also remain completely confidential, as will your interviews. West Virginia University’s Institutional Review Board (IRB) has an acknowledgment of this study on file.

Please email me back within five days whether you will or will not participate in the study. If you have questions or concerns, please do not hesitate to contact me. Thank you for your time and consideration.

Sincerely,

Julia Byers 